\title{
Investigation of organic precursors and plasma mixtures allowing control of carbon passivation when etching HgCdTe in hydrocarbon-based inductively coupled plasmas
}

Running title: a concise title

Running Authors: Piet et al.

\author{
J. Piet ${ }^{1}$, W. Faider ${ }^{1}$, A. Girard ${ }^{1}$, F. Boulard ${ }^{2}$, C. Cardinaud ${ }^{1, a)}$ \\ 'Université de Nantes, CNRS, Institut des Matériaux Jean Rouxel, IMN, F-44000 Nantes, France \\ 2Univ. Grenoble Alpes, CEA, LETI, F-38000 Grenoble, France \\ a) Electronic mail: christophe.cardinaud@cnrs-imn.fr
}

The interest of introducing oxygen and/or nitrogen atoms in $\mathrm{CH}_{4} / \mathrm{H}_{2} / \mathrm{Ar}$ plasma mixtures, by means of organic precursors in the place of $\mathrm{CH}_{4}$ or by partly substituting $\mathrm{O}_{2}$ or $\mathrm{N}_{2} \mathrm{O}$ for $\mathrm{H}_{2}$ and thereby control carbon deposition and surface passivation when etching $\mathrm{HgCdTe}$ under low substrate bias conditions is investigated. Using in situ ellipsometry, in situ x-ray photoelectron spectroscopy, atomic force microscopy and secondary electron microscopy, we show that nitromethane as precursor and $\mathrm{N}_{2} \mathrm{O}$ substitution are attractive alternatives: absence of deposition although no bias is applied, equivalent post-etch surface composition and for the latter comparable performances in terms of etch rate and surface roughness. Such approach could provide the soft dry etching conditions needed to reduce the pixel pitch of $\mathrm{HgCdTe}$ infrared photovoltaic detectors. The mechanisms that allow suppressing carbon deposition upon $\mathrm{O}_{2}$ or $\mathrm{N}_{2} \mathrm{O}$ substitution in $\mathrm{CH}_{4} / \mathrm{H}_{2} / \mathrm{Ar}$ plasmas is studied by combining plasma diagnostics (optical emission spectroscopy and actinometry, ion flux measurements) and surface characterisations. Firstly, using Si as a reference substrate, it is shown that deposition is suppressed whenever the $\mathrm{O}_{2}$ and $\mathrm{N}_{2} \mathrm{O}$ flow rate is half and twice 
that of $\mathrm{CH}_{4}$ respectively. Moreover the study reveals that oxygen is the true etch reactant controlling the competition between film growth and etching in both substituted processes, whereas incorporation of nitrogen in the film upon $\mathrm{N}_{2} \mathrm{O}$ substitution favours simultaneously its etching kinetics. Secondly, on $\mathrm{HgCdTe}$, deposition of a hydrocarbonitride film is observed at low $\mathrm{N}_{2} \mathrm{O} / \mathrm{CH}_{4}$ ratio ( 0.6). SEM and SEM-EDS imaging suggest that the film nucleates and grows preferentially on regions where the $\mathrm{Cd}$ removal mechanisms happens to be less efficient. At high $\mathrm{N}_{2} \mathrm{O} / \mathrm{CH}_{4}$ ratio ( 4), oxidation of the $\mathrm{HgCdTe}$ surface is observed.

\section{INTRODUCTION}

The II-VI compound Mercury Cadmium Telluride $\left(\mathrm{Hg}_{(1-\mathrm{x})} \mathrm{Cd}_{\mathrm{x}} \mathrm{Te}\right)$ is widely used for fabrication of high performance infrared photovoltaic detector due to a bandgap tunability achieved by varying the cadmium content of the alloy ${ }^{1,2}$. Thus, it covers a wide spectral range from near to far infrared $(0.8-30 \mu \mathrm{m})$. The other important advantages of this compound are a high absorption coefficient, a great mobility and a long lifetime of carriers as well as a fast response time ${ }^{3}$. At last one can also point out the nearly invariant lattice parameter with composition ( $0.2 \%$ from CdTe to $\mathrm{HgTe})$, which allows to epitaxy heterostructures addressing multi spectral ranges. Fabrication of a detector matrix requires etching steps in the form of deep trenches or low aspect ratio holes, to respectively define the pixel's dimension and pitch and to open the material for electrical contacts ${ }^{4,5}$. In both 
cases etching can induce damages at the surface and even into the material. The most frequent concern the degradation of the electrical properties, the change of composition, the development of surface roughness and presence of process residues. The latter two complicate the deposition of electrical passivation layers and the making of electrical contacts.

Dry etching of $\mathrm{HgCdTe}$ is mainly performed with $\mathrm{CH}_{4} / \mathrm{H}_{2} / \mathrm{Ar}$ plasmas. Although some parts of the etching mechanism are still not thoroughly interpreted, past studies and literature data converge on the fact that the methyl group $\mathrm{CH}_{3}$ allows to form the volatile product $\mathrm{Cd}\left(\mathrm{CH}_{3}\right)_{2}$, Te desorbs from surface due to formation of $\mathrm{TeH}_{2}$ and $\mathrm{Te}\left(\mathrm{CH}_{3}\right)_{2}$ and $\mathrm{Hg}$ desorbs spontaneously due to its high vapour pressure ${ }^{6,7}$. During the etching, a sufficient substrate bias is necessary to provide to the ion bombardment the required energy capable to prevent or remove carbon deposition at the bottom of the etched feature ${ }^{8}$, while at the pattern sidewall, carbon species can contribute to the etching anisotropy through the formation of a passivation layer. The $\mathrm{CH}_{4} / \mathrm{H}_{2}$ ratio is an important parameter of the plasmamaterial interaction mechanism. On the one hand, the greater this ratio, the larger the bias threshold between carbon film deposition and material etching ${ }^{8}$ and thus the larger the bias to be applied, with potential damage to the material ${ }^{8,9,10,11}$. On the other hand the larger this ratio, the less disequilibrium between the removal mechanism of the HgTe fraction of the material and that of the CdTe fraction ${ }^{7}$ and the better chance to limit $\mathrm{Hg}$ depletion from the surface layer. Besides, the etched surface is generally reported to be rough and, in relation to the etch mechanism, plasmas rich in $\mathrm{H}_{2}$ were observed to cause significantly rougher surfaces than plasmas with large $\mathrm{CH}_{4} / \mathrm{H}_{2} \operatorname{ratios}^{10,11}$. The origin being attributed to carbon deposition ${ }^{6,12}$, residues rich in $\mathrm{Cd}^{13}$ or formation of a porous surface layer ${ }^{7}$. Literature 
reports a few studies carried out to minimize these defects. Most notably, $\mathrm{N}_{2}$ and Ar have been added to $\mathrm{CH}_{4} / \mathrm{H}_{2}$ plasma to improve surface aspect and roughness ${ }^{14}$. This improvement is associated with the reduction of the hydrogen concentration, as $\mathrm{H}$ is consumed to form $\mathrm{NH}_{3}{ }^{14}$. An increase of $\mathrm{CH}_{3}$ concentration is also observed with presence of $\mathrm{N}_{2}$ in the mixture ${ }^{14,15}$. Other works investigated $\mathrm{O}_{2}$ addition to avoid polymer deposition for InP etching ${ }^{16,17}$. In conclusion the etching mechanism of $\mathrm{HgCdTe}_{\mathrm{in}} \mathrm{CH}_{4} / \mathrm{H}_{2} / \mathrm{Ar}$ plasma obeys to an ion assisted chemical etching mechanism, as introduced by Coburn and Winters in the late $1970 \mathrm{~s}^{18,19,20,21}$ for the etching of Si based materials in fluorine plasmas ${ }^{22}$ and verified since in a very large number of systems. In addition, the mechanism faces a situation of competition between etching and deposition as in fluorocarbon plasmas with the complication of a fragile ternary material and a strong requirement to limit plasmainduced damage, in particular with respect to ion bombardment.

Here we report on the interest of replacing $\mathrm{CH}_{4}$ by other organic precursors whose chemical formula contains oxygen and nitrogen atoms or by adding $\mathrm{N}_{2} \mathrm{O}$ or $\mathrm{O}_{2}$ to a $\mathrm{CH}_{4} / \mathrm{H}_{2} / \mathrm{Ar}$ plasma. Purpose is to progress in the understanding of the impact of changing the precursor or the plasma chemistry on the plasma-surface interaction mechanism and notably for etching $\mathrm{HgCdTe}$ without carbon residues even at low or without substrate bias. In a first step, we used in situ ellipsometry to study the hydrocarbon film deposition produced on silicon by various organic precursors capable to etch $\mathrm{HgCdTe}$ and the removal of this deposit in an oxidizing plasma, described hereinafter as sample cleaning. Then, we analysed the composition of the plasma produced with the most interesting mixtures by optical emission spectroscopy (OES), in addition the total flux of positive ions was measured using a home-made capacitive planar probe ${ }^{23,24}$, which design is inspired from 
the work of Braithwaite ${ }^{25}$. Electron density and temperature were estimated using a cylindrical Langmuir probe. Finally, we etched $\mathrm{HgCdTe}$ samples for several precursor flow rates; overall surface composition was characterised thanks to in situ x-ray photoelectron spectroscopy (XPS). And it is worth to point out or recall that the pioneer work of J. Coburn in the use of in situ surface analysis for the understanding plasma or ion surface interaction mechanisms ${ }^{26}$. Secondary electron microscopy (SEM) and energy dispersive x-ray spectroscopy (SEM-EDS) imaging allowed to probe the surface topography and surface chemical homogeneity in the micrometre scale range respectively and surface roughness was measured by atomic force microscopy (AFM).

\section{EXPERIMENTAL SET UP AND METHODOLOGY}

The etching vessel used in the study associates an inductively coupled plasma (ICP) source and a diffusion chamber in which the sample holder is located. The ICP source is composed of a $185 \mathrm{~mm}$ in diameter alumina tube surrounded by a circular antenna connected to a RF generator $(13.56 \mathrm{MHz})$. The sample holder, located $240 \mathrm{~mm}$ below the plane of the source antenna, is biased using a variable power supply at $13.56 \mathrm{MHz}$. The substrate self-bias enables to control the ion energy independently from the production of the plasma. The sample holder receives $\mathrm{Si}$ wafers $100 \mathrm{~mm}$ in diameter that are clamped mechanically via an anodised aluminum ring. A cryostat ensures the temperature regulation of the sample holder, heat exchange between the wafer and the holder is obtained by a 10 mbar He static pressure at the wafer backside; in the present study temperature regulation was fixed to $20^{\circ} \mathrm{C}$. Typical plasma process conditions are $1000 \mathrm{~W}$ for the source power, 4 mTorr of total pressure, 10 min of exposure time, no bias is applied to the sample holder 
unless indicated. Gas mixture, which is the main variable experimental parameter is indicated along the text. Plasma cleaning conditions are carried out in $\mathrm{O}_{2} / \mathrm{Ar}(40 / 20) \mathrm{sccm}$ mixture, or $\mathrm{N}_{2} \mathrm{O} / \mathrm{Ar}(40 / 20)$ in the case of the $\mathrm{N}_{2} \mathrm{O}$ additive, at $1000 \mathrm{~W}$ source power and 4 mTorr total pressure, no bias is applied to the Si sample holder.

The OES measurements are carried out with a Jobin-Yvon iHR 550 monochromator that is fitted with a $1800 \mathrm{gr} / \mathrm{mm}$ holographic grating blazed for $250 \mathrm{~nm}$. The light signal is measured with a CCD Open Electrode 1024x256 pixels from Synapse that enables to cover a $22 \mathrm{~nm}$ spectral range with a nominal resolution of $0.06 \mathrm{~nm}$. The characteristic spectra are recorded with an exposure time of $0.1 \mathrm{~s}$ and a slot opening of $20 \mu \mathrm{m}$. The evolution of relative concentration of the species is monitored by using the $8 \%$ Ar present in the gas mixture as an actinometer, through the emission line at $750.4 \mathrm{~nm}$.

The carbon film deposition and subsequent sample cleaning study is carried out with an in situ multi wavelengths ellipsometer M44 from Woollam Co. Measurement is carried out every $2.4 \mathrm{~s}$. The model used to analyse the experimental data is composed of three layers: a $\mathrm{Si}$ bulk layer for the substrate, $\mathrm{a} \mathrm{SiO}_{2}$ layer to model the substrate initial native oxide as well as the $\mathrm{Si}$ oxidation after the sample cleaning. For both materials, optical parameters are taken from the WVase software library. The third layer is the deposition layer whose composition is unknown and represented by a Cauchy model. For each deposition condition, the Cauchy parameters are adjusted considering the data acquired during a period of time of 2 min (corresponding to 50 measurements) after the end of the deposition sequence when the layer is the thickest; the parameters are then taken fixed when analysing the complete set of temporal experimental data for this deposition condition. Comparing the values of the Cauchy parameters from one precursor to another 
and when using additives, we did not observe very significant variations. The experiments are carried out one after the other, each deposition being followed by an oxydising plasma for cleaning. The evaluation of the silicon oxidation, and therefore the $\mathrm{SiO}_{2}$ thickness, is fulfilled after each cleaning in order to adjust the model before a new deposition measurement.

The $\operatorname{Hg}_{(1-\mathrm{x})} \mathrm{Cd}_{\mathrm{x}}$ Te layers $(\mathrm{x}=0.2)$ used in this work are grown by liquid phase epitaxy on (111)-oriented CdZnTe substrates ${ }^{27,28}$. Before use the HgCdTe wafer is etched in a $\mathrm{Br}_{2} /$ methanol solution; this allows to remove about $1 \mu \mathrm{m}$ out of the $8 \mu \mathrm{m}$ thick $\mathrm{HgCdTe}$ layer and ensures to carry on the experiments on a reproducible material surface. The wafers are then cut into $1 \mathrm{~cm}^{2}$ samples and experiments are carried out on samples from the same wafer. These samples are fixed onto the Si wafer using a thermal paste (HTCP from Electrolube) at the back of the sample, which ensures a good thermal contact.

The sample surface is analysed by quasi in situ X-ray photoelectron spectroscopy, using a Phoibos HR150 analyser and a Focus500 monochromator from Specs GmbH. Transfer sequence is as follows. After the process the plasma vessel is pumped down to its nominal base pressure (5E-7 mbar) then the sample is transferred to a buffer chamber (base pressure 5E-9 mbar), in a third step the sample is transferred to the XPS chamber (base pressure 1E-9 mbar); this procedure prevents the XPS from a direct connection with the plasma vessel and allows to maintain vacuum and surfaces as clean as possible. Spectrum emission is achieved with a monochromatic $\mathrm{AlK} \alpha$ at $1486.74 \mathrm{eV}$ powered at $400 \mathrm{~W}$ (15 $\mathrm{kV}, 27 \mathrm{~mA}$ ). Survey spectra and narrow spectra are recorded with a pass energy of 30 and $14 \mathrm{eV}$ and an energy step of 0.5 and $0.025 \mathrm{eV}$ respectively; the latter combination giving an experimental spectral width at half maximum of $0.51 \mathrm{eV}$ on $\mathrm{Ag} 3 \mathrm{~d} 5 / 2$. The XPS 
measurement angle with respect to the sample surface normal is $0^{\circ}$, the angle between the X-ray and the analyser is $60^{\circ}$. Data treatment was carried out with Casa XPS ${ }^{29}$.

The etch rate is measured on patterned samples with a Veeco Dektak 8 profilometer. Atomic force microscopy is used to characterise the surface roughness and morphology. The equipment used is a Nano Wizard 3 from JPK Instruments with a tip PPP-NCHR-50b from Nanosensors with a radius of curvature less than $7 \mathrm{~nm}$. Scanning is carried out in intermittent contact mode, the scan is $10 \times 10 \mu \mathrm{m}^{2}$. SEM and SEM-EDS imaging are carried out with JEOL JSM 7600F and 5800LV instruments respectively and operated at $5 \mathrm{kV}$, no metallization is necessary prior to the analysis.

\section{STUDY OF VARIOUS PRECURSORS AND ADDITIVES}

\section{A. Choice of precursors}

Precursors are chosen according to their predisposition to produce $\mathrm{CH}_{3}$ radicals upon dissociation and according to their vapour pressure. An additional selection is made by studying the time required to etch in the oxygen plasma the carbonaceous film previously deposited in the process plasma (precursor/ $\mathrm{H}_{2} / \mathrm{Ar}$ mixture) at various precursor flow rates. Experiments are carried out by monitoring the deposition and the cleaning sequences using in situ ellipsometry on a silicon wafer. The same procedure is used when $\mathrm{O}_{2}$ or $\mathrm{N}_{2} \mathrm{O}$ are partly substituted for $\mathrm{H}_{2}$ in the $\mathrm{CH}_{4}-\mathrm{H}_{2}-\mathrm{Ar}$ mixture. In such case the cleaning is carried out in $\mathrm{O}_{2} / \mathrm{Ar}$ or $\mathrm{N}_{2} \mathrm{O} / \mathrm{Ar}$ respectively.

Figure 1 reports the evolution of the ratio between the oxygen plasma cleaning time and the plasma process time in a precursor $/ \mathrm{H}_{2} / \mathrm{Ar}$ mixture as a function of the precursor 
flow, for the precursors methane, ethane, methanol, ethanol, acetone, isopropanol and nitromethane. Results show that clean time/process time ratio $(\mathrm{Tc} / \mathrm{Tp}$ ) for methanol is smaller than for methane; in the case of nitromethane the ratio is even null since no deposition occurs and all other precursors tested show larger Tc/Tp values. This leads to select methanol or nitromethane as organic precursor alternative to methane.

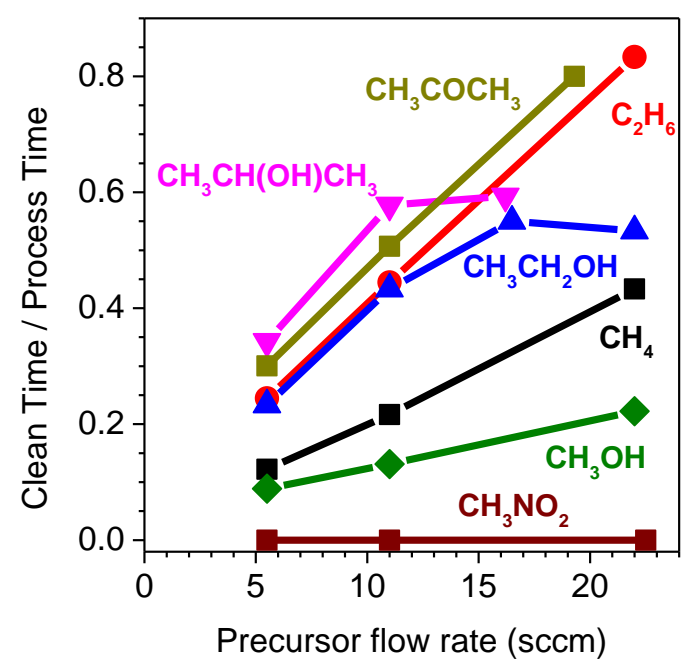

Figure 1: Ratio between the oxygen plasma cleaning time and the plasma process time in a precursor/ $\mathrm{H}_{2} / \mathrm{Ar}$ mixture $(\mathrm{X} /(55-\mathrm{X}) / 5 \mathrm{sccm})$ as a function of the precursor flow, for the precursors methane $(\bullet)$ and ethane $(\bullet)$ methanol $(\diamond)$, ethanol $(\boldsymbol{\Delta})$, acetone $(\bullet)$, isopropanol $(\nabla)$ and nitromethane $(\bullet)$.

Figure 2 presents the evolution of the deposition rate and $\mathrm{Tc} / \mathrm{Tp}$ ratio versus the $\mathrm{O}_{2}$ or $\mathrm{N}_{2} \mathrm{O}$ flow rate as these gases are partly substituted to $\mathrm{H}_{2}$ in $\mathrm{CH}_{4} / \mathrm{H}_{2} / \mathrm{Ar}$ mixtures. One can observe that when $\mathrm{O}_{2}$ is introduced into the $\mathrm{CH}_{4} / \mathrm{H}_{2} / \mathrm{Ar}$ mixture the deposition rate decreases. For $10 \mathrm{sccm}$ of $\mathrm{CH}_{4}, 4 \mathrm{sccm}$ of $\mathrm{O}_{2}$ are necessary to reach a deposition rate of zero. Replacing $\mathrm{O}_{2}$ by $\mathrm{N}_{2} \mathrm{O}$ brings a different result. At low $\mathrm{N}_{2} \mathrm{O}$ flow rates deposition rate increases when increasing the $\mathrm{N}_{2} \mathrm{O}$ flow rate. A maximum deposition rate is observed at 5 
sccm, beyond which the deposition rate decreases. $18 \mathrm{sccm}$ of $\mathrm{N}_{2} \mathrm{O}$ is necessary to avoid deposition. Thus introducing small amounts of $\mathrm{N}_{2} \mathrm{O}$ to a $\mathrm{CH}_{4} / \mathrm{H}_{2} / \mathrm{Ar}$ plasma favours the growth of a hydrocarbon film on the $\mathrm{Si}$ wafer. Introducing $4 \mathrm{sccm}$ of $\mathrm{O}_{2}$ or $18 \mathrm{sccm}$ of $\mathrm{N}_{2} \mathrm{O}$ allow respectively to suppress deposition and therefore validates the concept of $\mathrm{O}_{2}$ or $\mathrm{N}_{2} \mathrm{O}$ partial substitution for $\mathrm{H}_{2}$ to suppress deposition. Above $4 \mathrm{sccm} \mathrm{O}$ or $18 \mathrm{sccm} \mathrm{N}_{2} \mathrm{O}$ the "deposition rate" observed is attributed to the oxidation of the Si substrate. Comparing the $\mathrm{Tc} / \mathrm{Tp}$ ratio for the $\mathrm{CH}_{4} / \mathrm{H}_{2} / \mathrm{Ar}$ situation (i.e. no additives) one observes values of 0.2 and 0.5 when the $\mathrm{O}_{2} /$ Ar plasma (Figure 2-a) and $\mathrm{N}_{2} \mathrm{O} / \mathrm{Ar}$ plasma (Figure 2-b) are used for cleaning respectively. This puts forward the better cleaning efficiency of the former. 

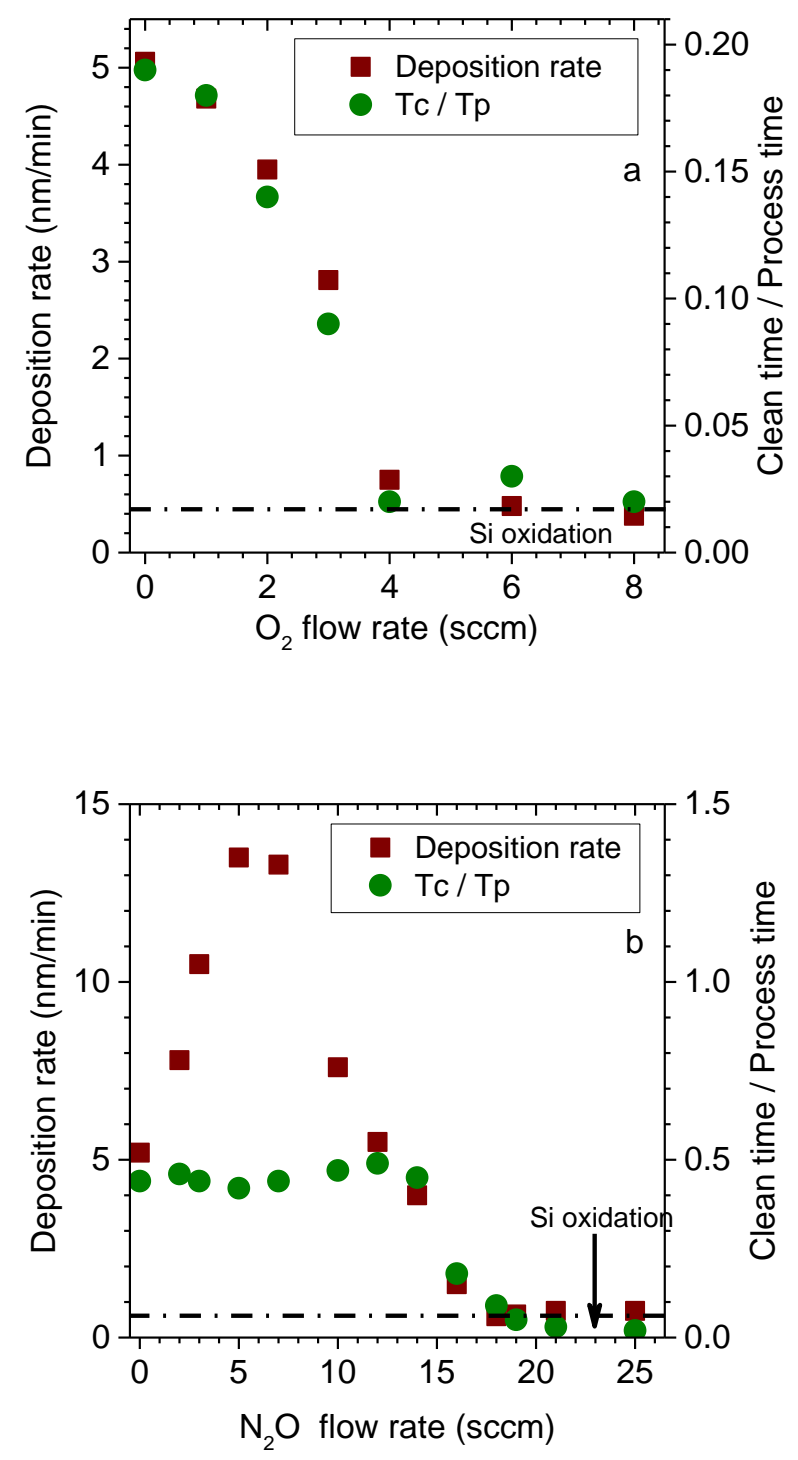

Figure 2: Deposition rate and $\mathrm{Tc} / \mathrm{Tp}$ ratio versus $\mathrm{O}_{2}$ and $\mathrm{N}_{2} \mathrm{O}$ flow rate in (a) a $\mathrm{CH}_{4} / \mathrm{O}_{2} / \mathrm{H}_{2} / \mathrm{Ar}$ and (b) a $\mathrm{CH}_{4} / \mathrm{N}_{2} \mathrm{O} / \mathrm{H}_{2} / \mathrm{Ar}$ plasma. Gas mixture is $10 / \mathrm{Y} /(45-\mathrm{Y}) / 5 \mathrm{sccm}$.

\section{B. Plasma study}

Figure 3 compares typical plasma emission spectra using methane, methanol and nitromethane precursors. When $\mathrm{O}_{2}$ and $\mathrm{N}_{2} \mathrm{O}$ are partly substituted for $\mathrm{H}_{2}$ in $\mathrm{CH}_{4} / \mathrm{H}_{2} / \mathrm{Ar}$, the plasma emission is similar to that of methanol and nitromethane, respectively. For the first 
mixture, characteristics lines of argon and hydrogen are principally detected. We also note that we do not detect the characteristic band of $\mathrm{CH}^{*}$ at $431.2 \mathrm{~nm}$, which suggests that hydrocarbon radicals produced upon dissociation of the precursors react rapidly with other reagents, including the surface of the vessel, to form various compounds. Thereafter, we will mainly focus on $\mathrm{H} \alpha$ and $\mathrm{Ar} *$ lines at $656.3 \mathrm{~nm}$ and $750.4 \mathrm{~nm}$ respectively. When oxygen is present is the mixture, i.e. when using methanol or with the substitution of $\mathrm{O}_{2}$ for $\mathrm{H}_{2}$, the characteristic line and bands of $\mathrm{O}^{*}$, although very weak in the case of methanol, CO* and $\mathrm{OH}^{*}$ appear. In the case of $\mathrm{CH}_{3} \mathrm{NO}_{2} / \mathrm{H}_{2} / \mathrm{Ar}$ and $\mathrm{CH}_{4} / \mathrm{N}_{2} \mathrm{O} / \mathrm{H}_{2} / \mathrm{Ar}$, introducing nitrogen induces the appearance of additional bands characteristic of $\mathrm{N}_{2}{ }^{*}, \mathrm{NO}^{*}, \mathrm{NH}^{*}$ and $\mathrm{CN}^{*}$, which again indicates that numerous recombination pathways exist from precursor dissociation products and reactions with the vessel walls. The species studied subsequently by pseudo-actinometry are presented in Table 1 . In the presentation hereinafter, to lighten the text we will call $\mathrm{X} *$ the actinometry ratios $\mathrm{X} * / \mathrm{Ar}^{*}$ (where $\mathrm{X}=\mathrm{CO}, \mathrm{CN}, \mathrm{O}, \mathrm{H} \alpha, \mathrm{NH}$, $\mathrm{OH})$. The correct denomination is however kept in the Figures. 

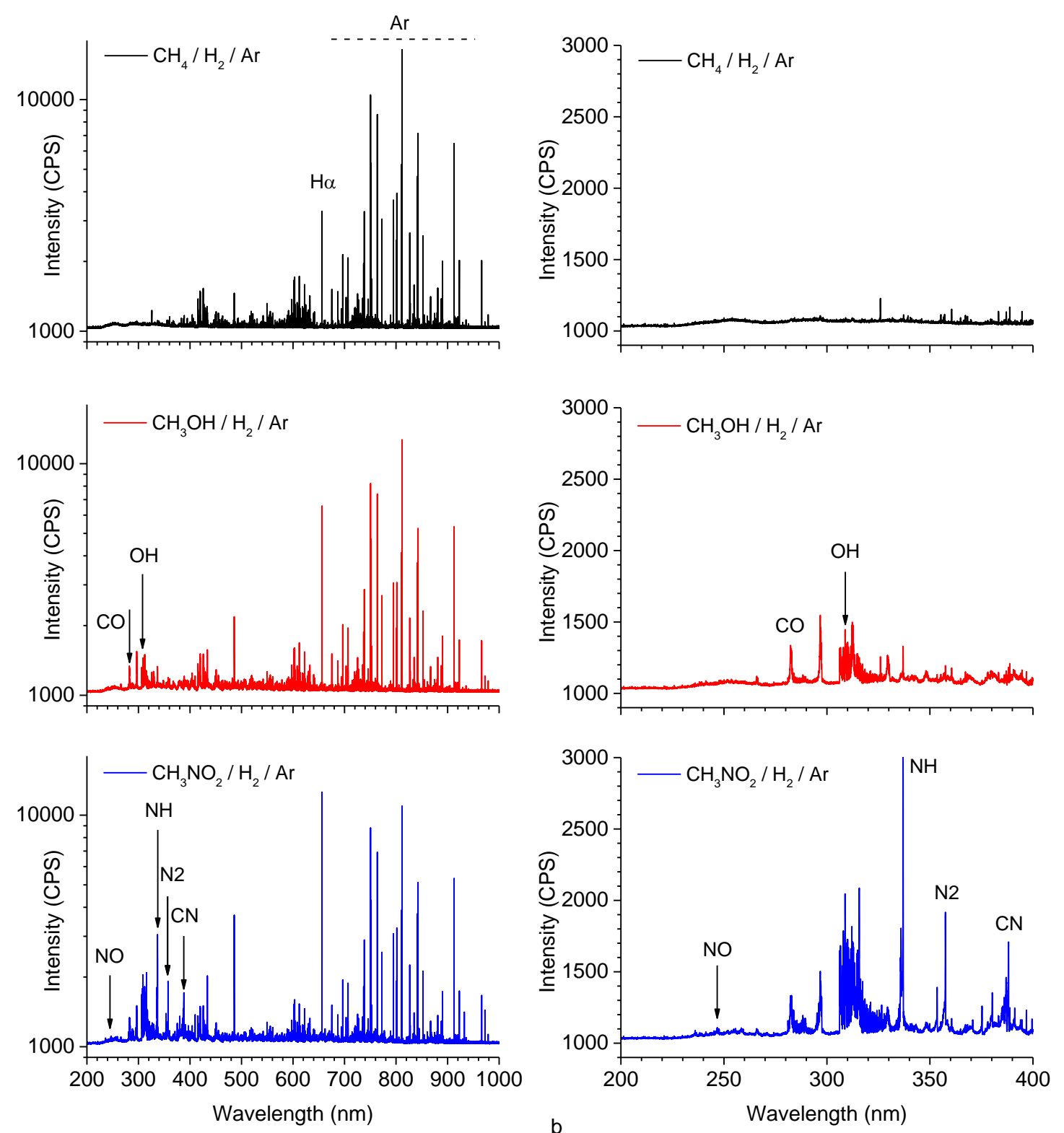

Figure 3: Typical optical emission spectra of $\mathrm{CH}_{4} / \mathrm{H}_{2} / \mathrm{Ar}, \mathrm{CH}_{3} \mathrm{OH} / \mathrm{H}_{2} / \mathrm{Ar}, \mathrm{CH}_{3} \mathrm{NO}_{2} / \mathrm{H}_{2} / \mathrm{Ar}$ plasmas obtained at $1000 \mathrm{~W}$ excitation power, 4 mTorr pressure, gas mixture is 8.5/46.5/5 sccm. Whole UV-vis. spectral range (a), blow up on the 200-400 $\mathrm{nm}$ range (b). Spectra are not corrected from the optical response of the measuring chain (fiber, monochromator, detector). 
Table 1: Plasma species studied by optical emission spectroscopy.

\begin{tabular}{cccrc}
\hline \hline Species & $\begin{array}{c}\text { Wavelength } \\
(\mathrm{nm})\end{array}$ & Electronic transition & $\begin{array}{c}\text { Energy of } \\
\text { the upper } \\
\text { level }(\mathrm{eV})\end{array}$ & Reference \\
\hline \hline $\mathrm{NO}^{*}$ & 247.1 & $A^{2} \Sigma^{+} \rightarrow X^{2} \Pi$ & 5.46 & 30,33 \\
$\mathrm{CO}^{*}$ & 283.3 & $b^{3} \Sigma \rightarrow a^{3} \Pi$ & 10.41 & 30,34 \\
$\mathrm{OH}^{*}$ & 308.9 & $A^{2} \Sigma^{+} \rightarrow X^{2} \Pi$ & 4.04 & 30,35 \\
$\mathrm{NH}^{*}$ & 336.0 & $A^{3} \Pi \rightarrow X^{3} \Sigma$ & 3.69 & 30,35 \\
$\mathrm{~N}^{*}$ & 357.7 & $C^{3} \Pi_{u} \rightarrow B^{3} \Pi_{g}$ & 11.06 & 30,36 \\
$\mathrm{CN}^{*}$ & 388.3 & $B^{2} \Sigma \rightarrow X^{2} \Sigma$ & 3.20 & 30,37 \\
$\mathrm{H}^{*}$ & 656.3 & $\mathrm{H}_{\alpha}$ & 12.09 & 31,38 \\
$\mathrm{Ar}^{*}$ & 750.4 & $3 s^{2} 3 p^{5} 4 p^{1}\left({ }^{3} P_{0}\right) \rightarrow 3 s^{2} 3 p^{5} 4 s^{1}\left({ }^{1} P_{1}\right)$ & 13.48 & $31, \underline{39}$ \\
$\mathrm{O}^{*}$ & 777.2 & $2 s^{2} 2 p^{3} 3 p^{1}\left({ }^{5} P_{1,2,3}\right) \rightarrow 2 s^{2} 2 p^{3} 3 s^{1}\left({ }^{5} S_{2}\right)$ & 10.74 & 31,40 \\
\hline \hline
\end{tabular}

From Table 1 on can see that the energy required to excite $\mathrm{NO}, \mathrm{NH}, \mathrm{OH}$ and $\mathrm{CN}$ species to the transition upper level (from 3.20 to $5.46 \mathrm{eV}$ ) is much smaller than that required to excite $\mathrm{Ar}, \mathrm{H}, \mathrm{O}$ atoms and $\mathrm{CO}$ (from 10.41 to $13.48 \mathrm{eV}$ ). Therefore the evolution of the intensity ratios presented below in Figure 4 and Figure 5 versus the $\mathrm{N}_{2} \mathrm{O}$ and $\mathrm{O}_{2}$ flow rate could be affected if the electron temperature changes along with this variable. Some electrical measurement (not shown) were carried out in methane, methanol and nitromethane based plasmas using a cylindrical Langmuir probe. No significant variation of electron temperature is observed when varying the precursor flow rate between 4 to 25 sccm, with typical values of $2.9 \pm 0.04 \mathrm{eV}, 2.7 \pm 0.1 \mathrm{eV}$ and $3.0 \pm 0.15 \mathrm{eV}$ for methane, methanol and nitromethane precursors respectively. Such experiments could not be carried out when $\mathrm{O}_{2}$ and $\mathrm{N}_{2} \mathrm{O}$ are partly substituted for hydrogen. However the close values observed when changing the precursor $(2.9,2.7$ and $3.0 \mathrm{eV})$ and the very close overall composition of the input gas mixture comparing on one hand $\mathrm{CH}_{4}(10) / \mathrm{O}_{2}(\mathrm{Y}) / \mathrm{H}_{2}(45$ Y)/Ar(5) with $\mathrm{CH}_{3} \mathrm{OH}(\mathrm{X}) / \mathrm{H}_{2}(55-\mathrm{X}) / \mathrm{Ar}(5)$ and on another hand $\mathrm{CH}_{4}(10) / \mathrm{N}_{2} \mathrm{O}(\mathrm{Y}) / \mathrm{H}_{2}(45-$ 
$\mathrm{Y}) / \mathrm{Ar}(5)$ with $\mathrm{CH}_{3} \mathrm{NO}_{2}(\mathrm{X}) / \mathrm{H}_{2}(55-\mathrm{X}) / \mathrm{Ar}(5)$ as $\mathrm{X}$ varies from 4 to $25 \mathrm{sccm}$ and $\mathrm{Y}$ from 0 to $20 \mathrm{sccm}$ make us believe that the electron temperature is likely to be weakly affected when varying the $\mathrm{O}_{2}$ and $\mathrm{N}_{2} \mathrm{O}$ flow rate within the investigated range. Under this assumption the evolution of intensity ratios reported in Figure 4 and Figure 5 should quite reasonably represent the evolution of the species density ratios.

For methanol and nitromethane precursors, intensity of the new characteristic lines and bands, i.e. $\mathrm{O}^{*}, \mathrm{OH}^{*}, \mathrm{CO}^{*}$ for the former and the same plus $\mathrm{N}_{2}{ }^{*}, \mathrm{NH}^{*}$ and $\mathrm{CN}^{*}$ for the latter, increases typically linearly as the amount of precursor is increased in the gas mixture (not shown). When substituting $\mathrm{O}_{2}$ or $\mathrm{N}_{2} \mathrm{O}$ the situation is quite different as shown in Figure 4 and Figure 5. In the $\mathrm{CH}_{4} / \mathrm{O}_{2} / \mathrm{H}_{2} / \mathrm{Ar}$ plasma the $\mathrm{CO}^{*}$ and $\mathrm{H} \alpha$ emission first increase sharply upon incorporation of $\mathrm{O}_{2}$ to the gas phase (Figure 4-a); but a saturation is observed above $5 \mathrm{sccm}$ of $\mathrm{O}_{2}$, which corresponds typically to the amount of $\mathrm{O}_{2}$ needed to suppress carbon deposition onto the $\mathrm{Si}$ wafer. Opposite the constant increase of $\mathrm{O}^{*}$ and $\mathrm{OH}^{*}$ bands indicates a constant rise of production of atomic oxygen and reaction products $\left(\mathrm{OH}, \mathrm{H}_{2} \mathrm{O}\right)$ between oxygen and hydrogen or hydrocarbon radicals. In the $\mathrm{CH}_{4} / \mathrm{N}_{2} \mathrm{O} / \mathrm{H}_{2} / \mathrm{Ar}$ plasma the $\mathrm{CN}^{*}$ emission increases sharply from 0 to $10 \mathrm{sccm} \mathrm{N}_{2} \mathrm{O}$ before decreasing (Figure 5-a). Meanwhile the $\mathrm{NO}^{*}$ emission first remains low before rising significantly. Our interpretation is that the formation of cyanyl is first limited by the amount of $\mathrm{N}_{2} \mathrm{O}$ incorporated in the gas mixture $(\mathrm{Y}<10)$ and then limited by the amount of $\mathrm{CH}_{4}(\mathrm{Y}>10)$. The transition between these two regimes takes place typically as the amount of $\mathrm{N}_{2} \mathrm{O}$ equals that of $\mathrm{CH}_{4}$. The $\mathrm{NH}^{*}$ emission increases up to $12 \mathrm{sccm}$ of $\mathrm{N}_{2} \mathrm{O}$ and then saturates (Figure 5-b); this saturation could be related to the fact that the addition of $\mathrm{N}_{2} \mathrm{O}$ is made to the detriment of the $\mathrm{H}_{2}$ flow. The intensity of the $\mathrm{H} \alpha$ line follows a similar evolution. 
Moreover, the intensity of the emission of $\mathrm{O}^{*}$ line, $\mathrm{OH}^{*}$ and $\mathrm{N}_{2} *$ bands increases linearly with the flow of $\mathrm{N}_{2} \mathrm{O}$; the formation of these species is therefore not affected by the reaction kinetics involving $\mathrm{CN}$ (Figure 5-c). The continuous increase in the intensity of the $\mathrm{CO}^{*}$ band indicates that, in the range studied, the formation of this molecule is globally proportional to the number of oxygen atoms brought by $\mathrm{N}_{2} \mathrm{O}$.
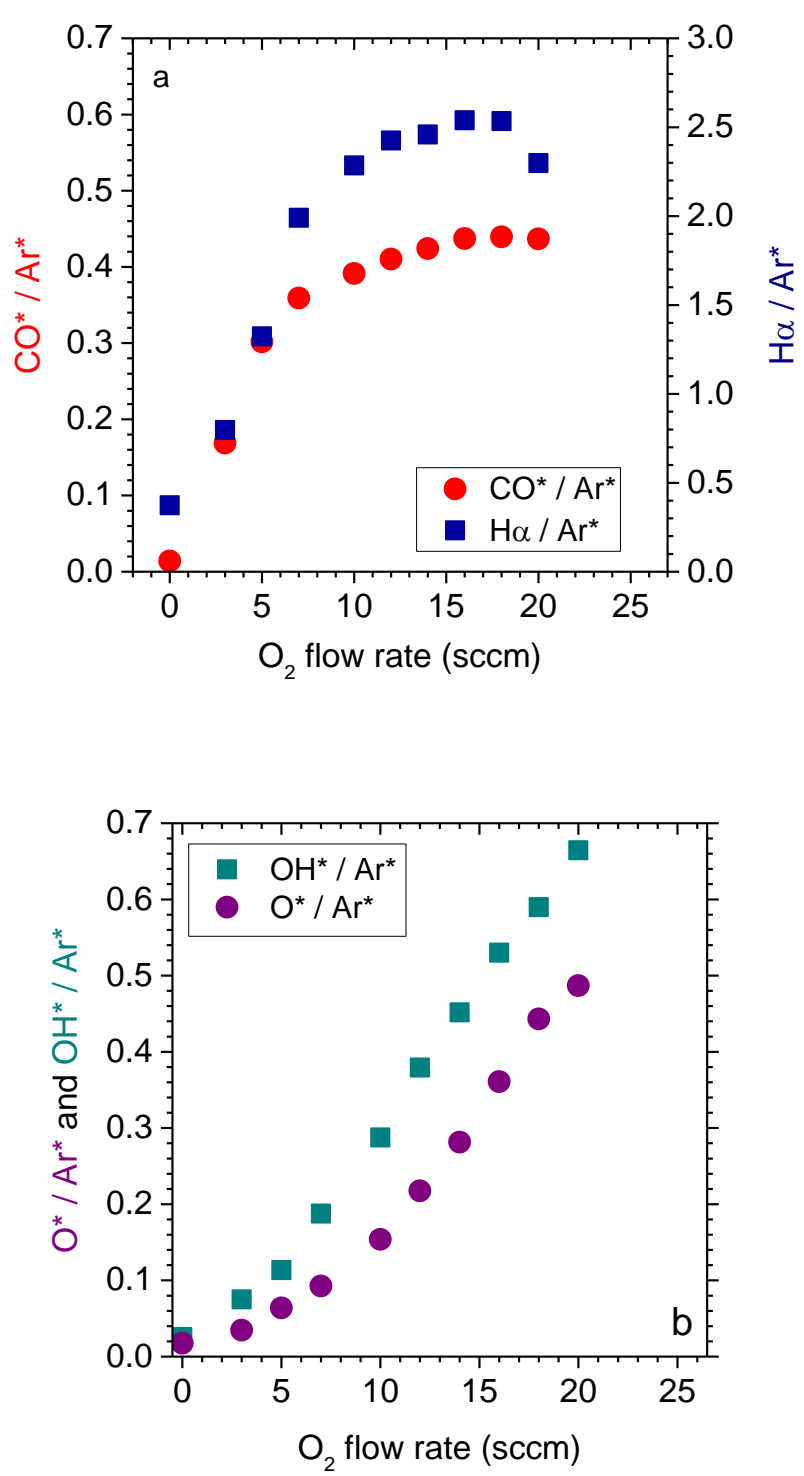
Figure 4: Evolution of the actinometry ratios $\mathrm{X}^{*} / \mathrm{Ar}^{*}$ for (a) $\mathrm{X}^{*}=\mathrm{CO}^{*}, \mathrm{H}^{*}$ and (b) $\mathrm{X}^{*}=$ $\mathrm{OH}^{*}$ and $\mathrm{O}^{*}$ when varying the amount of $\mathrm{O}_{2}$ in $\mathrm{CH}_{4} / \mathrm{O}_{2} / \mathrm{H}_{2} / \mathrm{Ar}(10 / \mathrm{Y} / 45-\mathrm{Y} / 5 \mathrm{sccm})$ mixture.
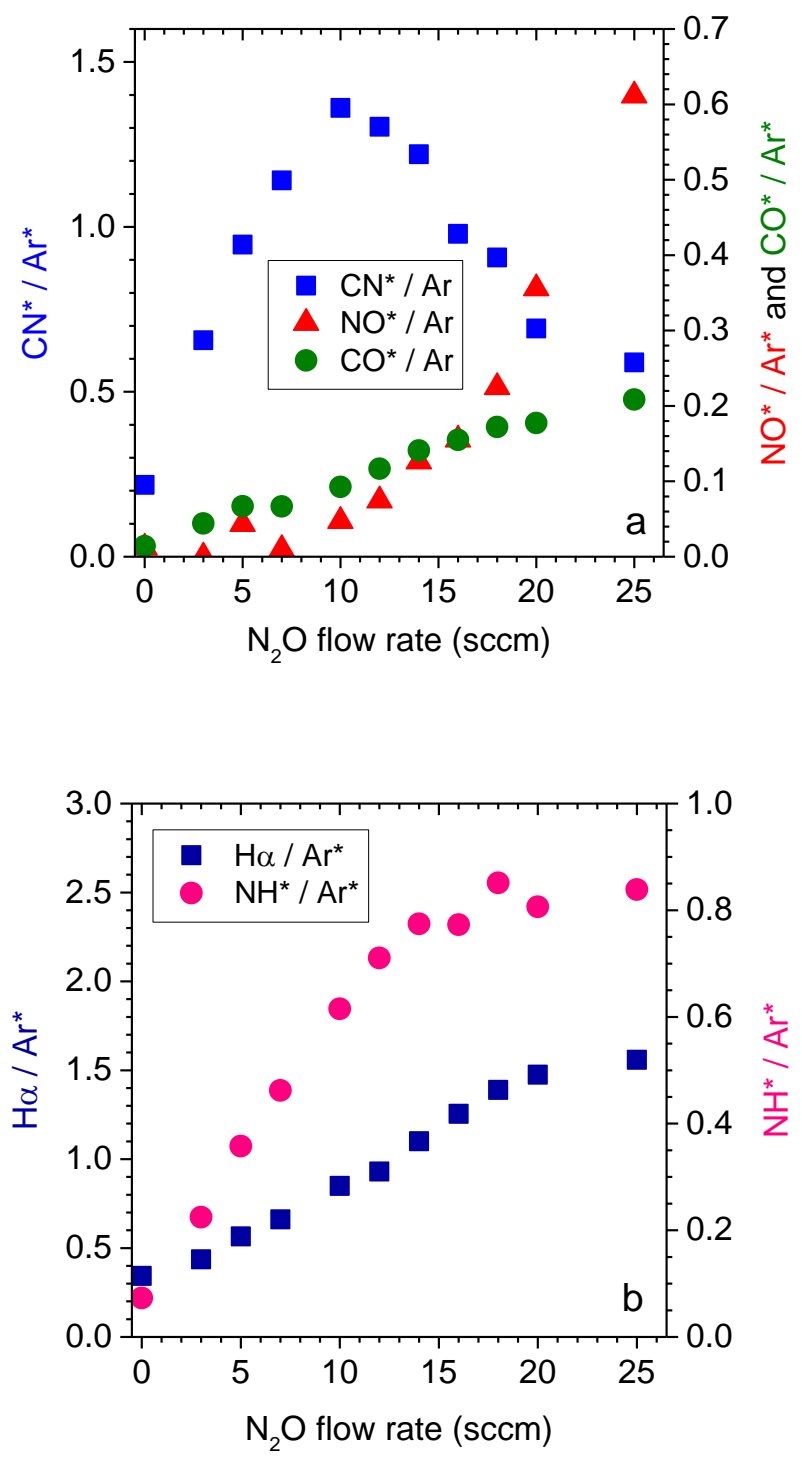


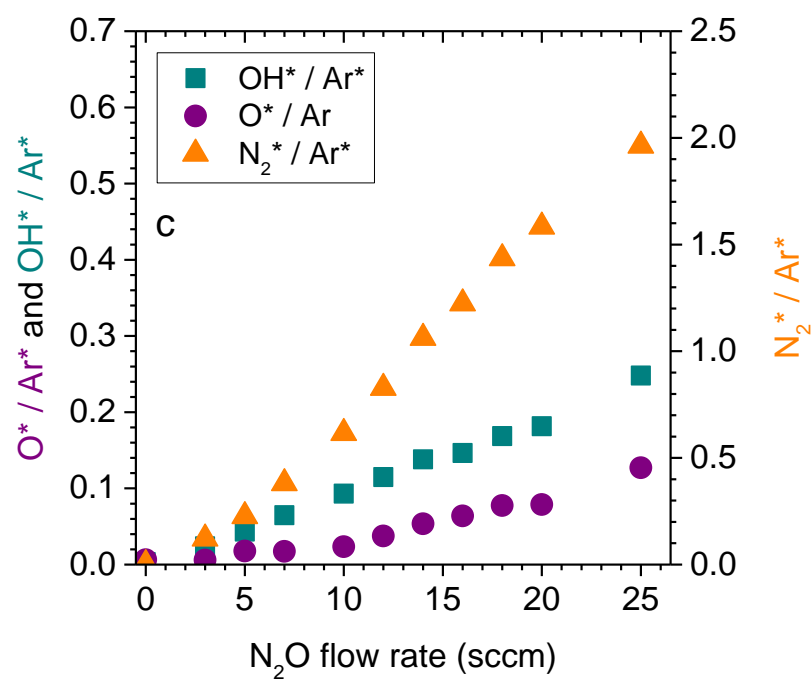

Figure 5: Evolution of the actinometry ratios $\mathrm{X}^{*} / \mathrm{Ar}^{*}$ for (a) $\mathrm{X}^{*}=\mathrm{CN}^{*}, \mathrm{NO}, \mathrm{CO} *$, (b) $\mathrm{X}^{*}$ $=\mathrm{NH}^{*}, \mathrm{H}^{*}$ and (c) $\mathrm{X}^{*}=\mathrm{OH}^{*}$ and $\mathrm{O}^{*}$ when varying the amount of $\mathrm{N}_{2} \mathrm{O}$ in $\mathrm{CH}_{4} / \mathrm{N}_{2} \mathrm{O} / \mathrm{H}_{2} / \mathrm{Ar}$ $(10 / \mathrm{Y} / 45-\mathrm{Y} / 5 \mathrm{sccm})$ mixture.

Ion flux measurements (not shown) reveal that whatever the precursor and whatever the flow rate within the investigated range, the flux of positive ions remains typically alike. This important result points out that, at constant substrate bias, changing the precursor between methane, methanol, or nitromethane does not affect the energy flux brought to the surface by the ion bombardment i.e. the physical contribution to the plasma surface interaction mechanism. Still, similarly to what is generally observed when varying the gas mixture ${ }^{15,41,42,43}$, the ion composition may evolve when changing the precursor, but such changes will contribute to the chemical part of the interaction mechanism. Therefore any change in the deposition mechanism on the Si wafer is likely to be due to a change in the overall chemical composition of the plasma. 


\section{Surface analysis of the film deposited at low amount of $\mathrm{O}_{2}$ and $\mathrm{N}_{2} \mathrm{O}$ additives}

The carbonaceous film deposited onto the $\mathrm{Si}$ wafer in $\mathrm{CH}_{4} / \mathrm{H}_{2} / \mathrm{Ar}$ plasma and when substituting in part $\mathrm{O}_{2}$ or $\mathrm{N}_{2} \mathrm{O}$ for $\mathrm{H}_{2}$ has been analysed by means of in situ XPS.

Survey scan results (not shown) can be resumed as follows. As expected the spectrum for the deposit formed in $\mathrm{CH}_{4} / \mathrm{H}_{2} / \mathrm{Ar}$ shows only a carbon signature with the $\mathrm{C} 1 \mathrm{~s}$ core level at $\sim 284.8 \mathrm{eV}$. With the introduction of $2 \mathrm{sccm}$ of $\mathrm{O}_{2}$ into the gas mixture, the analysis reveals the presence of oxygen in the layer deposited in $\mathrm{CH}_{4} / \mathrm{O}_{2} / \mathrm{H}_{2} / \mathrm{Ar}$ plasma, as shown by the $\mathrm{O} 1 \mathrm{~s}$ core level at $\sim 532.4 \mathrm{eV}$. Yet the amount is small as quantification gives only $\sim 8$ atom\% (Table 2). Finally, incorporation of $5 \mathrm{sccm} \mathrm{N}_{2} \mathrm{O}$ produces a $\mathrm{C}(\mathrm{H}) \mathrm{Nx}$ layer containing $\sim 8 \% \mathrm{O}, 28 \% \mathrm{~N}$ and $64 \% \mathrm{C}$ (Table 2), with an additional signal N1s signal at $\sim 398.7 \mathrm{eV}$.

High resolution spectra of the C1s and N1s core levels are shown in Figure 6 and curve fitting results are presented in Table 2. This detailed analysis confirms that oxygen is only a minor element in the film produced in $\mathrm{CH}_{4} / \mathrm{O}_{2} / \mathrm{H}_{2} / \mathrm{Ar}$ (Figure 6-b). For the film deposited in $\mathrm{CH}_{4} / \mathrm{N}_{2} \mathrm{O} / \mathrm{H}_{2} / \mathrm{Ar}$ both the $\mathrm{C} 1 \mathrm{~s}$ and $\mathrm{N} 1 \mathrm{~s}$ spectra show evidence of various chemical environments involving carbon and nitrogen atoms in the film network (Figure 6c, 6d). Following literature data ${ }^{44,45,46,47}$, the $\mathrm{C} 1 \mathrm{~s}$ components can be tentatively ascribed to $\mathrm{C}(\mathrm{sp} 2)-\mathrm{N}$ : $285.9 \mathrm{eV}, \mathrm{C}(\mathrm{sp} 3)-\mathrm{N}, \mathrm{C}=\mathrm{N}$ and $\mathrm{N}-\mathrm{C}(\mathrm{sp} 2)-\mathrm{N}$ : $287.3 \mathrm{eV}$ and $\mathrm{CN}$ (cyano group): $288.7 \mathrm{eV}$. In the same way we propose the following assignment, $\mathrm{N}-\mathrm{C}: 400.1 \mathrm{eV}, \mathrm{N}=\mathrm{C}$ and CN (cyano): $398.9 \mathrm{eV}$ and N-H: $397.8 \mathrm{eV}$, for the N1s components. Concerning oxygen, once again it appears as a minor element in the film composition. 

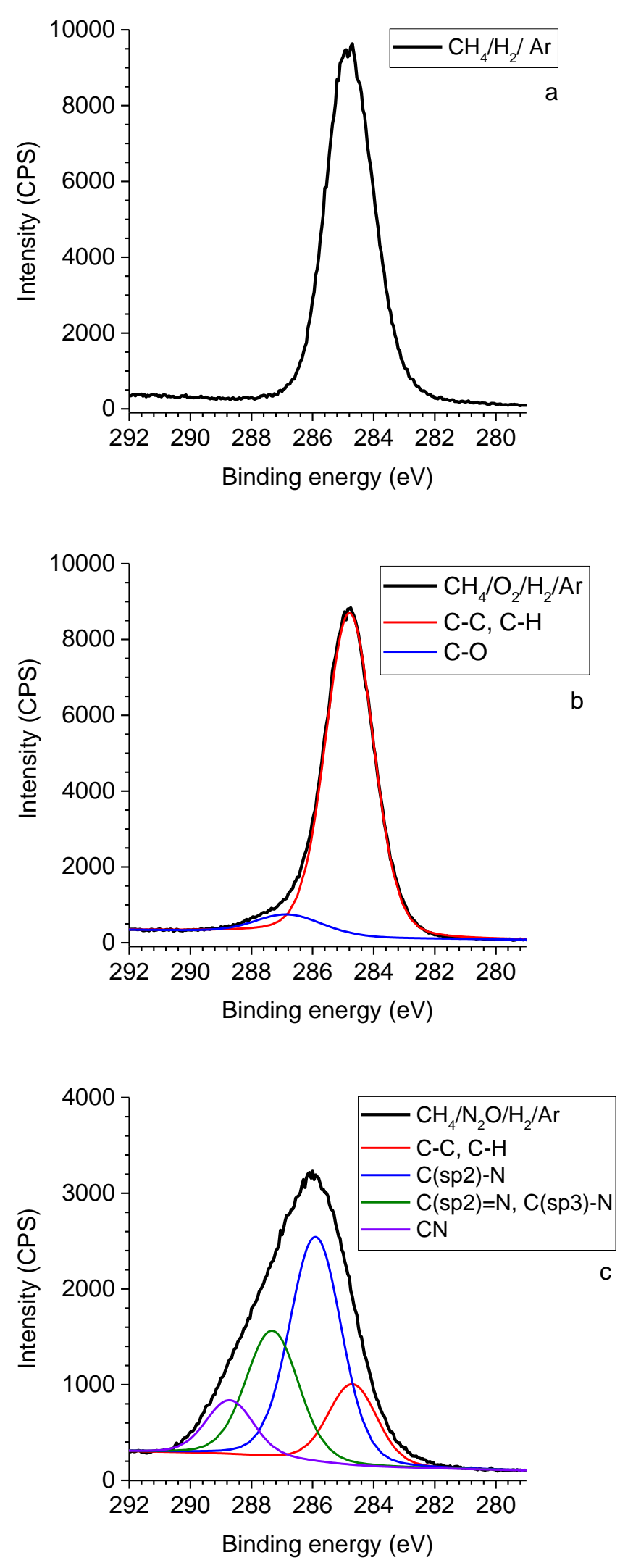


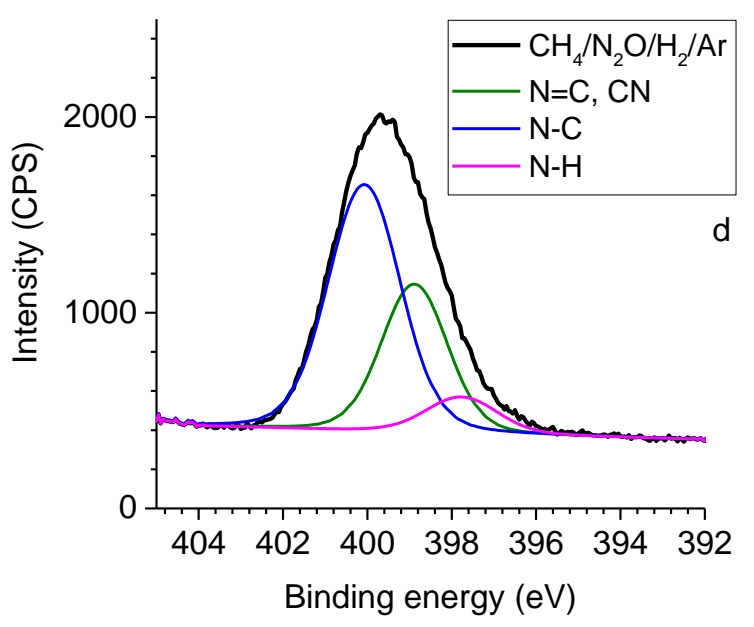

Figure 6: C 1s (a, b, c) and N1s (d) spectra of the layers deposited on $\mathrm{Si}$ in (a) $\mathrm{CH}_{4} / \mathrm{H}_{2} / \mathrm{Ar}$, (b) $\mathrm{CH}_{4} / \mathrm{O}_{2}(2 \mathrm{sccm}) / \mathrm{H}_{2} / \mathrm{Ar}$ and (c, d) $\mathrm{CH}_{4} / \mathrm{N}_{2} \mathrm{O}(5 \mathrm{sccm}) / \mathrm{H}_{2} / \mathrm{Ar}$ plasmas.

Table 2: In situ XPS quantification and spectrum curve fitting results for the layers deposited in $\mathrm{CH}_{4} / \mathrm{H}_{2} / \mathrm{Ar}, \mathrm{CH}_{4} / \mathrm{O}_{2}(2 \mathrm{sccm}) / \mathrm{H}_{2} / \mathrm{Ar}$ and $\mathrm{CH}_{4} / \mathrm{N}_{2} \mathrm{O}(5 \mathrm{sccm}) / \mathrm{H}_{2} / \mathrm{Ar}$ plasmas.

\begin{tabular}{|c|c|c|c|c|c|c|c|c|c|}
\hline & & \multicolumn{4}{|c|}{$\mathrm{C} 1 \mathrm{~s}$} & \multicolumn{2}{|l|}{ O1s } & \multicolumn{2}{|l|}{ N1s } \\
\hline & Species & $\begin{array}{l}\mathrm{C}-\mathrm{C}, \\
\mathrm{C}-\mathrm{H}\end{array}$ & $\begin{array}{l}\mathrm{C}-\mathrm{O} \\
\mathrm{C}-\mathrm{N} \\
\end{array}$ & $\mathrm{C}=\mathrm{N}$ & $\mathrm{CN}$ & $\mathrm{O}-\mathrm{C}$ & $\mathrm{N}-\mathrm{H}$ & $\mathrm{N}=\mathrm{C}$ & $\mathrm{N}-\mathrm{C}$ \\
\hline \multirow{4}{*}{ 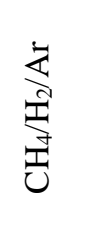 } & Atom $\%$ & \multicolumn{4}{|c|}{100} & - & & - & \\
\hline & $\mathrm{BE}(\mathrm{eV})$ & 284.8 & - & - & - & - & - & - & - \\
\hline & FWHM (eV) & 1.81 & - & - & - & - & - & - & - \\
\hline & Fraction $(\%)$ & 100 & - & - & - & - & - & - & - \\
\hline \multirow{3}{*}{ 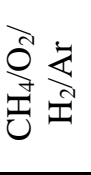 } & Atom $\%$ & \multicolumn{4}{|c|}{92} & 8 & & - & \\
\hline & $\mathrm{BE}(\mathrm{eV})$ & 284.8 & 286.8 & - & - & 532.4 & - & - & - \\
\hline & FWHM (eV) & 1.85 & 2.40 & - & - & 2.39 & - & - & - \\
\hline
\end{tabular}




\begin{tabular}{|c|c|c|c|c|c|c|c|c|c|}
\hline & Fraction $(\%)$ & 93 & 7 & - & - & 100 & - & - & - \\
\hline \multirow{4}{*}{ 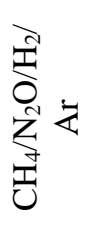 } & Atom \% & \multicolumn{4}{|c|}{64} & 8 & \multicolumn{3}{|c|}{28} \\
\hline & $\mathrm{BE}(\mathrm{eV})$ & 284.7 & 285.9 & 287.3 & 288.7 & 531.5 & 397.8 & 398.9 & 400.1 \\
\hline & FWHM (eV) & 1.89 & 1.99 & 2.02 & 1.81 & 2.66 & 1.99 & 1.83 & 2.02 \\
\hline & Fraction $(\%)$ & 16 & 47 & 27 & 10 & 100 & 9 & 32 & 59 \\
\hline
\end{tabular}

\section{Discussion on the role of the additives with respect to film deposition}

The Tc/Tp ratio evolves as the deposition rate for the $\mathrm{CH}_{4} / \mathrm{O}_{2} / \mathrm{H}_{2} / \mathrm{Ar}$ plasma (Figure 2-a). The process time (Tp) being fixed for all experiments, this "proportional regime" corresponds to a situation in which the cleaning time is proportional to layer thickness i.e. the clean rate is also constant. Therefore the presence of $\mathrm{O}_{2}$ in the gas mixture introduces an etching mechanism competing with the deposition mechanism.

In the case of the $\mathrm{CH}_{4} / \mathrm{N}_{2} \mathrm{O} / \mathrm{H}_{2} / \mathrm{Ar}$ plasma the $\mathrm{Tc} / \mathrm{Tp}$ ratio is typically constant for low $\mathrm{N}_{2} \mathrm{O}$ flux and becomes "proportional" to the deposition rate above $12 \mathrm{sccm}$ of $\mathrm{N}_{2} \mathrm{O}$ (Figure 2-b). Since the process time is fixed, a constant $\mathrm{Tc} / \mathrm{Tp}$ ratio in the first regime means a constant clean time, whatever the thickness deposited. This suggests that introducing small amounts $(\mathrm{Y}<12)$ of $\mathrm{N}_{2} \mathrm{O}$ in the gas mixture has an important impact on the layer composition and structure, but unfortunately we do not have XPS analyses of the film for other mixtures than $5 \mathrm{sccm} \mathrm{N}_{2} \mathrm{O}$. However the comparison of the deposition rate with the OES $\mathrm{CN}^{*}$ emission gives an interesting perception of the dominant mechanism (Figure 7). First, the deposition rate increases together with the amount of $\mathrm{CN}$ species formed in the plasma. Second, the $\mathrm{N}_{2} \mathrm{O}$ flow rate where the $\mathrm{CN}$ concentration starts to decrease is also typically the point where the $\mathrm{Tc} / \mathrm{Tp}$ ratio stops to be constant and becomes proportional to the deposition rate. 
Our interpretation is the following: The nitrogen species incorporated in the gas mixture by $\mathrm{N}_{2} \mathrm{O}$ favour the formation of a carbonaceous film onto the $\mathrm{Si}$ wafer. However film composition and structure evolve in such a way as the amount of $\mathrm{N}_{2} \mathrm{O}$ is increased that its further etching in an oxidising plasma is eased and most likely the higher the proportion of nitrogen in the film the more easy the etching. Since oxygen atoms are introduced simultaneously in the gas mixture, the film growth mechanism is in constant competition with an etching mechanism. This second one takes over gradually as $\mathrm{Y}>7 \mathrm{sccm}$, as supported by the decrease of the deposition rate from this point, which is accompanied by the rise of the $\mathrm{NO}^{*}$ and $\mathrm{CO} *$ (Figure 5-a). At $\mathrm{Y}=12$ the deposition rate has fall back to its initial value when no $\mathrm{N}_{2} \mathrm{O}$ is substituted $(\mathrm{Y}=0)$, this means that in relation to the proportion of methane in the mixture, the opposite effects of nitrogen and oxygen are balanced. And the film deposited at higher $\mathrm{N}_{2} \mathrm{O}$ behaves like those deposited with $\mathrm{O}_{2}$. Finally oxygen atoms appear as being the true etch reactant, whereas incorporation of nitrogen in the film favours its etching kinetics.

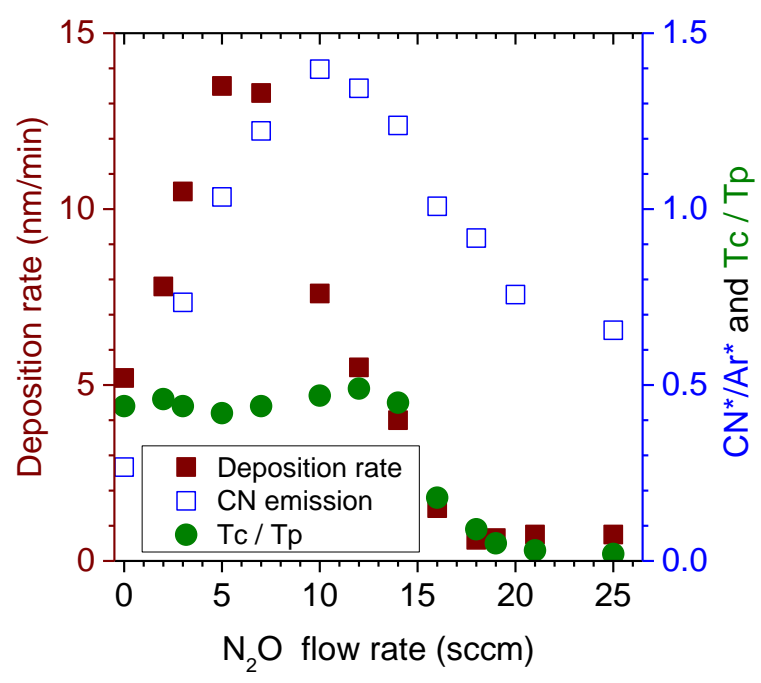


Figure 7: Deposition rate, clean time / process time ratio and CN*/Ar* ratio versus the $\mathrm{N}_{2} \mathrm{O}$ flow rate in a $\mathrm{CH}_{4} / \mathrm{N}_{2} \mathrm{O} / \mathrm{H}_{2} / \mathrm{Ar}$ plasma. Gas mixture is $10 / \mathrm{Y} /(45-\mathrm{Y}) / 5 \mathrm{sccm}$.

\section{INTEREST FOR HgCdTe ETCHING}

\section{A. Comparison of precursors}

Interest of methanol and nitromethane precursors or partial substitution of $\mathrm{N}_{2} \mathrm{O}$ for $\mathrm{H}_{2}$ in $\mathrm{CH}_{4} / \mathrm{H}_{2} / \mathrm{Ar}$ mixture for the etching of $\mathrm{HgCdTe}$ at low bias and potentially with low carbon contamination is investigated. Substitution of $\mathrm{O}_{2}$ is not studied. $\mathrm{HgCdTe}$ samples are etched at a pressure of 4 mTorr and a source power of $1000 \mathrm{~W}$. A substrate bias is necessary with the $\mathrm{CH}_{4} / \mathrm{H}_{2} / \mathrm{Ar}$ and $\mathrm{CH}_{3} \mathrm{OH} / \mathrm{H}_{2} / \mathrm{Ar}$ plasmas in order to avoid carbon deposition and ensure the etching; bias power of $50 \mathrm{~W}$ and $10 \mathrm{~W}$ are chosen respectively. No substrate bias is applied with the nitromethane precursor or with incorporation of $\mathrm{N}_{2} \mathrm{O}$. For the latter case, following the data presented in Figure 2 the amount of $\mathrm{N}_{2} \mathrm{O}$ is fixed as twice that of methane.

Table 3 collects typical data for the etch rate and surface roughness and presents typical AFM and SEM images. The etch rate is larger with the methanol precursor than with any other precursor, but the average roughness is also significantly greater; this observation led us not to further develop studies with this precursor. Looking at nitromethane precursor and incorporation of $\mathrm{N}_{2} \mathrm{O}$ to $\mathrm{CH}_{4} / \mathrm{H}_{2} / \mathrm{Ar}$, it comes out that etching $\mathrm{HgCdTe}$ without bias is possible with these two mixtures and the etch rate for the latter case is only $25 \%$ less than with the methane precursor, with a comparable average roughness. Another observation is the presence of small bumps on the surface etched in 
$\mathrm{CH}_{4} / \mathrm{H}_{2} / \mathrm{Ar}$ as seen on the AFM and SEM images. These bumps are not observed when replacing methane by nitromethane or using $\mathrm{CH}_{4} / \mathrm{N}_{2} \mathrm{O} / \mathrm{H}_{2} / \mathrm{Ar}$.

Table 3: AFM image, average roughness and SEM image after etching in $\mathrm{CH}_{4} / \mathrm{H}_{2} / \mathrm{Ar}$, $\mathrm{CH}_{3} \mathrm{OH} / \mathrm{H}_{2} / \mathrm{Ar}, \mathrm{CH}_{3} \mathrm{NO}_{2} / \mathrm{H}_{2} / \mathrm{Ar}$ and $\mathrm{CH}_{4} / \mathrm{N}_{2} \mathrm{O} / \mathrm{H}_{2} / \mathrm{Ar}$ plasmas.

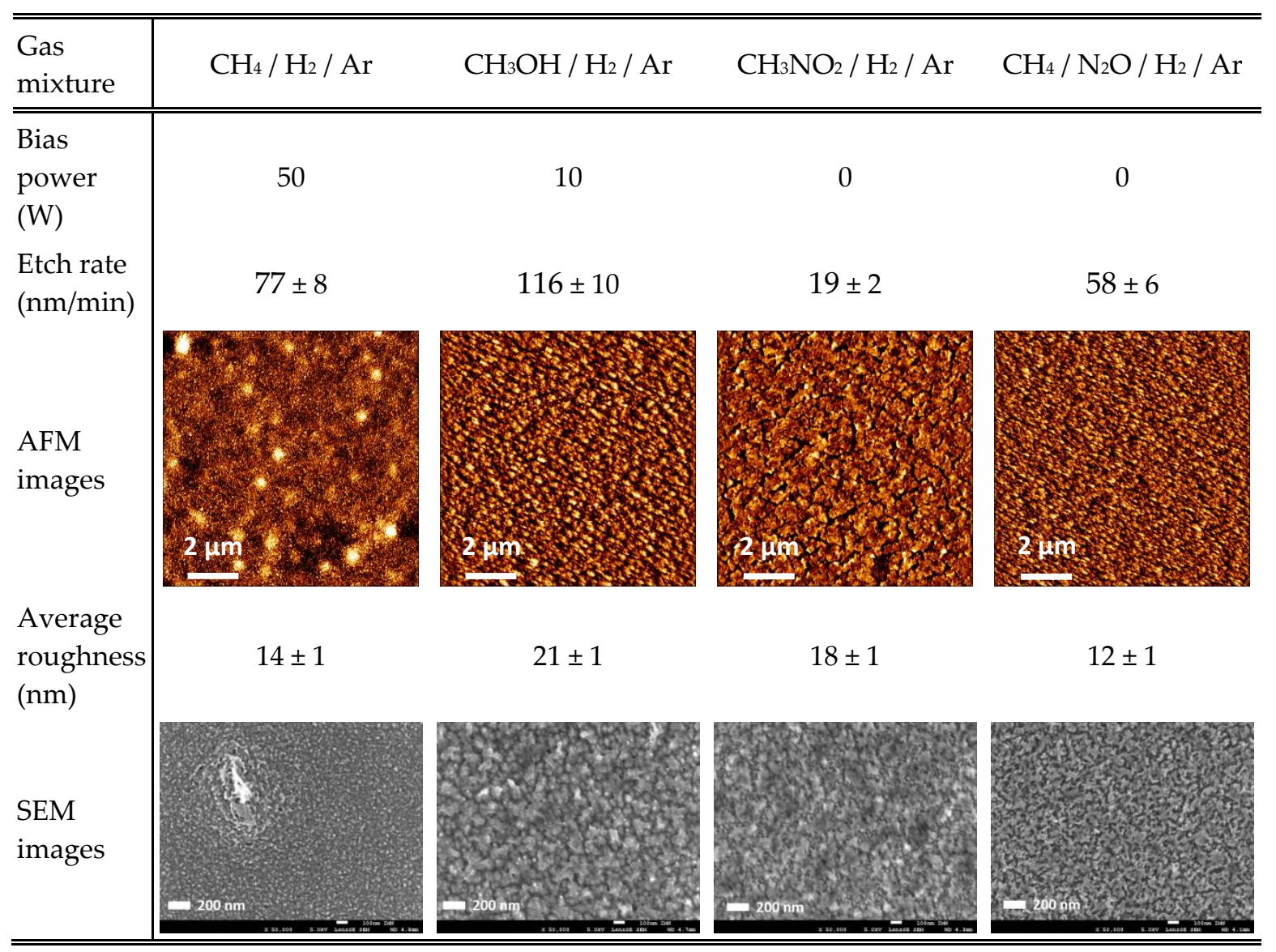

In situ XPS analysis were carried out on sample etched in $\mathrm{CH}_{4} / \mathrm{H}_{2} / \mathrm{Ar}$, $\mathrm{CH}_{3} \mathrm{NO}_{2} / \mathrm{H}_{2} / \mathrm{Ar}$ and $\mathrm{CH}_{4} / \mathrm{N}_{2} \mathrm{O} / \mathrm{H}_{2} / \mathrm{Ar}$ plasmas and compared to the reference material before etching. Results from high resolution spectra are presented in Figure 8 and Table 4. 
The reference sample presents $\mathrm{Te} 3 \mathrm{~d}, \mathrm{Cd} 3 \mathrm{~d}$ and $\mathrm{Hg} 4 \mathrm{f}$ core level spectra characteristic of the $\mathrm{HgCdTe}$ material $^{48,49}$. However the surface presents slight contributions from $\mathrm{TeO}_{2}(\mathrm{Te} 3 \mathrm{~d} 5 / 2 \text { at } 576.3 \mathrm{eV})^{49}$ and $\mathrm{Te}^{0}($ elemental Te, $\mathrm{Te} 3 \mathrm{~d} 5 / 2$ at 573.4 $\mathrm{eV})^{50,51}$. Presence of $\mathrm{Te}^{0}$ on the surface results from the sample cleaning procedure involving $\mathrm{Br}_{2} /$ methanol wet etching ${ }^{51,52}$. For the three precursors, analysis after etching reveals only one contribution corresponding to the $\mathrm{HgCdTe}$ material (Figure 8 and Table 4). In particular no Te oxide component nor $\mathrm{Te}^{0}$ component are observable. Two significant differences with respect to the reference material are noticed: the first is the increase of the intensity of the Cd signal, accompanied by the decrease of the $\mathrm{Hg}$ signal, which is the signature of the depletion in mercury in the surface layer. The second is an increase of the spectral widths (FWHM) that can be interpreted as due to the surface amorphisation and disorganisation caused by the etching mechanism (Table 4).

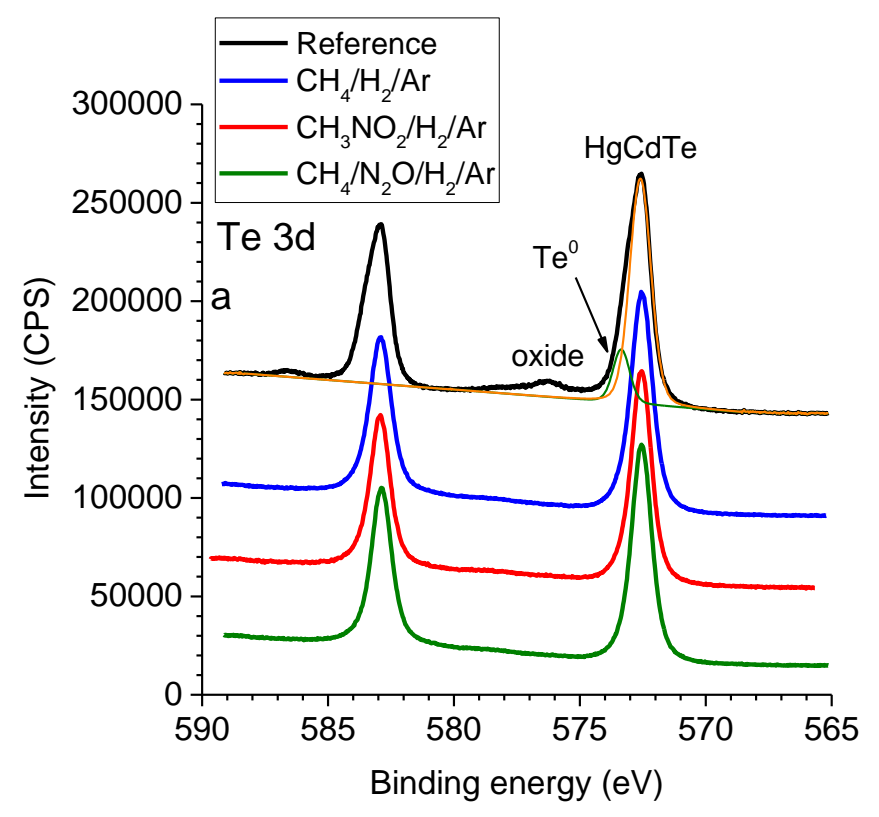



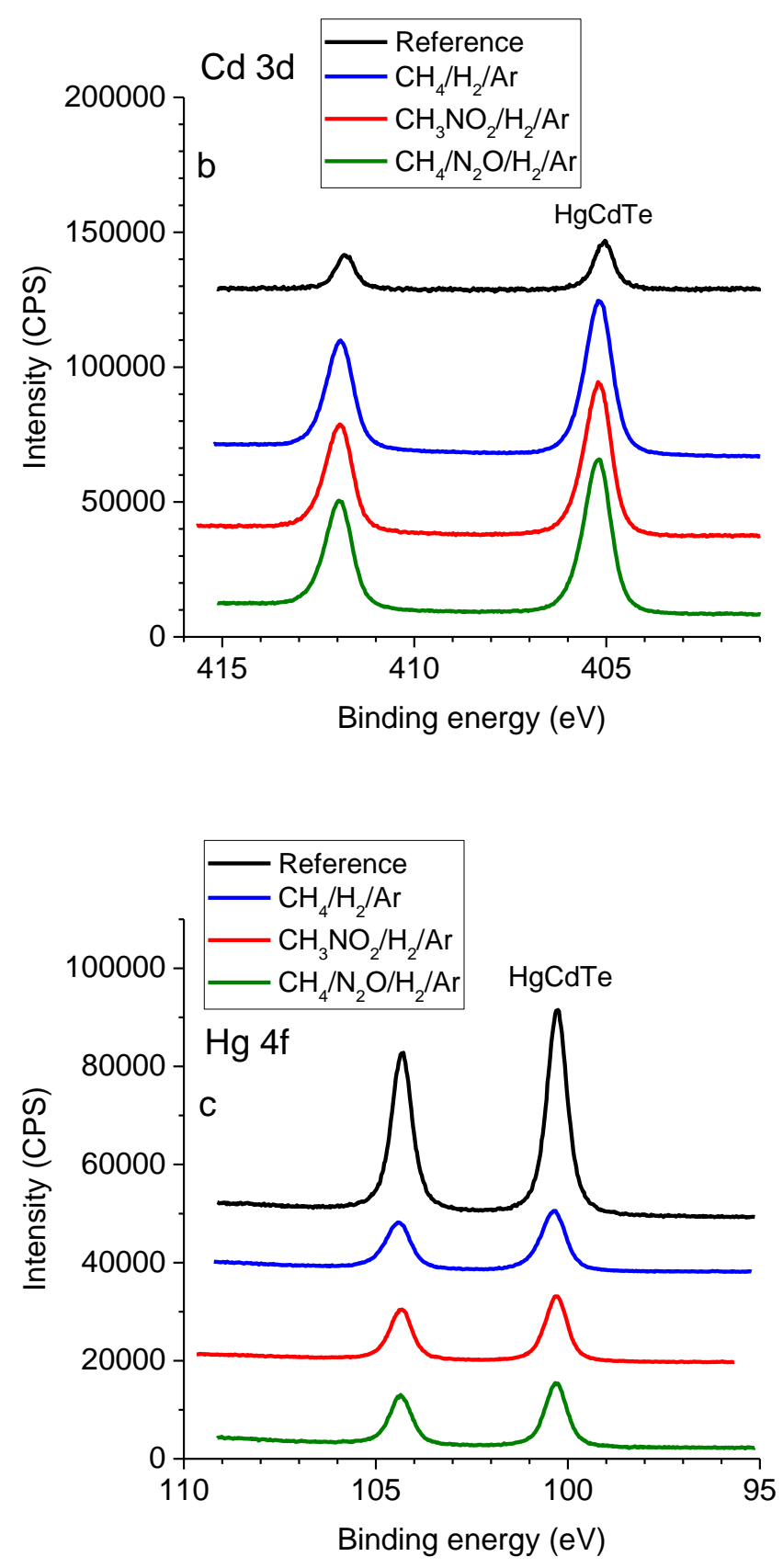

Figure 8: Te3d (a), Cd3d (b) and $\mathrm{Hg} 4 \mathrm{f}$ (c) spectra for the $\mathrm{HgCdTe}$ samples etched in $\mathrm{CH}_{4} / \mathrm{H}_{2} / \mathrm{Ar}, \mathrm{CH}_{3} \mathrm{NO}_{2} / \mathrm{H}_{2} / \mathrm{Ar}$ and $\mathrm{CH}_{4} / \mathrm{N}_{2} \mathrm{O} / \mathrm{H}_{2} / \mathrm{Ar}$ plasmas. 
Table 4: In situ XPS spectrum curve fitting results for $\mathrm{HgCdTe}$ reference and samples etched in $\mathrm{CH}_{4} / \mathrm{H}_{2} / \mathrm{Ar}, \mathrm{CH}_{3} \mathrm{NO}_{2} / \mathrm{H}_{2} / \mathrm{Ar}$ and $\mathrm{CH}_{4} / \mathrm{N}_{2} \mathrm{O} / \mathrm{H}_{2} / \mathrm{Ar}$ plasmas.

\begin{tabular}{|c|c|c|c|c|c|c|}
\hline & & & $\mathrm{Te} 3 \mathrm{~d} 5 / 2$ & & $\mathrm{Cd} 3 \mathrm{~d} 3 / 2$ & $\mathrm{Hg} 4 \mathrm{f} 7 / 2$ \\
\hline & Species & $\mathrm{HgCdTe}$ & element & oxide & $\mathrm{HgCdTe}$ & $\mathrm{HgCdTe}$ \\
\hline \multirow{4}{*}{ Reference } & Atom \% ( $\mathrm{HgCdTe})$ & & 70 & & 6 & 24 \\
\hline & $\mathrm{BE}(\mathrm{eV})$ & 572.6 & 573.4 & 576.3 & 405.1 & 100.3 \\
\hline & FWHM (eV) & 0.99 & 0.78 & 0.99 & 0.64 & 0.66 \\
\hline & Fraction $\%$ & 82 & 15 & 2 & 100 & 100 \\
\hline \multirow{3}{*}{$\begin{array}{l}\mathrm{CH}_{4} / \mathrm{H}_{2} / \mathrm{Ar} \\
50 \mathrm{~W} \text { bias }\end{array}$} & Atom \% ( $\mathrm{HgCdTe})$ & & 53 & & 37 & 10 \\
\hline & $\mathrm{BE}(\mathrm{eV})$ & 572.5 & - & - & 405.2 & 100.4 \\
\hline & FWHM (eV) & 1.09 & - & - & 0.85 & 0.77 \\
\hline \multirow{3}{*}{$\begin{array}{l}\mathrm{CH}_{3} \mathrm{NO}_{2} / \mathrm{H}_{2} / \mathrm{Ar} \\
\text { No bias }\end{array}$} & Atom \% ( $\mathrm{HgCdTe})$ & & 52 & & 32 & 16 \\
\hline & $\mathrm{BE}(\mathrm{eV})$ & 572.6 & - & - & 405.2 & 100.3 \\
\hline & FWHM (eV) & 1.02 & - & - & 0.85 & 0.70 \\
\hline \multirow{3}{*}{$\begin{array}{l}\mathrm{CH}_{4} / \mathrm{N}_{2} \mathrm{O} / \mathrm{H}_{2} / \mathrm{Ar} \\
\text { No bias }\end{array}$} & Atom \% ( $\mathrm{HgCdTe})$ & & 57 & & 36 & 7 \\
\hline & $\mathrm{BE}(\mathrm{eV})$ & 572.6 & - & - & 405.2 & 100.3 \\
\hline & FWHM (eV) & 1.04 & - & - & 0.86 & 0.69 \\
\hline
\end{tabular}

\section{B. Effect of $\mathrm{N}_{2} \mathrm{O}$ in the $\mathrm{CH}_{4} / \mathrm{N}_{2} \mathrm{O} / \mathrm{H}_{2} /$ Ar mixture}

In the comparison presented above, the amount of $\mathrm{N}_{2} \mathrm{O}$ substituted to $\mathrm{H}_{2}$ $\mathrm{CH}_{4} / \mathrm{N}_{2} \mathrm{O} / \mathrm{H}_{2} / \mathrm{Ar}$ was adjusted according to the deposition rate results obtained on $\mathrm{Si}$ to suppress deposition. To complete this study we carried out etching experiments on $\mathrm{HgCdTe}$ samples for the following three characteristic conditions: $5 \mathrm{sccm}, 17 \mathrm{sccm}, 35 \mathrm{sccm}$ of $\mathrm{N}_{2} \mathrm{O}$, which correspond on the Si wafer to, the larger deposition rate, the suppression of the deposition and a clearly non depositing regime respectively.

SEM and SEM-EDS images of HgCdTe samples are presented in Table 5. At 5 sccm $\mathrm{N}_{2} \mathrm{O}$, the SEM image shows large patches on the surface. To these patches corresponds high intensity domains in the carbon ( $\mathrm{C} \mathrm{K \alpha}$ line) and cadmium ( $\mathrm{Cd} \mathrm{L} \alpha_{1,2}$ line) 
energy filtered images and low intensity domains in the mercury image ( $\mathrm{Hg} \mathrm{M} \alpha_{1}$ line) whereas the tellurium image ( $\mathrm{Te} L \alpha_{1,2}$ line) is rather homogeneous. Therefore at low $\mathrm{N}_{2} \mathrm{O}$ flow rate the natural propensity for the plasma to produce deposition also occurs on the $\mathrm{HgCdTe}$ surface, although the mechanism is more balanced towards etching since the film is discontinuous. The correspondence between domains "rich in $\mathrm{Cd}$ " and "rich in C" suggest a correlation with the $\mathrm{Cd}$ removal mechanisms that involves $\mathrm{CH}_{\mathrm{x}}$ species and the formation of $\mathrm{Cd}\left(\mathrm{CH}_{3}\right)_{2}$ as etch product. Our interpretation is that regions were, whatever the reason, the Cd removal mechanisms happens to be less efficient, the subsequent local accumulation of $\mathrm{C}(\mathrm{N}) \mathrm{Hx}$ species act as seeds for the growth of a carbonaceous film. The $17 \mathrm{sccm} \mathrm{N}_{2} \mathrm{O}$ flow rate condition shows homogeneous SEM-EDS images that indicate that the deposition/etching balance is definitely on the etching side. Finally at $35 \mathrm{sccm} \mathrm{N}_{2} \mathrm{O}$, the energy filtered images show a homogeneous intensity, which indicates a homogeneous composition; but the SEM image clearly shows some structuration of the surface in the form of a (pale gray) overlayer above the (darker) underlying material. 
Table 5: SEM and SEM-EDS images of $\mathrm{HgCdTe}$ samples etched in $\mathrm{CH}_{4} / \mathrm{N}_{2} \mathrm{O} / \mathrm{H}_{2} / \mathrm{Ar}$ for 5 , 17 and $35 \mathrm{sccm}$ of $\mathrm{N}_{2} \mathrm{O}$.

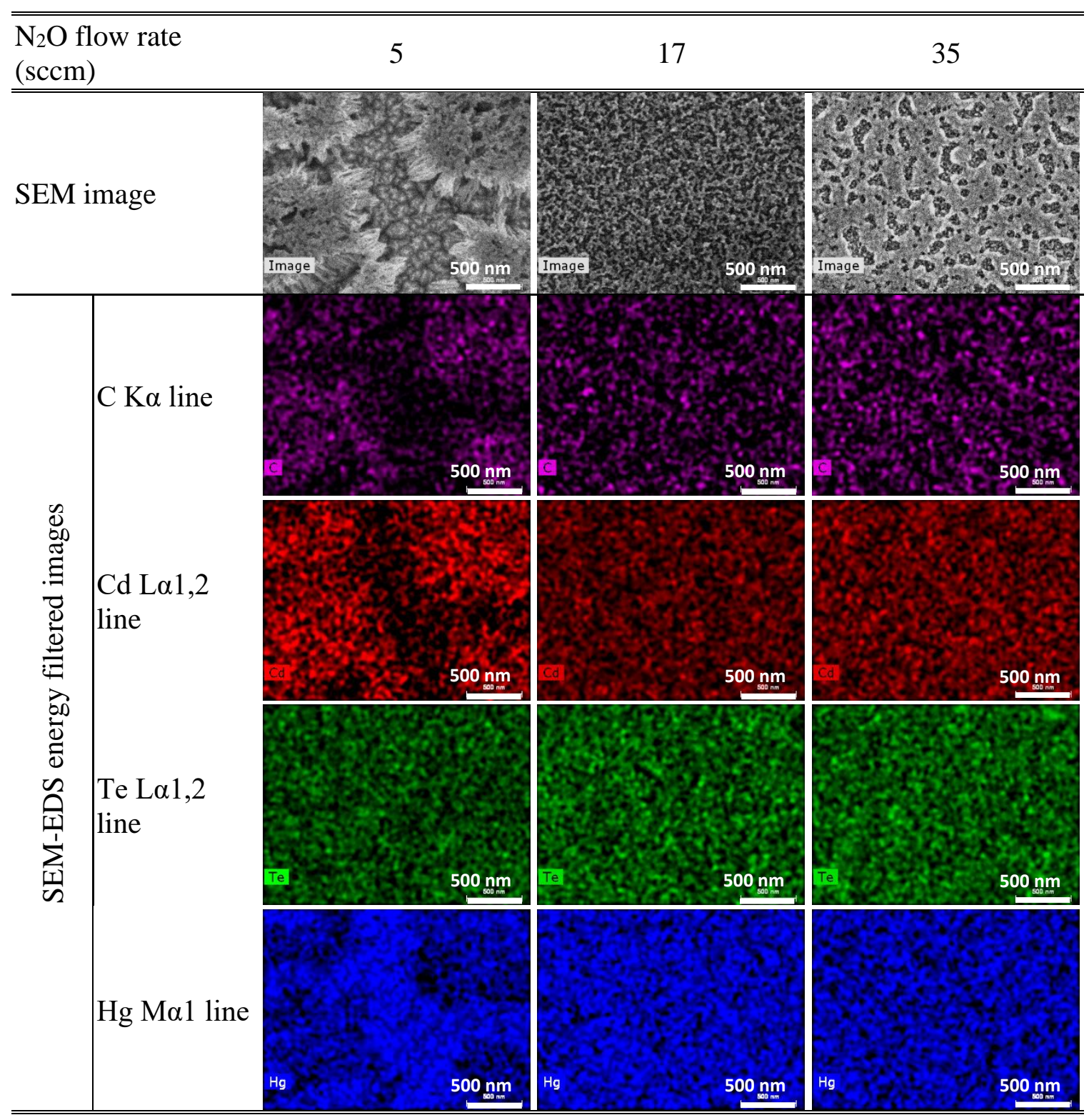

In situ XPS analysis results are presented in Figure 9. At $5 \mathrm{sccm} \mathrm{N}_{2} \mathrm{O}$, the signal for the $\mathrm{HgCdTe}$ core levels ( $\mathrm{Te} 3 \mathrm{~d}, \mathrm{Cd} 3 \mathrm{~d}$ and $\mathrm{Hg} 4 \mathrm{f}$ ) is characteristic of the etched material, in terms of position and shape (FWHM data are given in each figure). However the most important fact is the observation of a significant carbon contribution as evidenced by the 
C1s signal. Furthermore the observation of the N1s core level (see Cd3d spectrum) and the evidence of more than one carbon environment are a strong indication that this carbon layer contains $\mathrm{CNx}$ groups. Considering the curve fitting analysis, the main $\mathrm{C} 1 \mathrm{~s}$ component falls at $\sim 286.3 \mathrm{eV}$ and the two minor ones at $287.7 \mathrm{eV}$ and $289.3 \mathrm{eV}$, which is about $1.6 \mathrm{eV}$ greater than the nominal position for C-C/C-H species $(284.7 \mathrm{eV})$ and $\mathrm{CNx}$ species (285.9 for $\mathrm{C}-\mathrm{N}$ and 287.3 for $\mathrm{C}=\mathrm{N}$ as identified in Table 2) respectively. In relative accordance the same observation can be made for the N1s spectra with the major component at 401.0 $\mathrm{eV}$ and the minor at $399.8 \mathrm{eV}$ i.e. $0.9 \mathrm{eV}$ greater than nominal position for $\mathrm{N}-\mathrm{C}(400.1 \mathrm{eV})$ and $\mathrm{N}=\mathrm{C}(398.9 \mathrm{eV})$ (Table 2). Our conclusion is that the patches observed on the SEM image correspond to the hydrocarbonitride XPS signal. The discrepancy with the nominal binding energy positions can be attributed to a specific charging effect as this layer is most probably not in good electrical contact with the $\mathrm{HgCdTe}$ sample. Since the layer is not "infinite" in thickness no reliable quantification of the layer composition can be made by XPS. The presence of this layer attenuates the signal coming from the HgCdTe material, this is the reason why the intensity of the $\mathrm{Te} 3 \mathrm{~d}, \mathrm{Cd} 3 \mathrm{~d}$ and $\mathrm{Hg} 4 \mathrm{f}$ is significantly lower as compared to the $17 \mathrm{sccm}$ case that we will present now. At $17 \mathrm{sccm} \mathrm{N}_{2} \mathrm{O}$ the $\mathrm{Cd} 3 \mathrm{~d}$, Te3d and $\mathrm{Hg} 4 \mathrm{f}$ core levels spectra again are characteristic of the $\mathrm{HgCdTe}$ material. The carbon signal is negligible, therefore the inhibition effect concerning the carbon deposition observed on the $\mathrm{Si}$ wafer when introducing $17 \mathrm{sccm}$ of $\mathrm{N}_{2} \mathrm{O}$ in the gas mixture is also efficient on the HgCdTe surface. The absence of carbon layer can be correlated with the homogeneity of the SEM and SEM-EDS images. At $35 \mathrm{sccm} \mathrm{N} \mathrm{N}_{2} \mathrm{O}$ the surface is free of carbon (not shown), but the main change with respect to the $17 \mathrm{sccm}$ case is the presence of additional components on the Te3d and $\mathrm{Cd} 3 \mathrm{~d}$ spectra. These new components are 
located at $576.7 \mathrm{eV}$ and $578.1 \mathrm{eV}(\mathrm{Te} 3 \mathrm{~d} 5 / 2)$ and $406.5 \mathrm{eV}(\mathrm{Cd} 3 \mathrm{~d} 5 / 2)$. The first corresponds to $\mathrm{Te}$ oxide in the $\mathrm{TeO}_{2}$ environment ${ }^{48,49}$. To this component one can associate the $\mathrm{O} 1 \mathrm{~s}$ component at $530.9 \mathrm{eV}^{48,52}$, a binding energy position characteristic for metal oxides ${ }^{53}$. The second $\mathrm{Te} 3 \mathrm{~d}$ and $\mathrm{O} 1 \mathrm{~s}$ component and that of $\mathrm{Cd} 3 \mathrm{~d}$ are shifted by $1.3 \mathrm{eV}$ from the first or from the $\mathrm{Cd}(\mathrm{HgCdTe})$ component respectively. Cadmium oxides ${ }^{49,50,54}$ and $\mathrm{Hg}$ oxides $^{54}$ present very limited chemical shifts $(<0.5 \mathrm{eV})$ with respect to $\mathrm{HgCdTe}$. Therefore $\mathrm{CdO}$ or $\mathrm{HgO}$ species, corresponding to the Te oxide and the $\mathrm{O} 1 \mathrm{~s}$ component at $530.9 \mathrm{eV}$ could exist under the same envelope as the $\mathrm{Cd}(\mathrm{HgCdTe})$ contribution $^{48}$, in the same way $\mathrm{CdOH}$ could produce the O1s component at $533.8 \mathrm{eV}$; however the FWHM of the $\mathrm{Cd} 3 \mathrm{~d}$ and $\mathrm{Hg} 4 \mathrm{f}$ spectra showing no significant widening with respect to the $17 \mathrm{sccm}$ case, the existence of such species remain a hypothesis. We interpret the second group of peaks including the $\mathrm{Te} 3 \mathrm{~d} 5 / 2$ at $578.1 \mathrm{eV}$, the $\mathrm{Cd} 3 \mathrm{~d} 5 / 2$ at 406.5 and the $\mathrm{O} 1 \mathrm{~s}$ at $535.3 \mathrm{eV}$, which are all shifted from the nominal oxide positions, to oxide species $\left(\mathrm{TeO}_{2}\right.$ and $\left.\mathrm{CdO}\right)$ shifted by differential surface electrical charging. We envisage the possibility that such species correspond to the (pale grey) regions observed on the SEM image. In any case the XPS analysis shows that introducing in the gas mixture more $\mathrm{N}_{2} \mathrm{O}$ than necessary leads to the oxidation of the material surface and some surface structuration. 

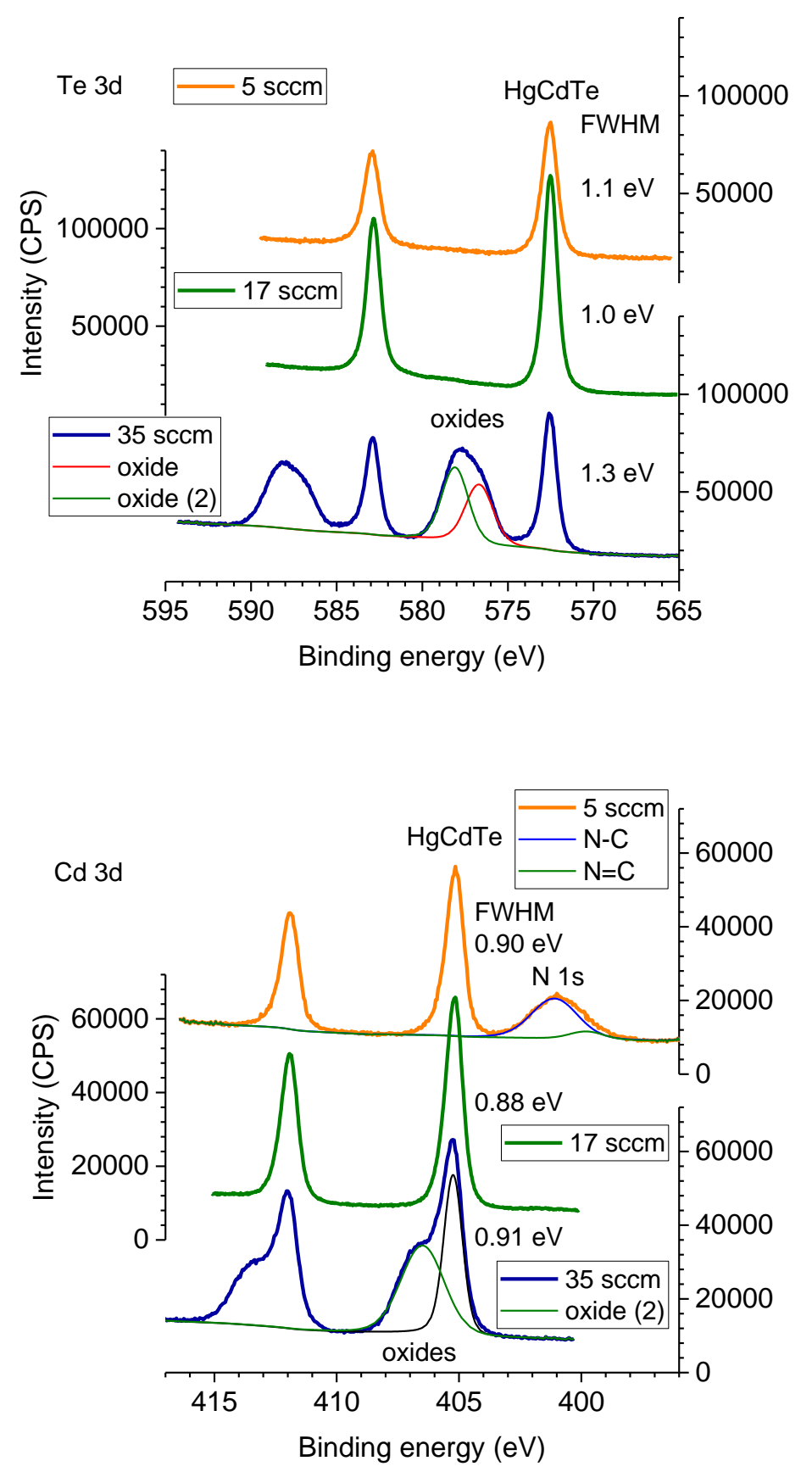

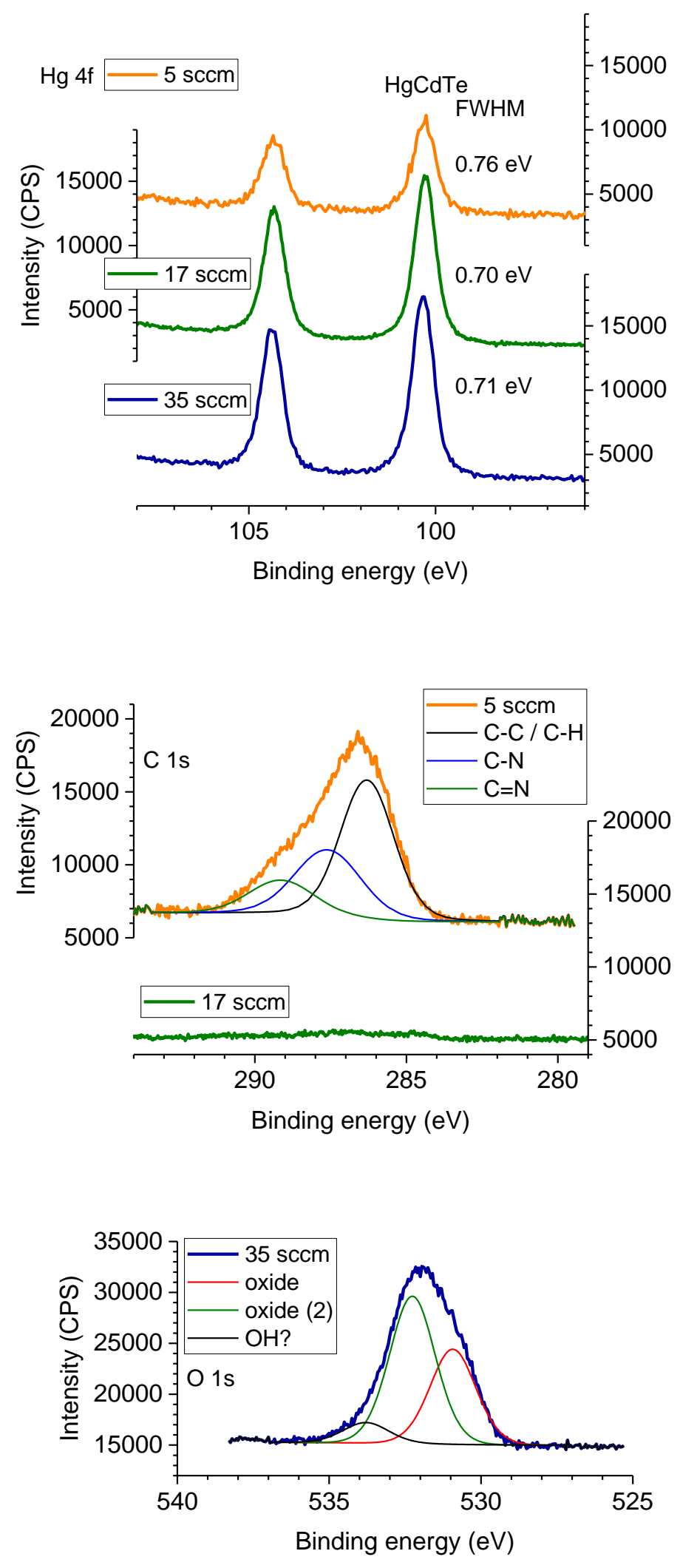
Figure 9: Analysis of $\mathrm{HgCdTe}$ samples etched in $\mathrm{CH}_{4} / \mathrm{N}_{2} \mathrm{O} / \mathrm{H}_{2} / \mathrm{Ar}$ for 5,17 and $35 \mathrm{sccm}$ of $\mathrm{N}_{2} \mathrm{O}$ : $\mathrm{Te} 3 \mathrm{~d}, \mathrm{Cd} 3 \mathrm{~d}, \mathrm{Hg} 4 \mathrm{f}, \mathrm{C} 1 \mathrm{~s}$ and $\mathrm{O} 1 \mathrm{~s}$ spectral regions. Each region containing more than one spectrum presents the equivalent number of ordinate scales, alternatively on the left and right axis; all scales are the same, only one is labelled to lighten the figure.

\section{SUMMARY AND CONCLUSIONS}

The interest of introducing oxygen and/or nitrogen atoms in $\mathrm{CH}_{4} / \mathrm{H}_{2} / \mathrm{Ar}$ plasma mixtures to control carbon deposition and surface passivation when etching $\mathrm{HgCdTe}$ under low substrate bias conditions has been investigated. This was carried out either by replacing methane by other organic precursors or by substituting in part $\mathrm{O}_{2}$ or $\mathrm{N}_{2} \mathrm{O}$ for hydrogen. The study (in situ ellipsometry) of the carbon deposition onto $\mathrm{Si}$, without bias, and the subsequent cleaning sequence lead to select methanol and nitromethane as alternative precursors and to determine the necessary amount of $\mathrm{O}_{2}$ (half that of $\mathrm{CH}_{4}$ ) or $\mathrm{N}_{2} \mathrm{O}$ (twice that of $\mathrm{CH}_{4}$ ) substituent to be used in $\mathrm{CH}_{4} / \mathrm{H}_{2} / \mathrm{Ar}$ mixture to suppress deposition. Optical emission spectroscopy brought information on the change in the plasma chemical species. Considering the invariance of the ion flux measurements with the change of precursor, we concluded that any modification in the plasma-surface interaction mechanisms would be uniquely due to the change in the chemical composition of the plasma.

Using the OES data and in situ XPS analysis results, the role of the substituents with respect to film deposition and composition was investigated. We concluded that $\mathrm{O}_{2}$ induces an etching mechanism that directly competes with the deposition mechanism. Opposite, $\mathrm{N}_{2} \mathrm{O}$ contributes to the film growth in correlation with formation of $\mathrm{CN}$ plasma species, as shown by the presence of nitrogen in the film in the form of various $\mathrm{CNx}$ species. However this growth mechanisms is in competition with the etching mechanisms 
induced by the oxygen atoms brought by the substituent and the final dominant mechanism depends on the $\mathrm{N}_{2} \mathrm{O} / \mathrm{CH}_{4}$ ratio. Comparing the subsequent etching sequences of the carbon film we come to the conclusion that oxygen atoms appear as the true etch reactant, during the deposition and cleaning sequences and for both substituents, and that incorporation of nitrogen in the film grown in $\mathrm{CH}_{4} / \mathrm{N}_{2} \mathrm{O} / \mathrm{H}_{2} / \mathrm{Ar}$ plasma favours its etching kinetics.

On $\mathrm{HgCdTe}$ demonstration is made that etching without sample bias is possible by using nitromethane as precursor or in $\mathrm{CH}_{4} / \mathrm{N}_{2} \mathrm{O} / \mathrm{H}_{2} / \mathrm{Ar}$ mixtures (at a $\mathrm{N}_{2} \mathrm{O} / \mathrm{CH}_{4}$ ratio $=2$ ), with a significant advantage for the latter with respect to the former concerning etch rate ( $60 \mathrm{~nm} / \mathrm{min} v s \sim 20 \mathrm{~nm} / \mathrm{min})$ and surface roughness (12 $\mathrm{nm} v s 18 \mathrm{~nm})$. In situ XPS analysis shows that surface composition is very similar when comparing $\mathrm{CH}_{4} / \mathrm{H}_{2} / \mathrm{Ar}$ (50 W bias power), $\mathrm{CH}_{3} \mathrm{NO}_{2} / \mathrm{H}_{2} / \mathrm{Ar}$ and $\mathrm{CH}_{4} / \mathrm{N}_{2} \mathrm{O} / \mathrm{H}_{2} / \mathrm{Ar}$ plasma processes. In line with the study onto $\mathrm{Si}$, deposition in the form of a hydrocarbonitride is observed onto $\mathrm{HgCdTe}$ at low $\mathrm{N}_{2} \mathrm{O} / \mathrm{CH}_{4}$ ratio (i.e. 0.6). Moreover SEM and SEM-EDS imaging suggest that the film nucleates and grows preferentially on regions where the Cd removal mechanisms happens to be less efficient. Opposite, at high $\mathrm{N}_{2} \mathrm{O} / \mathrm{CH}_{4}$ ratio (i.e. 4), oxidation of the $\mathrm{HgCdTe}$ surface is observed.

In terms of application, the $\mathrm{CH}_{4} / \mathrm{N}_{2} \mathrm{O} / \mathrm{H}_{2} / \mathrm{Ar}$ mixture has the advantage, compared to the $\mathrm{CH}_{3} \mathrm{NO}_{2} / \mathrm{H}_{2} / \mathrm{Ar}$ mixture, of allowing fine adjustment of the amount of "carbon deposition inhibitor" introduced into the process. Tuning the plasma chemistry and the substrate bias, one can think about obtaining an efficient etching with low surface roughness, no residues nor oxidation under low ion energy on surfaces strongly exposed to the ion bombardment (hole and trench bottom) while controlling deposition/passivation on the surfaces weakly exposed to the ion bombardment (typically feature sidewalls). 
Applying these findings to $\mathrm{HgCdTe}$ patterning could provide the soft dry etching needed to reduce the pixel pitch of infrared photovoltaic detectors.

No conclusion can be drawn between $\mathrm{O} 2$ and $\mathrm{N} 2 \mathrm{O}$ addition as regards $\mathrm{HgCdTe}$ etching

\section{ACKNOWLEDGMENTS}

The authors acknowledge the French Ministry of Defence, Délégation Générale de l'Armement and the Région Pays de la Loire for financing a PhD grant.

${ }^{1}$ G.L. Hansen, J.L. Schmidt, and T.N. Casselman, J. Appl. Phys. 153, 7099 (2007).

${ }^{2}$ A. Rogalski, Infrared Phys. \& Technol. 50, 240 (2007).

${ }^{3}$ M.A. Kinch, State of the art infrared detector technology, (SPIE Press, 2014).

${ }^{4}$ J. Baylet, et al. J. Electron. Mater. 35(6), 1153 (2006).

${ }^{5}$ E.P.G. Smith et al. J. Electron. Mater. 35(6), 1145 (2006).

${ }^{64}$ C.R. Eddy, D. Leonhardt, V.A. Shamamian, J.R. Meyer, C.A. Hoffman, and J.E. Butler, J. Electron. Mater. 28(4), 347 (1999).

${ }^{75}$ R.C. Keller, M. Seelmann-Eggebert and H.J. Richter, J. Electron. Mater. 24(9), 1155 (1995).

${ }^{86}$ J. Baylet et al., J. Electron. Mater. 33(6), 690 (2004).

${ }^{97}$ G. Bahir and E. Finkman, J. Vac. Sci. Technol. A 7, 348 (1989).

${ }^{108}$ J.L. Elkind and G.J. Orloff, J. Vac. Sci. Technol. A 10, 1106 (1992). 
${ }^{119}$ L. Liu, Y. Chen, Z. Ye, and R. Ding, Infrared Phys. \& Technol. 90, 175 (2018).
${ }^{1210}$ C.R. Eddy, E.A. Dobisz, J.R. Meyer and C.A. Hoffman, J. Vac. Sci. Technol. A 11, 1763 (1993).

${ }^{1311}$ J. Kim et al., J. Electron. Mater. 32(7), 677 (2003).

${ }^{1412}$ R.C. Keller, M. Seelmann-Eggebert and H.J. Richter, Appl. Phys. Lett. 67, 3750 (1995).

${ }^{1513}$ F. Boulard, J. Baylet and C. Cardinaud, J. Vac. Sci. Technol. A 27, 855 (2009).

${ }^{1614}$ J.E. Schramm, D.I. Babic, E.L. Hu, J.E. Bowers and J.L. Merz, Proceedings IEEE 6th International Conference on Indium Phosphide and Related Materials (IPRM), Santa Barbara, CA, USA, 1994, pp. 383-386.

${ }^{1715}$ T. Suzuki, N. Haneji, K. Tada, Y. Shimogaki and Y. Nakano, Jap. J. Appl. Phys. 41, 15 (2002).

${ }^{18}$ J.W. Coburn, H.F. Winters and T. J. Chuang, J. Appl. Phys. 48, 3532 (1977).

${ }^{19}$ J.W. Coburn and H.F. Winters, J. Vac. Sci. Technol. 15, 327 (1978).

${ }^{20}$ J.W. Coburn and H.F. Winters, J. Appl. Phys. 50, 3189 (1979).

${ }^{21}$ J.W. Coburn and H.F. Winters, J. Vac. Sci. Technol. 16, 391 (1979).

${ }^{22}$ H.F. Winters and J.W Coburn, Surf. Sci. Rep. 14 (4-6), 162 (1992). ${ }^{2316}$ S Jacq, C Cardinaud, L. Le Brizoual and A. Granier, Plasma Sources Sci. Technol. 22, 055004 (2013).

${ }^{2417}$ V. Raballand Gravure en plasma dense fluorocarboné de matériaux organosiliciés à faible constante diélectrique (SiOCH,SiOCH poreux). Etude d'un procédé de

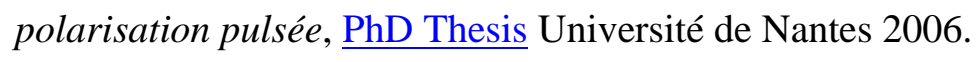

${ }^{25}$ N.St.J Braithwaite, J.P. Booth and G. Cunge, Plasma Sources Sci. Technol. 5, 677 (1996). 


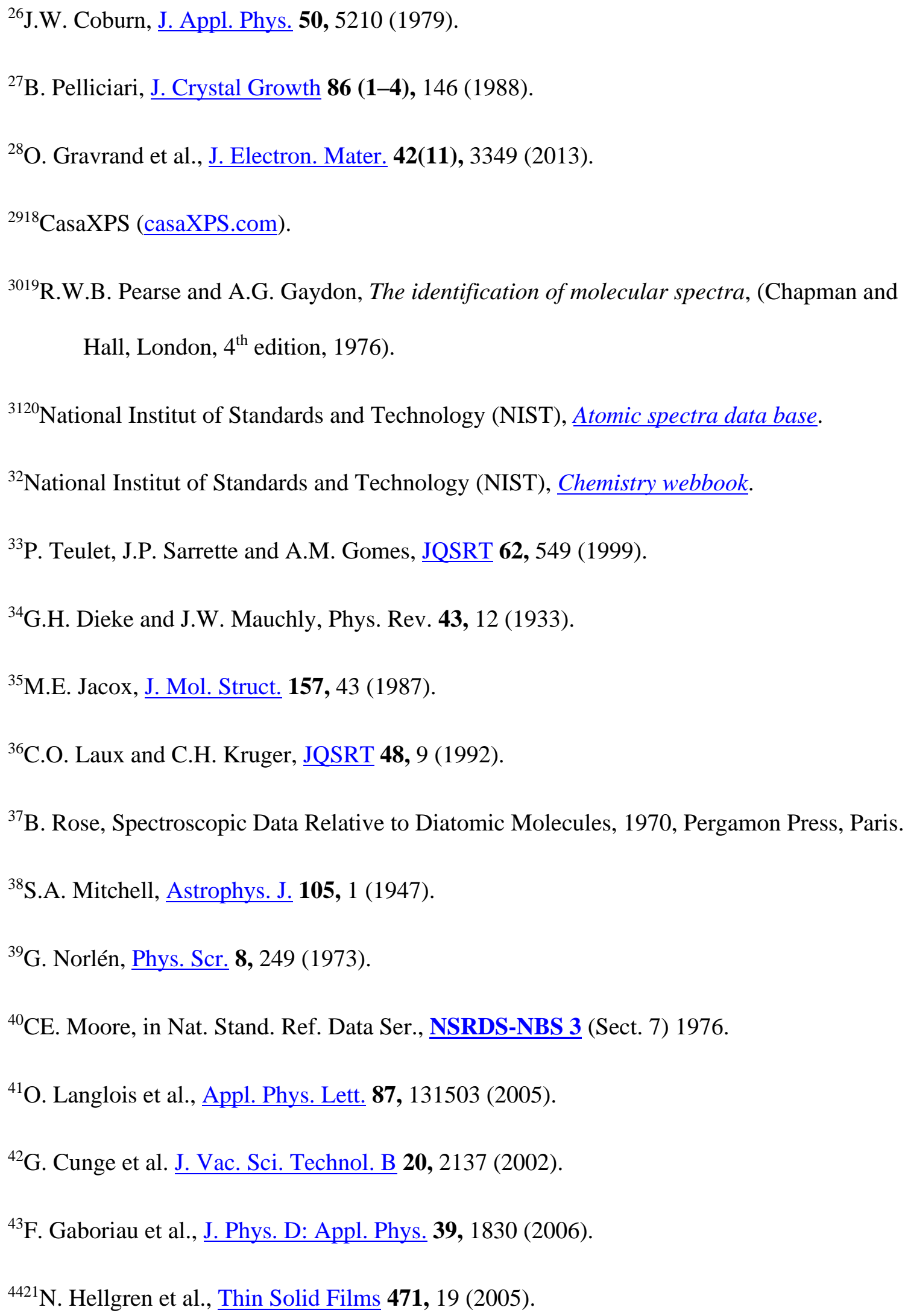


${ }^{4522}$ S.E. Rodil and S. Muhl, Diamond Rel. Mater. 13, 1521 (2004).

${ }^{4623}$ J. Pereira, I. Géraud-Grenier, V. Massereau-Guilbaud, André Plain and V. Fernandez, Surf. Coatings Technol. 200, 6414 (2006).

${ }^{4724}$ B. Angleraud, N. Mubumbila, P.Y. Tessier, V. Fernandez and G. Turban, Diamond Rel. Mater. 10, 1142 (2001).

${ }^{4825}$ T.S. Sun, S.P. Buchner and N.E. Byer, J. Vac. Sci. Technol 17, 1067 (1980).

${ }^{4926}$ B.H. Erné et al., Appl. Surf. Sci. 175-176, 579 (2001).

${ }^{5027}$ G. Badano, A. Million, B. Canava, P. Tran-Van, and A. Etcheberry, J. Electron. Mater. 36, 1077 (2007).

${ }^{5128}$ A. Causier et al., J. Electron. Mater. 40(8), 1823 (2011).

${ }^{5229}$ R. Sporken et al., J. Electron. Mater. 38(8), 1781 (2009).

${ }^{5330}$ J.F. Moulder, W.F. Stickle, P.E. Sobol and K.D. Bomben, Handbook of X-ray

Photoelectron Spectroscopy, (Ed. Perkin-Elmer Corp. 1992).

${ }^{5431}$ R. Nokhwal et al., J. Electron. Mater. 46(12), 6795 (2017). 
Figure 1

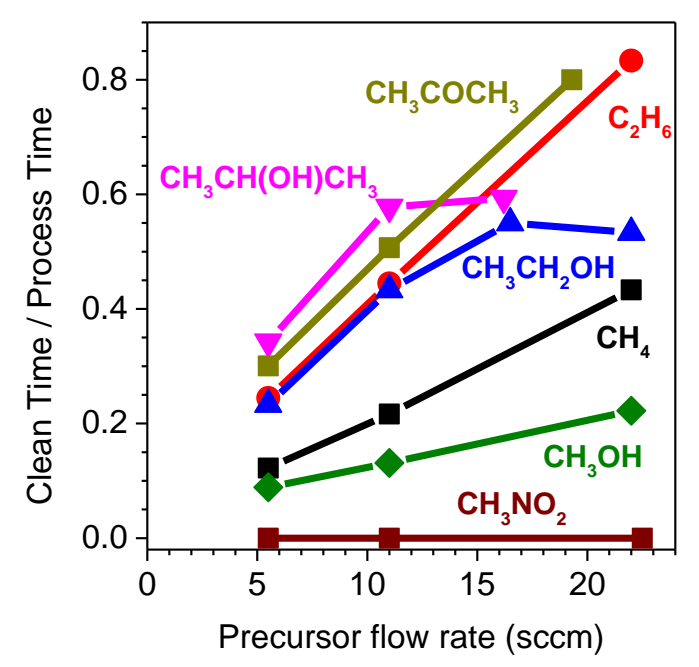

Figure 1: Ratio between the oxygen plasma cleaning time and the plasma process time in a precursor/ $\mathrm{H}_{2} / \mathrm{Ar}$ mixture $(\mathrm{X} /(55-\mathrm{X}) / 5 \mathrm{sccm})$ as a function of the precursor flow, for the precursors methane $(\bullet)$ and ethane $(\bullet)$ methanol $(\diamond)$, ethanol $(\boldsymbol{\Delta})$, acetone $(\bullet)$, isopropanol $(\nabla)$ and nitromethane $(\boldsymbol{\bullet})$. 
Figure 2
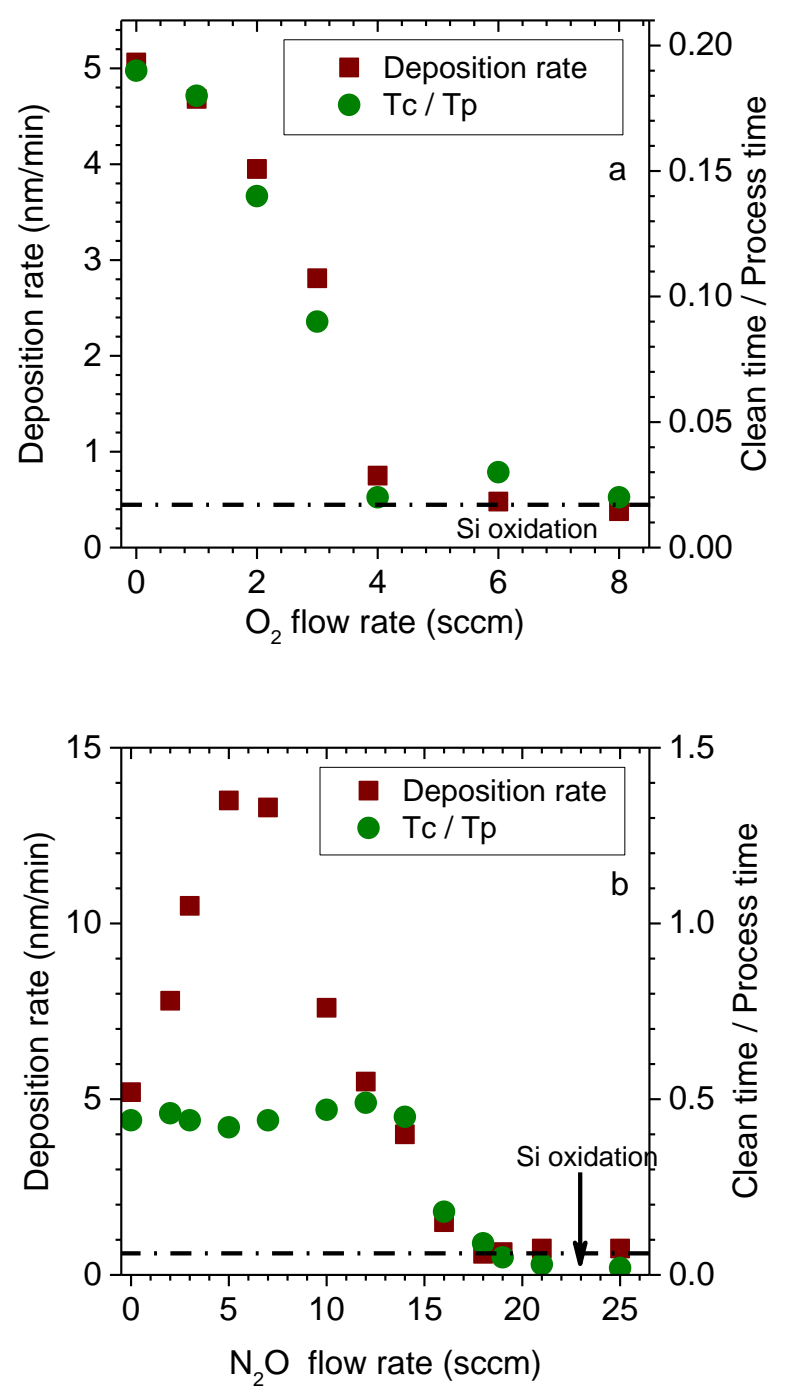

Figure 2: Deposition rate and $\mathrm{Tc} / \mathrm{Tp}$ ratio versus $\mathrm{O}_{2}$ and $\mathrm{N}_{2} \mathrm{O}$ flow rate in (a) a $\mathrm{CH}_{4} / \mathrm{O}_{2} / \mathrm{H}_{2} / \mathrm{Ar}$ and (b) a $\mathrm{CH}_{4} / \mathrm{N}_{2} \mathrm{O} / \mathrm{H}_{2} / \mathrm{Ar}$ plasma. Gas mixture is $10 / \mathrm{Y} /(45-\mathrm{Y}) / 5 \mathrm{sccm}$. 
Figure 3
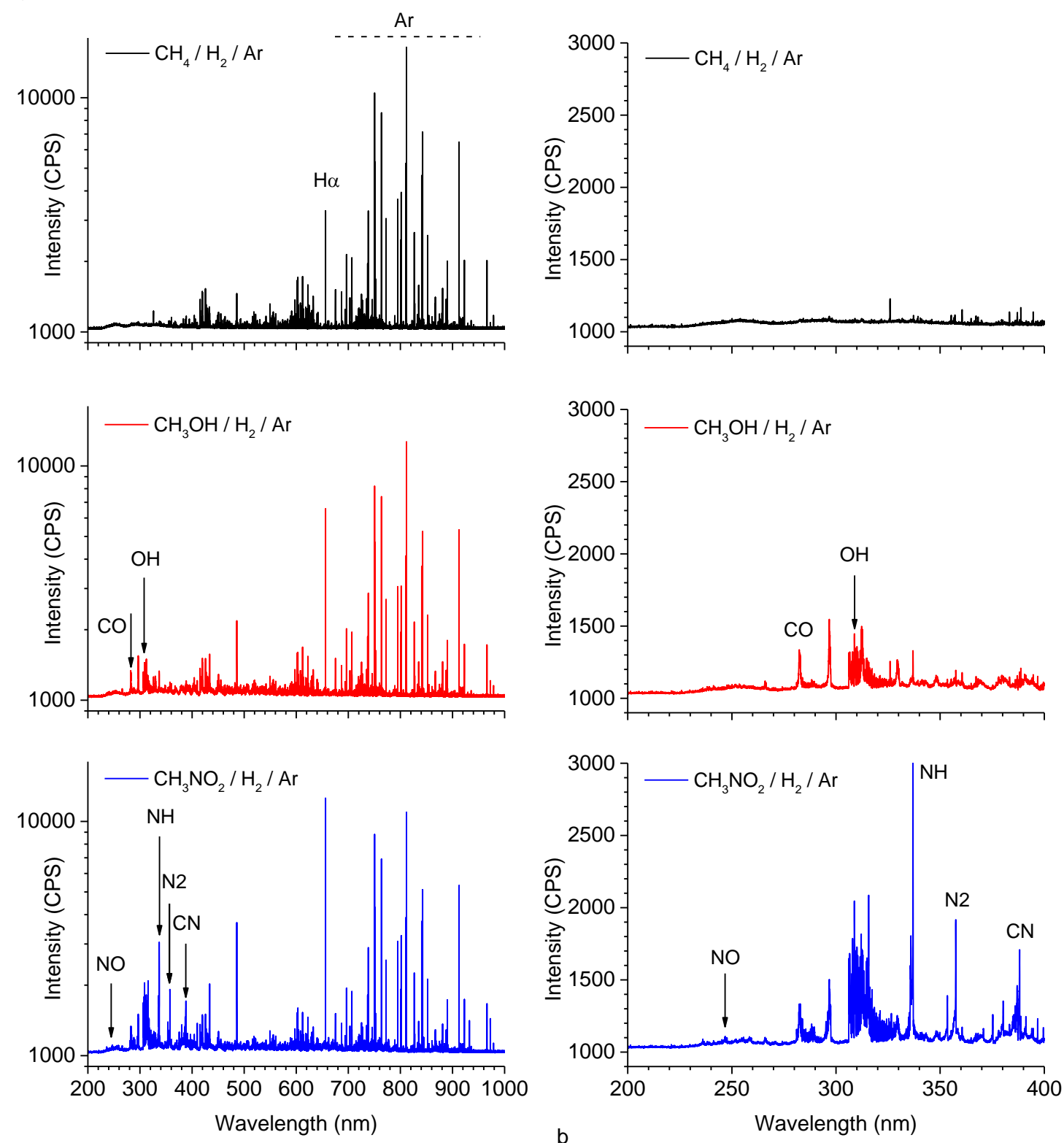

Figure 3: Typical optical emission spectra of $\mathrm{CH}_{4} / \mathrm{H}_{2} / \mathrm{Ar}, \mathrm{CH}_{3} \mathrm{OH} / \mathrm{H}_{2} / \mathrm{Ar}, \mathrm{CH}_{3} \mathrm{NO}_{2} / \mathrm{H}_{2} / \mathrm{Ar}$ plasmas obtained at $1000 \mathrm{~W}$ excitation power, 4 mTorr pressure, gas mixture is 8.5/46.5/5 sccm. Whole UV-vis. spectral range (a), blow up on the 200-400 $\mathrm{nm}$ range (b). Spectra are not corrected from the optical response of the measuring chain (fiber, monochromator, detector). 
Figure 4
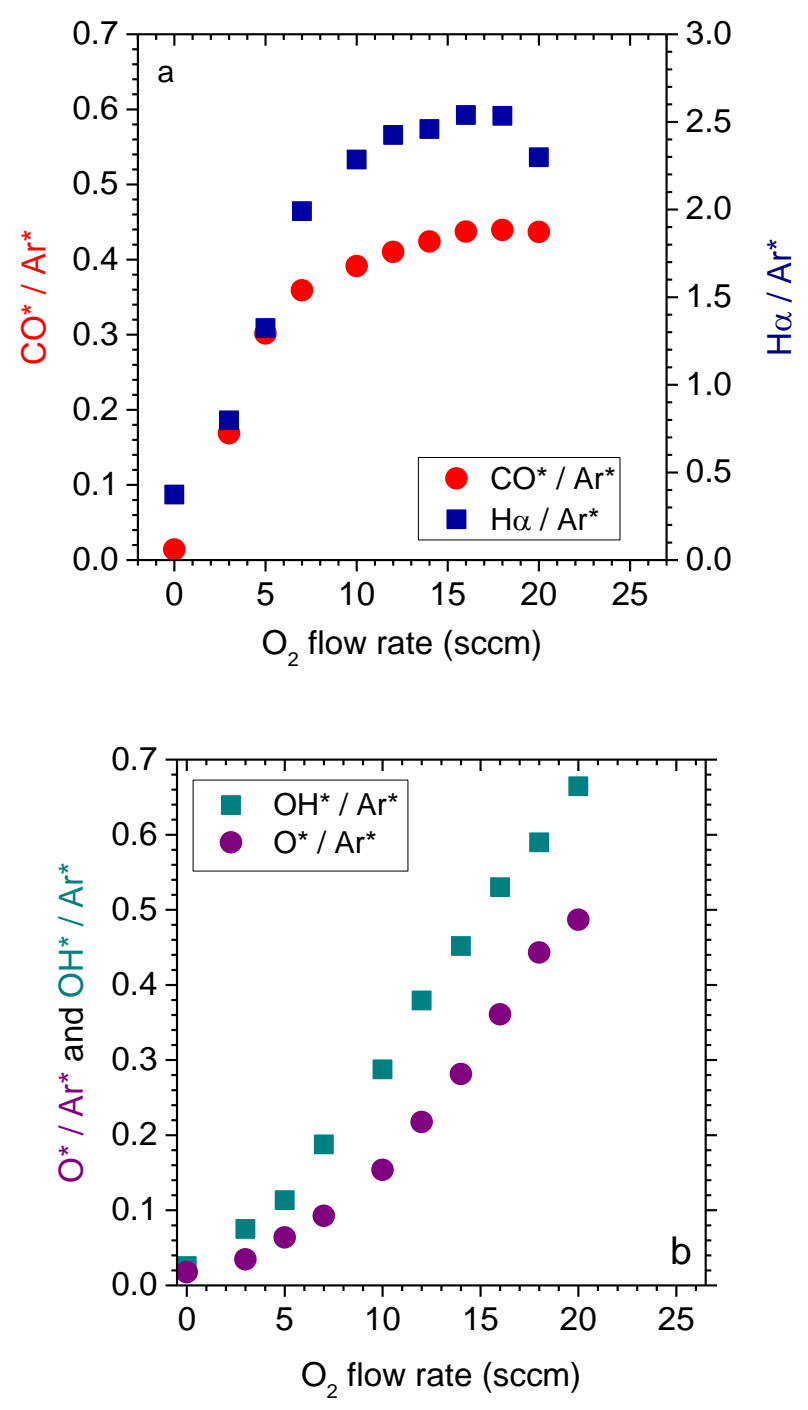

Figure 4: Evolution of the actinometry ratios $\mathrm{X}^{*} / \mathrm{Ar}^{*}$ for (a) $\mathrm{X}^{*}=\mathrm{CO}^{*}, \mathrm{H}^{*}$ and (b) $\mathrm{X}^{*}=$ $\mathrm{OH}^{*}$ and $\mathrm{O}^{*}$ when varying the amount of $\mathrm{O}_{2}$ in $\mathrm{CH}_{4} / \mathrm{O}_{2} / \mathrm{H}_{2} / \mathrm{Ar}(10 / \mathrm{Y} / 45-\mathrm{Y} / 5 \mathrm{sccm})$ mixture. 
Figure 5
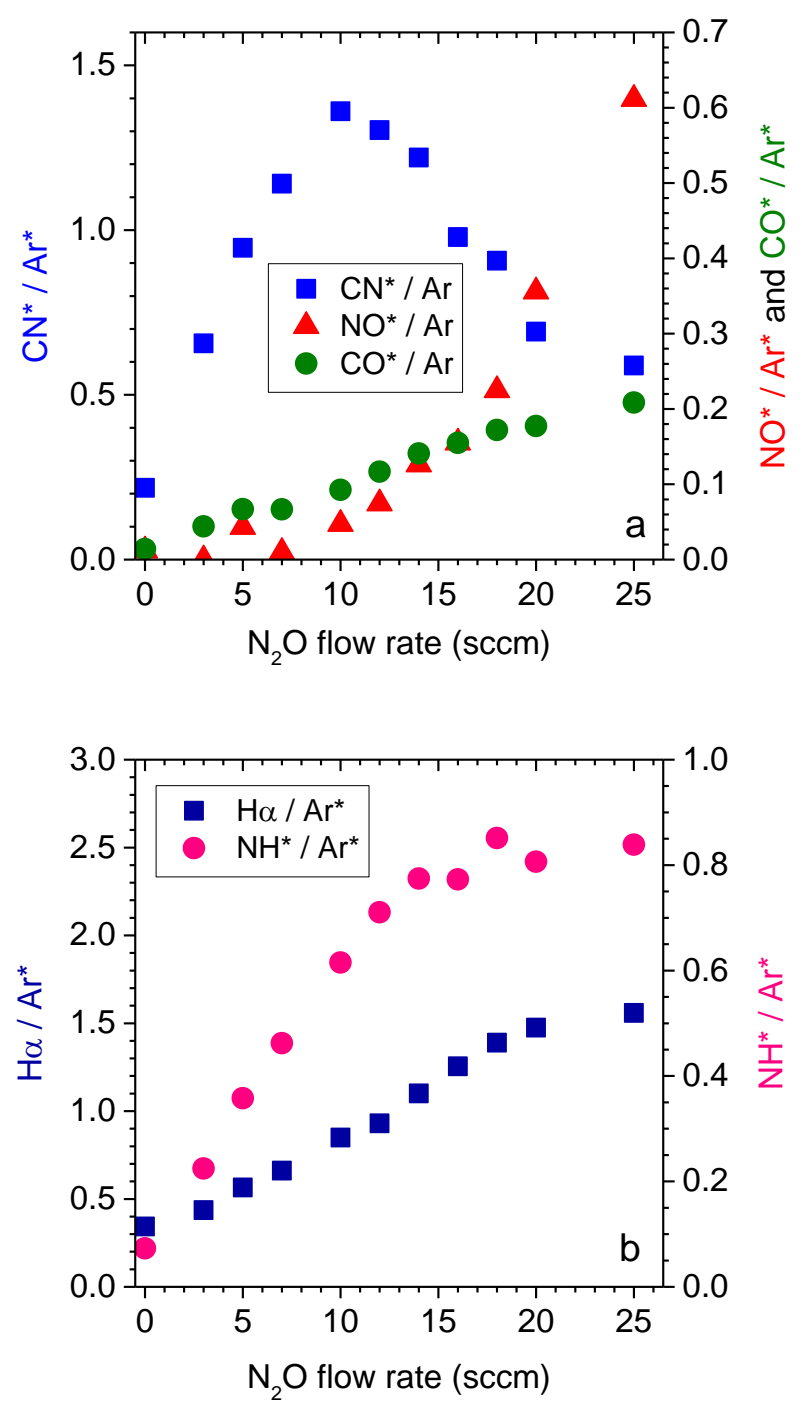
Figure 5 (end)

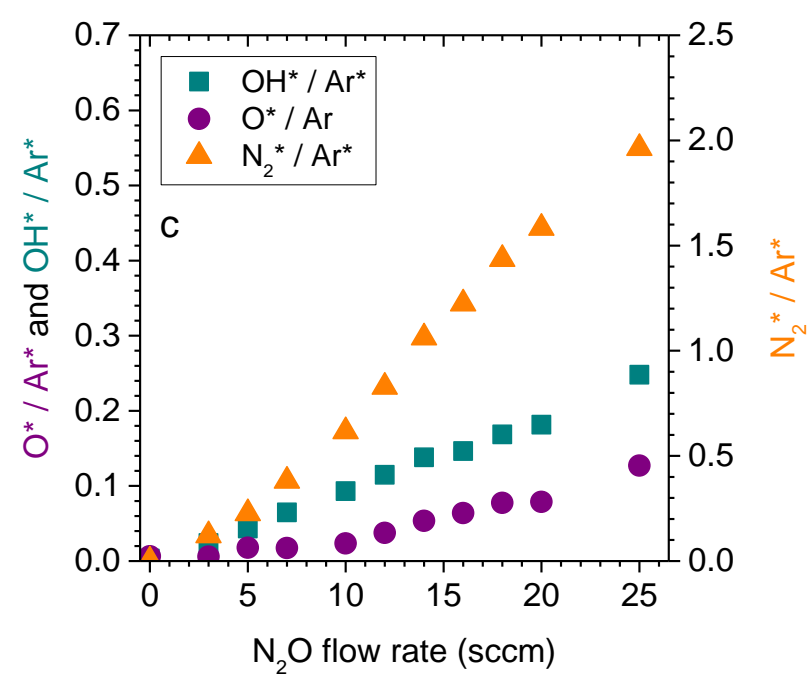

Figure 5: Evolution of the actinometry ratios $\mathrm{X}^{*} / \mathrm{Ar}^{*}$ for (a) $\mathrm{X}^{*}=\mathrm{CN}^{*}, \mathrm{NO}, \mathrm{CO} *$, (b) $\mathrm{X}^{*}$ $=\mathrm{NH}^{*}, \mathrm{H}^{*}$ and (c) $\mathrm{X}^{*}=\mathrm{OH}^{*}$ and $\mathrm{O}^{*}$ when varying the amount of $\mathrm{N}_{2} \mathrm{O}$ in $\mathrm{CH}_{4} / \mathrm{N}_{2} \mathrm{O} / \mathrm{H}_{2} / \mathrm{Ar}$ $(10 / \mathrm{Y} / 45-\mathrm{Y} / 5 \mathrm{sccm})$ mixture. 
Figure 6
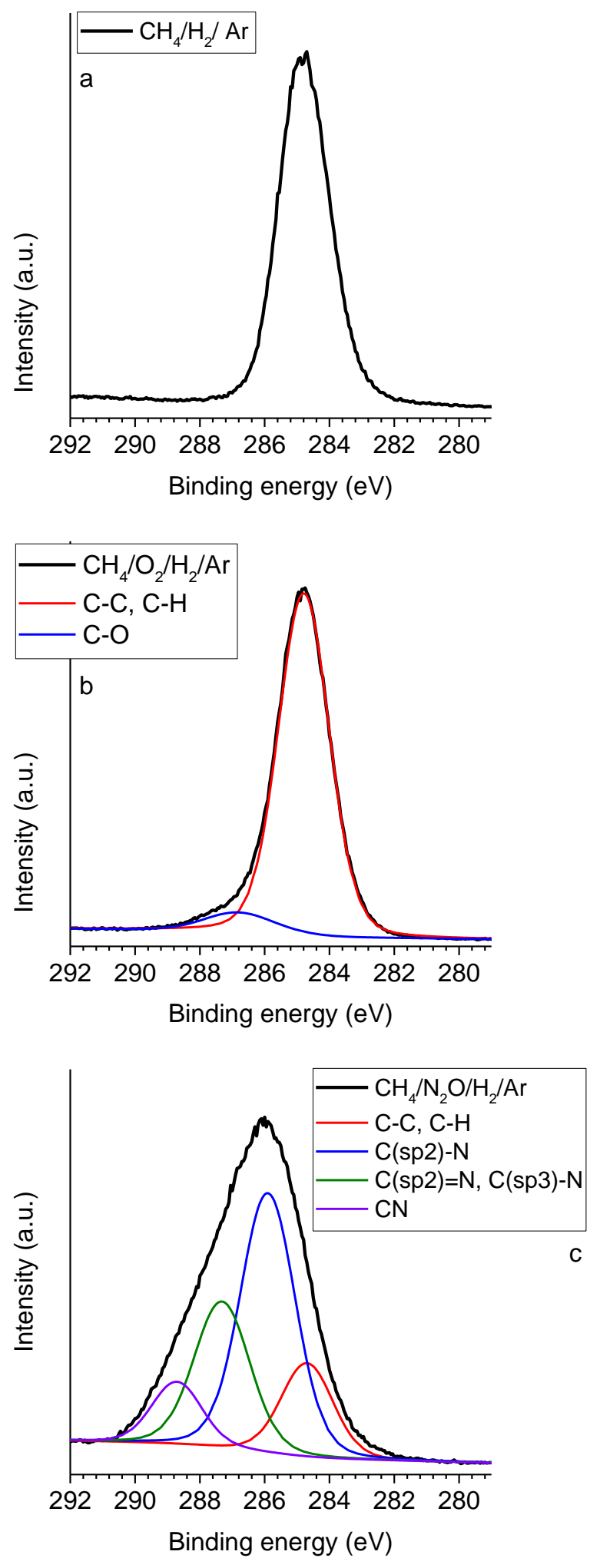
Figure 6 (end)

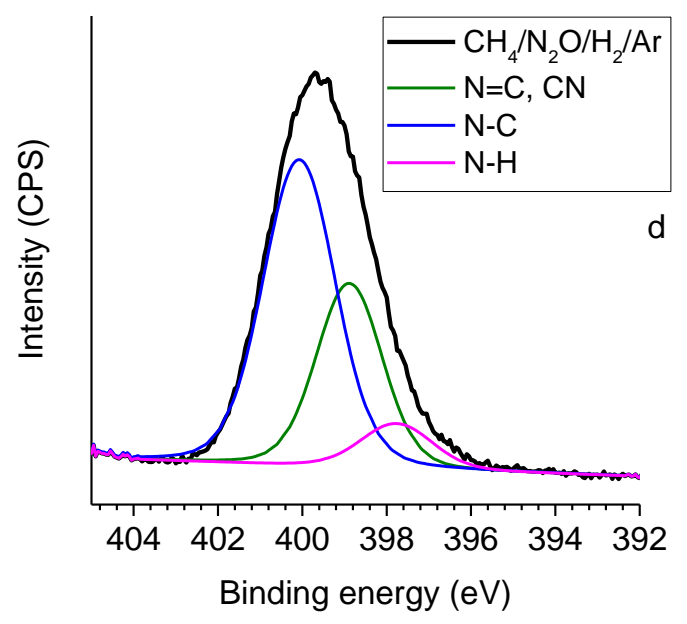

Figure 6: C 1s (a, b, c) and N1s (d) spectra of the layers deposited on $\mathrm{Si}$ in (a) $\mathrm{CH}_{4} / \mathrm{H}_{2} / \mathrm{Ar}$, (b) $\mathrm{CH}_{4} / \mathrm{O}_{2}(2 \mathrm{sccm}) / \mathrm{H}_{2} / \mathrm{Ar}$ and (c, d) $\mathrm{CH}_{4} / \mathrm{N}_{2} \mathrm{O}(5 \mathrm{sccm}) / \mathrm{H}_{2} / \mathrm{Ar}$ plasmas. 
Figure 7

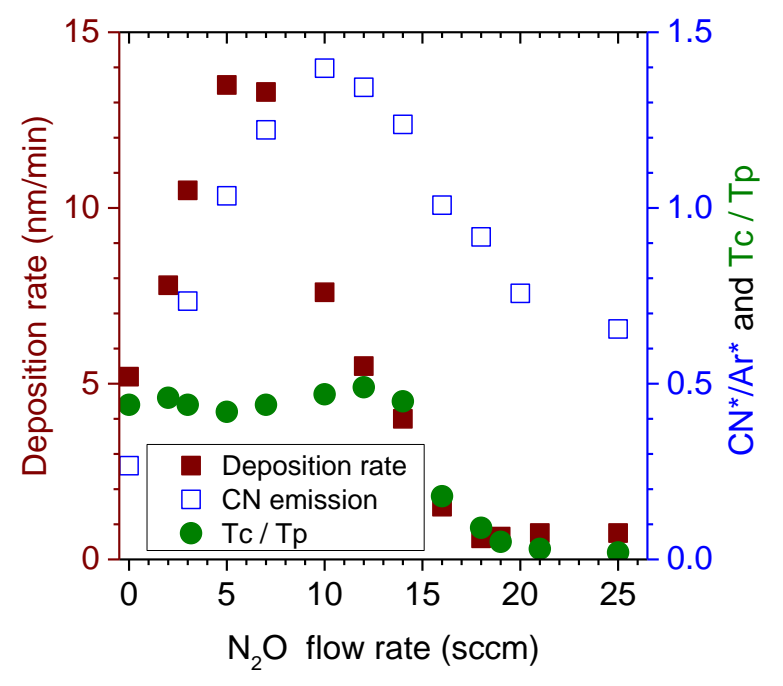

Figure 7: Deposition rate, clean time / process time ratio and $\mathrm{CN}^{*} / \mathrm{Ar}^{*}$ ratio versus the $\mathrm{N}_{2} \mathrm{O}$ flow rate in a $\mathrm{CH}_{4} / \mathrm{N}_{2} \mathrm{O} / \mathrm{H}_{2} / \mathrm{Ar}$ plasma. Gas mixture is $10 / \mathrm{Y} /(45-\mathrm{Y}) / 5 \mathrm{sccm}$. 
Figure 8
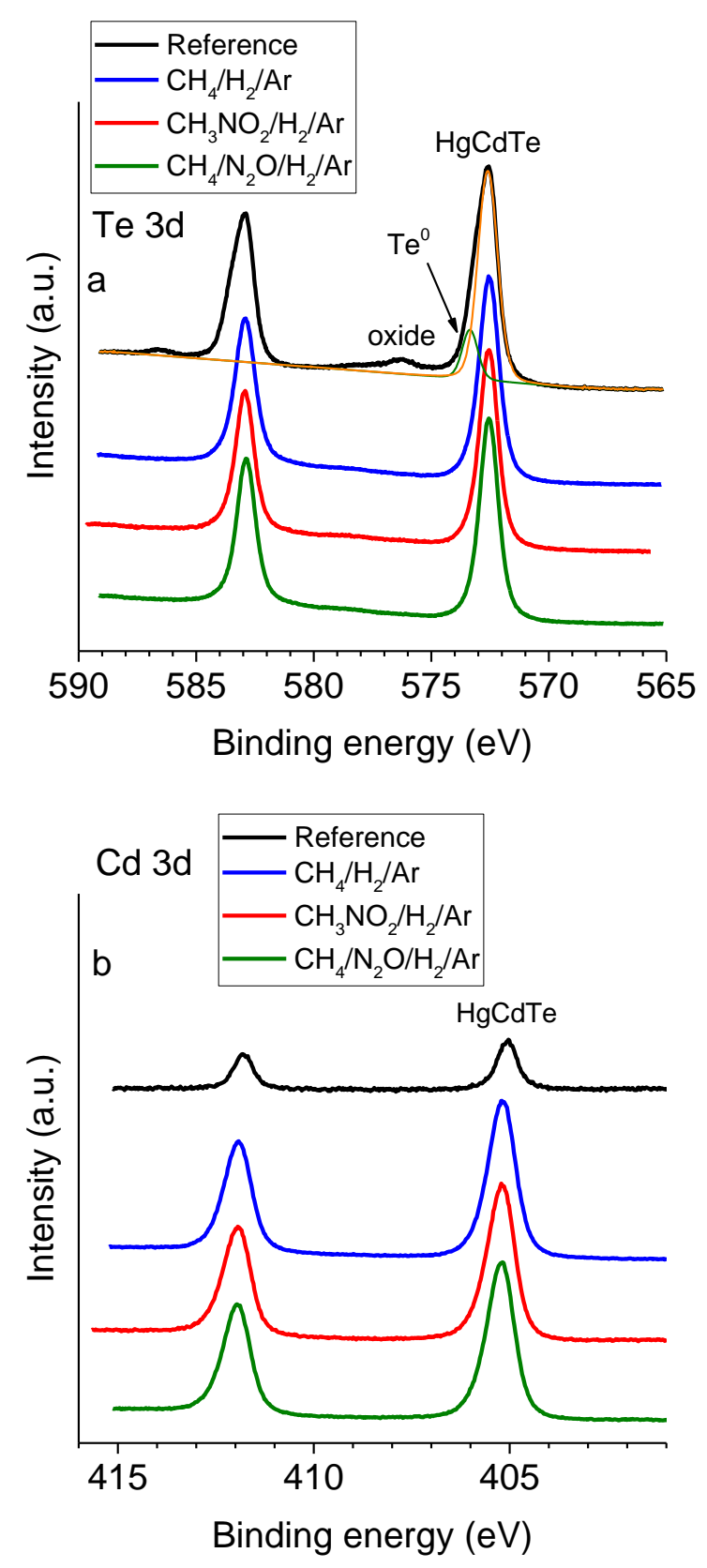
Figure 8 (end)

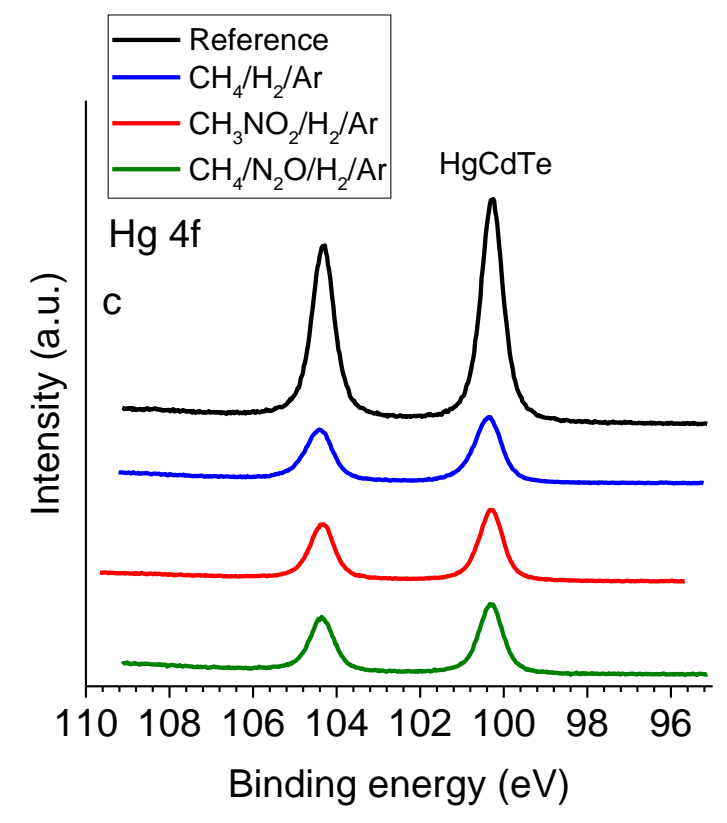

Figure 8: Te3d (a), Cd3d (b) and $\mathrm{Hg} 4 \mathrm{f}$ (c) spectra for the $\mathrm{HgCdTe}$ samples etched in $\mathrm{CH}_{4} / \mathrm{H}_{2} / \mathrm{Ar}, \mathrm{CH}_{3} \mathrm{NO}_{2} / \mathrm{H}_{2} / \mathrm{Ar}$ and $\mathrm{CH}_{4} / \mathrm{N}_{2} \mathrm{O} / \mathrm{H}_{2} / \mathrm{Ar}$ plasmas. 
Figure 9
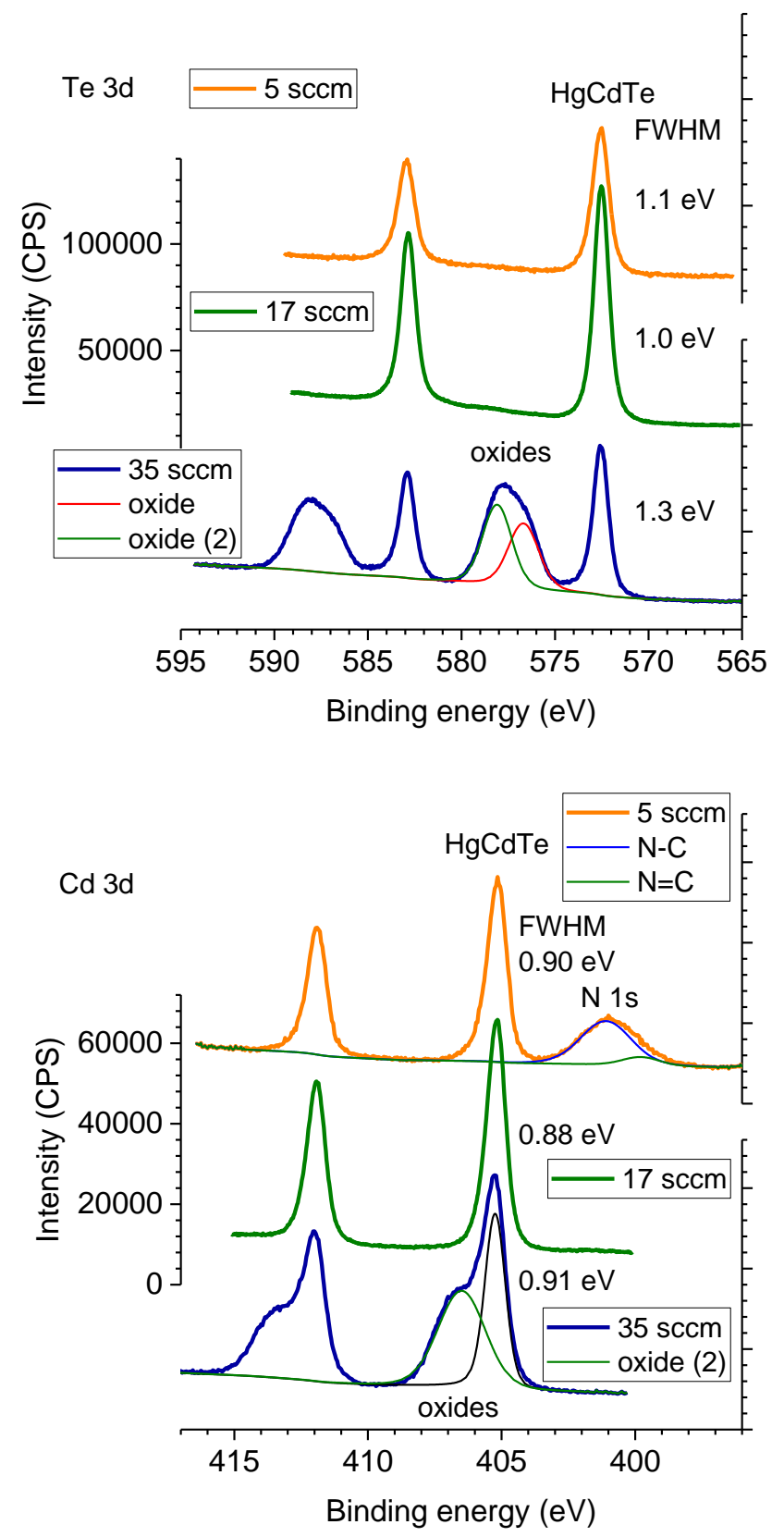
Figure 9 (continued)
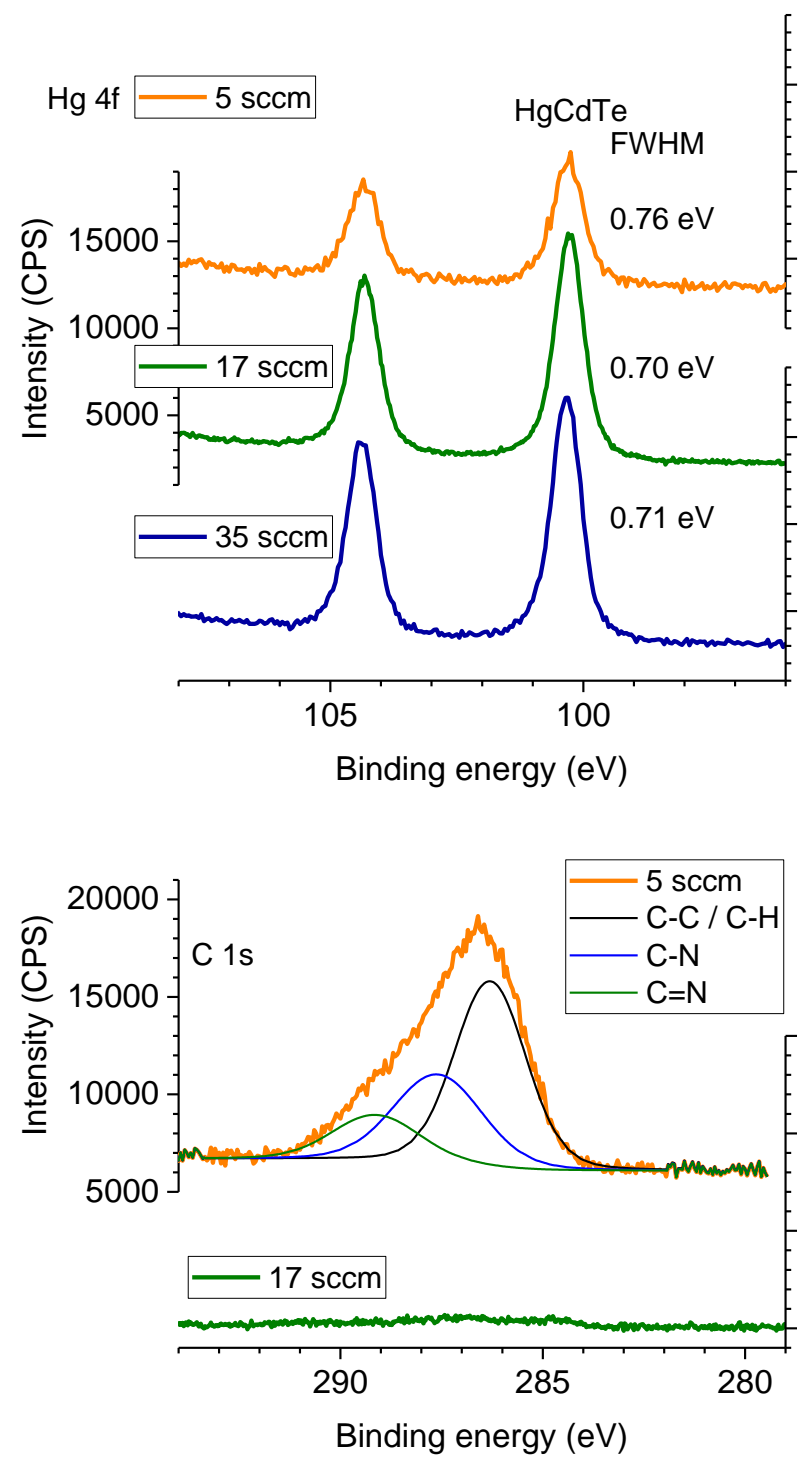
Figure 9 (end)

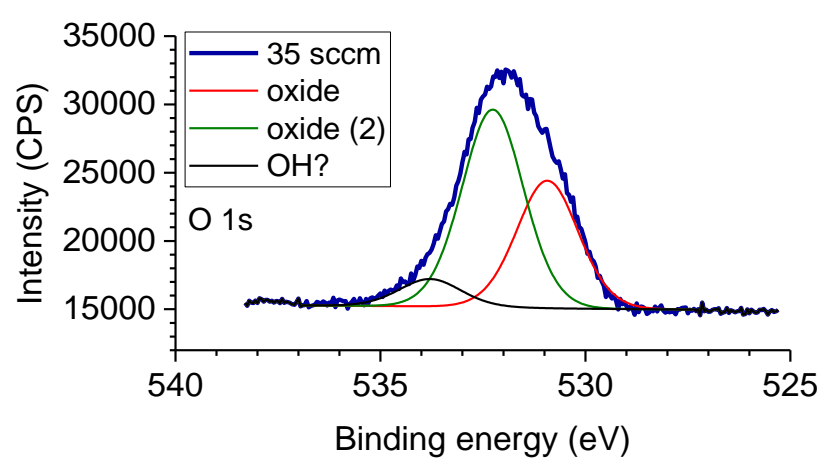

Figure 9: Analysis of $\mathrm{HgCdTe}$ samples etched in $\mathrm{CH}_{4} / \mathrm{N}_{2} \mathrm{O} / \mathrm{H}_{2} / \mathrm{Ar}$ for 5,17 and $35 \mathrm{sccm}$ of $\mathrm{N}_{2} \mathrm{O}$ : $\mathrm{Te} 3 \mathrm{~d}, \mathrm{Cd} 3 \mathrm{~d}, \mathrm{Hg} 4 \mathrm{f}, \mathrm{C} 1 \mathrm{~s}$ and $\mathrm{O} 1 \mathrm{~s}$ spectral regions. Each region containing more than one spectrum presents the equivalent number of ordinate scales, alternatively on the left and right axis; all scales are the same, only one is labelled to lighten the figure. 
Table 1

Table 1: Plasma species studied by actinometry.

\begin{tabular}{cccc}
\hline \hline Species & $\begin{array}{c}\text { Wavelength } \\
(\mathrm{nm})\end{array}$ & Electronic transition & Reference \\
\hline \hline $\mathrm{NO}^{*}$ & 247.1 & $A^{2} \Sigma^{+} \rightarrow X^{2} \Pi$ & 19 \\
$\mathrm{CO}^{*}$ & 283.3 & $b^{3} \Sigma \rightarrow a^{3} \Pi$ & 19 \\
$\mathrm{OH}^{*}$ & 308.9 & $A^{2} \Sigma^{+} \rightarrow X^{2} \Pi$ & 19 \\
$\mathrm{NH}^{*}$ & 336.0 & $A^{3} \Pi \rightarrow X^{2} \Sigma$ & 19 \\
$\mathrm{~N}^{*}$ & 357.7 & $C^{3} \Pi_{u} \rightarrow B^{3} \Pi_{g}$ & 19 \\
$\mathrm{CN}^{*}$ & 388.3 & $B^{2} \Sigma \rightarrow X^{2} \Sigma$ & 19 \\
$\mathrm{H}^{*}$ & 656.3 & $\mathrm{H}_{\alpha}$ & 20 \\
$\mathrm{Ar}^{*}$ & 750.4 & $3 s^{2} 3 p^{5} 4 p^{1}\left({ }^{3} P_{0}\right) \rightarrow 3 s^{2} 3 p^{5} 4 p^{1}\left({ }^{1} P_{1}\right)$ & 20 \\
$\mathrm{O}^{*}$ & 777.2 & $2 s^{2} 2 p^{3} 3 p^{1}\left({ }^{5} P_{1,2,3}\right) \rightarrow 2 s^{2} 2 p^{3} 3 s^{1}\left({ }^{5} S_{2}\right)$ & 20 \\
\hline \hline
\end{tabular}


Table 2

Table 2: In situ XPS quantification and spectrum curve fitting results for the layers deposited in $\mathrm{CH}_{4} / \mathrm{H}_{2} / \mathrm{Ar}, \mathrm{CH}_{4} / \mathrm{O}_{2}(2 \mathrm{sccm}) / \mathrm{H}_{2} / \mathrm{Ar}$ and $\mathrm{CH}_{4} / \mathrm{N}_{2} \mathrm{O}(5 \mathrm{sccm}) / \mathrm{H}_{2} / \mathrm{Ar}$ plasmas.

\begin{tabular}{|c|c|c|c|c|c|c|c|c|c|}
\hline & & \multicolumn{4}{|c|}{$\mathrm{C} 1 \mathrm{~s}$} & \multirow{2}{*}{$\frac{\mathrm{O} 1 \mathrm{~s}}{\mathrm{O}-\mathrm{C}}$} & \multicolumn{3}{|c|}{ N1s } \\
\hline & Species & $\begin{array}{l}\mathrm{C}-\mathrm{C} \\
\mathrm{C}-\mathrm{H}\end{array}$ & $\begin{array}{l}\mathrm{C}-\mathrm{O} \\
\mathrm{C}-\mathrm{N}\end{array}$ & $\mathrm{C}=\mathrm{N}$ & $\mathrm{CN}$ & & $\mathrm{N}-\mathrm{H}$ & $\mathrm{N}=\mathrm{C}$ & $\mathrm{N}-\mathrm{C}$ \\
\hline \multirow{4}{*}{ 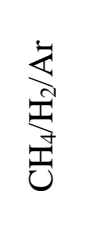 } & Atom \% & \multicolumn{4}{|c|}{100} & - & \multicolumn{3}{|c|}{-} \\
\hline & $\mathrm{BE}(\mathrm{eV})$ & 284.8 & - & - & - & - & - & - & - \\
\hline & FWHM $(\mathrm{eV})$ & 1.81 & - & - & - & - & - & - & - \\
\hline & Fraction $(\%)$ & 100 & - & - & - & - & - & - & - \\
\hline \multirow{4}{*}{ 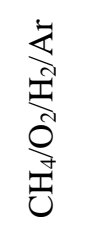 } & Atom \% & \multicolumn{4}{|c|}{92} & 8 & \multicolumn{3}{|c|}{ - } \\
\hline & $\mathrm{BE}(\mathrm{eV})$ & 284.8 & 286.8 & - & - & 532.4 & - & - & - \\
\hline & FWHM (eV) & 1.85 & 2.40 & - & - & 2.39 & - & - & - \\
\hline & Fraction (\%) & 93 & 7 & - & - & 100 & - & - & - \\
\hline \multirow{4}{*}{ 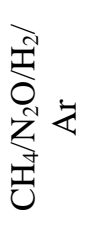 } & Atom \% & \multicolumn{4}{|c|}{64} & 8 & \multicolumn{3}{|c|}{28} \\
\hline & $\mathrm{BE}(\mathrm{eV})$ & 284.7 & 285.9 & 287.3 & 288.7 & 531.5 & 397.8 & 398.9 & 400.1 \\
\hline & FWHM (eV) & 1.89 & 1.99 & 2.02 & 1.81 & 2.66 & 1.99 & 1.83 & 2.02 \\
\hline & Fraction (\%) & 16 & 47 & 27 & 10 & 100 & 9 & 32 & 59 \\
\hline
\end{tabular}


Table 3

Table 3: AFM image, average roughness and SEM image after etching in $\mathrm{CH}_{4} / \mathrm{H}_{2} / \mathrm{Ar}$, $\mathrm{CH}_{3} \mathrm{OH} / \mathrm{H}_{2} / \mathrm{Ar}, \mathrm{CH}_{3} \mathrm{NO}_{2} / \mathrm{H}_{2} / \mathrm{Ar}$ and $\mathrm{CH}_{4} / \mathrm{N}_{2} \mathrm{O} / \mathrm{H}_{2} / \mathrm{Ar}$ plasmas.

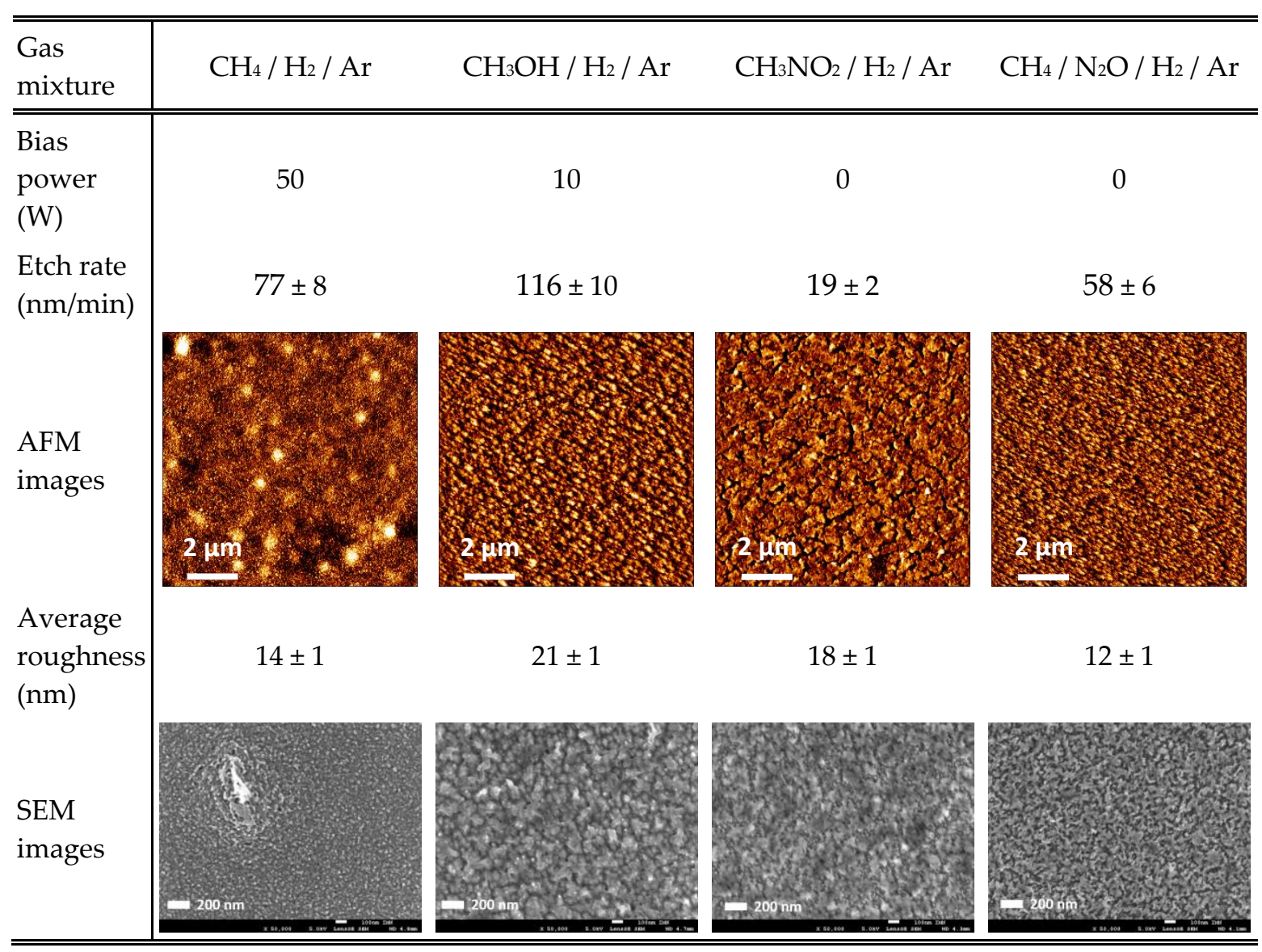


Table 4

Table 4: In situ XPS spectrum curve fitting results for $\mathrm{HgCdTe}$ reference and samples etched in $\mathrm{CH}_{4} / \mathrm{H}_{2} / \mathrm{Ar}, \mathrm{CH}_{3} \mathrm{NO}_{2} / \mathrm{H}_{2} / \mathrm{Ar}$ and $\mathrm{CH}_{4} / \mathrm{N}_{2} \mathrm{O} / \mathrm{H}_{2} / \mathrm{Ar}$ plasmas.

\begin{tabular}{|c|c|c|c|c|c|c|}
\hline & & & $\mathrm{Te} 3 \mathrm{~d} 5 / 2$ & & $\mathrm{Cd} 3 \mathrm{~d} 3 / 2$ & $\mathrm{Hg} 4 \mathrm{f} 7 / 2$ \\
\hline & Species & $\mathrm{HgCdTe}$ & element & oxide & $\mathrm{HgCdTe}$ & $\mathrm{HgCdTe}$ \\
\hline \multirow{4}{*}{ Reference } & Atom \% ( $\mathrm{HgCdTe})$ & & 70 & & 6 & 24 \\
\hline & $\mathrm{BE}(\mathrm{eV})$ & 572.6 & 573.4 & 576.3 & 405.1 & 100.3 \\
\hline & FWHM (eV) & 0.99 & 0.78 & 0.99 & 0.64 & 0.66 \\
\hline & Fraction $\%$ & 82 & 15 & 2 & 100 & 100 \\
\hline \multirow{3}{*}{$\begin{array}{l}\mathrm{CH}_{4} / \mathrm{H}_{2} / \mathrm{Ar} \\
50 \mathrm{~W} \text { bias }\end{array}$} & Atom \% ( $\mathrm{HgCdTe})$ & & 53 & & 37 & 10 \\
\hline & $\mathrm{BE}(\mathrm{eV})$ & 572.5 & - & - & 405.2 & 100.4 \\
\hline & FWHM $(\mathrm{eV})$ & 1.09 & - & - & 0.85 & 0.77 \\
\hline \multirow{3}{*}{$\begin{array}{l}\mathrm{CH}_{3} \mathrm{NO}_{2} / \mathrm{H}_{2} / \mathrm{Ar} \\
\text { No bias }\end{array}$} & Atom \% ( $\mathrm{HgCdTe})$ & & 52 & & 32 & 16 \\
\hline & $\mathrm{BE}(\mathrm{eV})$ & 572.6 & - & - & 405.2 & 100.3 \\
\hline & FWHM (eV) & 1.02 & - & - & 0.85 & 0.70 \\
\hline \multirow{3}{*}{$\begin{array}{l}\mathrm{CH}_{4} / \mathrm{N}_{2} \mathrm{O} / \mathrm{H}_{2} / \mathrm{Ar} \\
\text { No bias }\end{array}$} & Atom \% ( $\mathrm{HgCdTe})$ & & 57 & & 36 & 7 \\
\hline & $\mathrm{BE}(\mathrm{eV})$ & 572.6 & - & - & 405.2 & 100.3 \\
\hline & FWHM (eV) & 1.04 & - & - & 0.86 & 0.69 \\
\hline
\end{tabular}


Table 5

Table 5: SEM and SEM-EDS images of $\mathrm{HgCdTe}$ samples etched in $\mathrm{CH}_{4} / \mathrm{N}_{2} \mathrm{O} / \mathrm{H}_{2} / \mathrm{Ar}$ for 5 , 17 and $35 \mathrm{sccm}$ of $\mathrm{N}_{2} \mathrm{O}$.

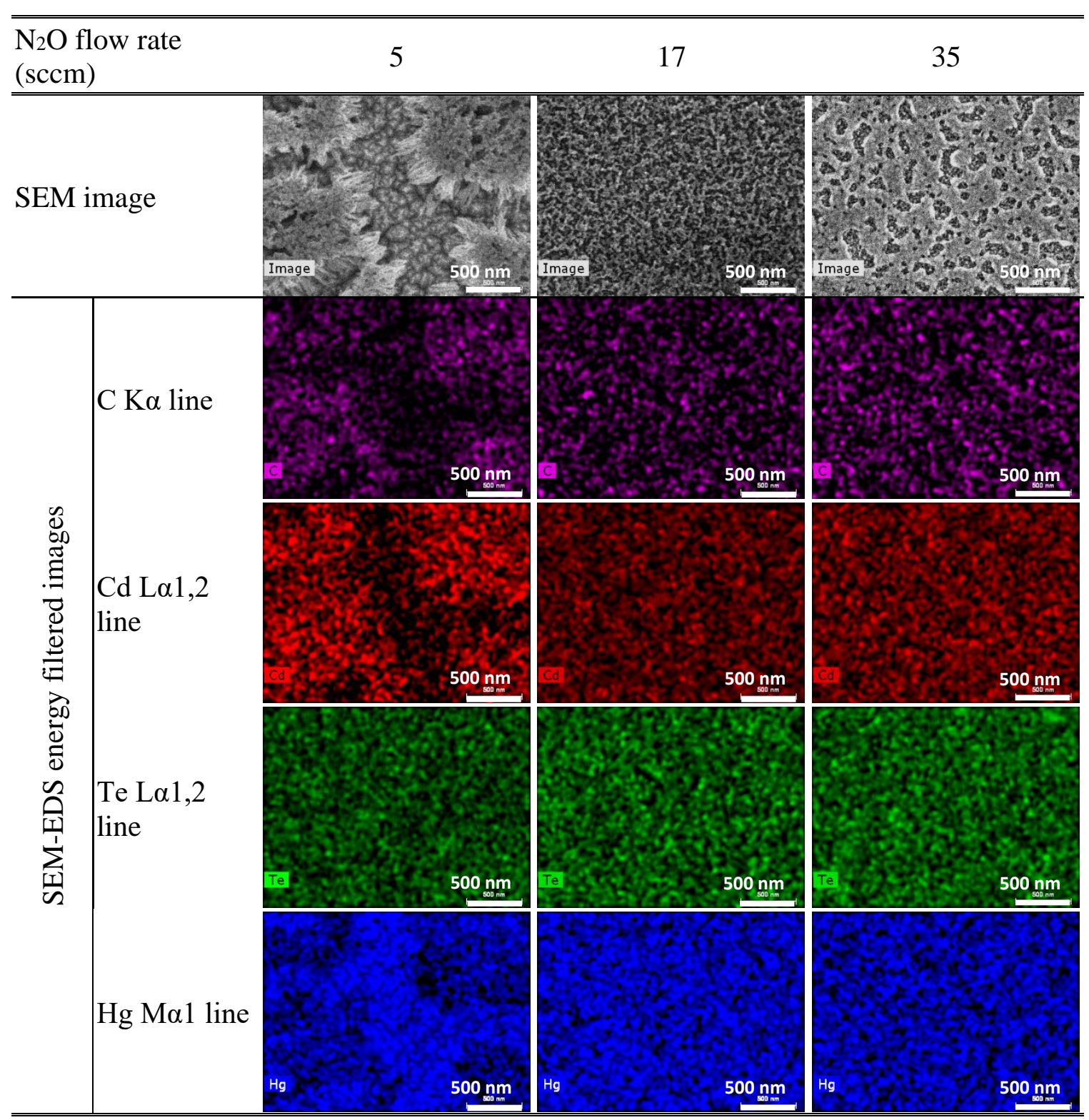




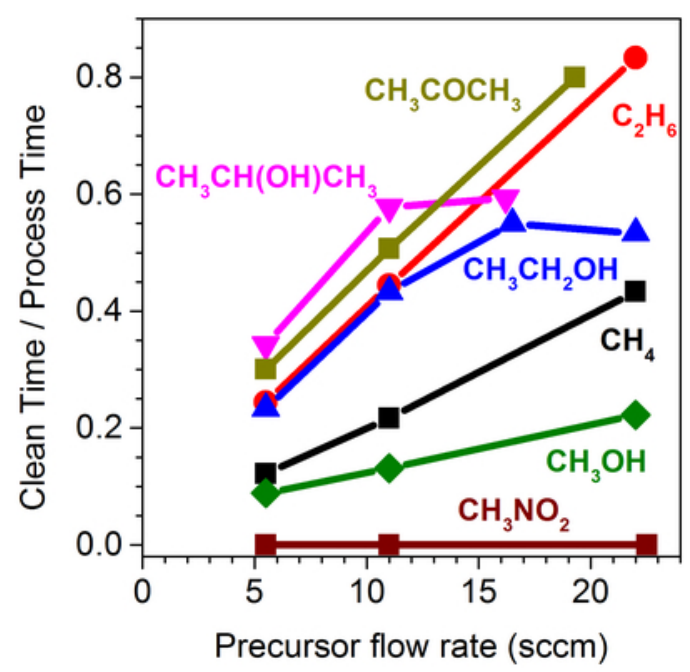




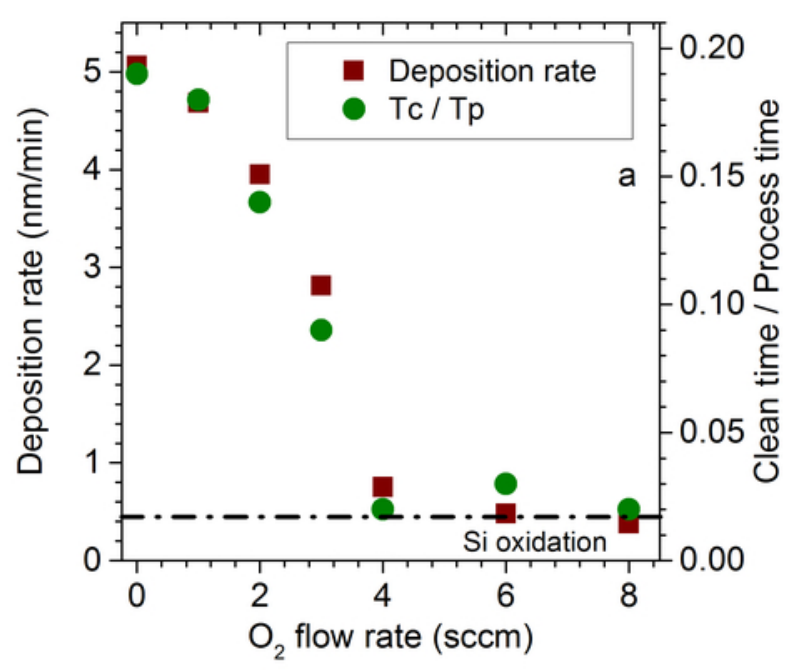




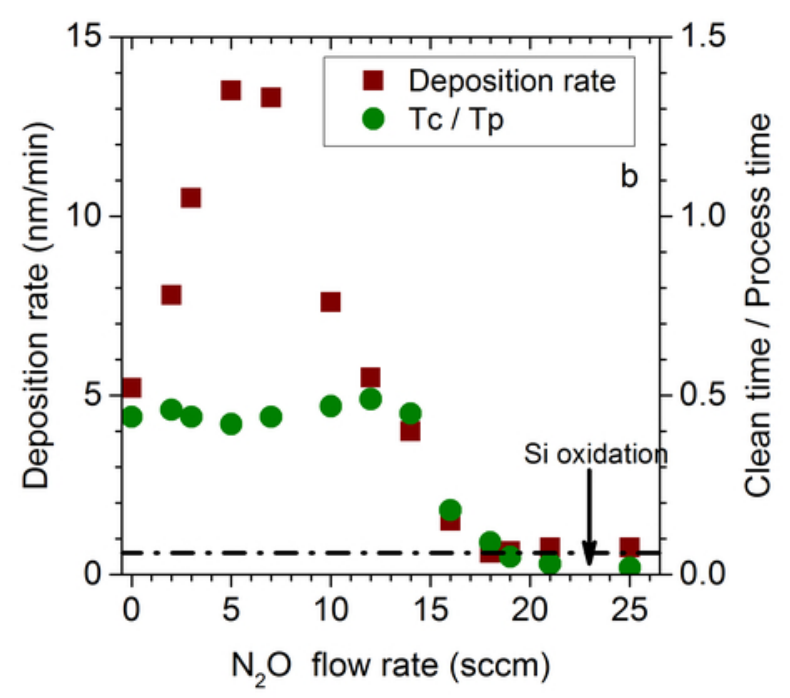




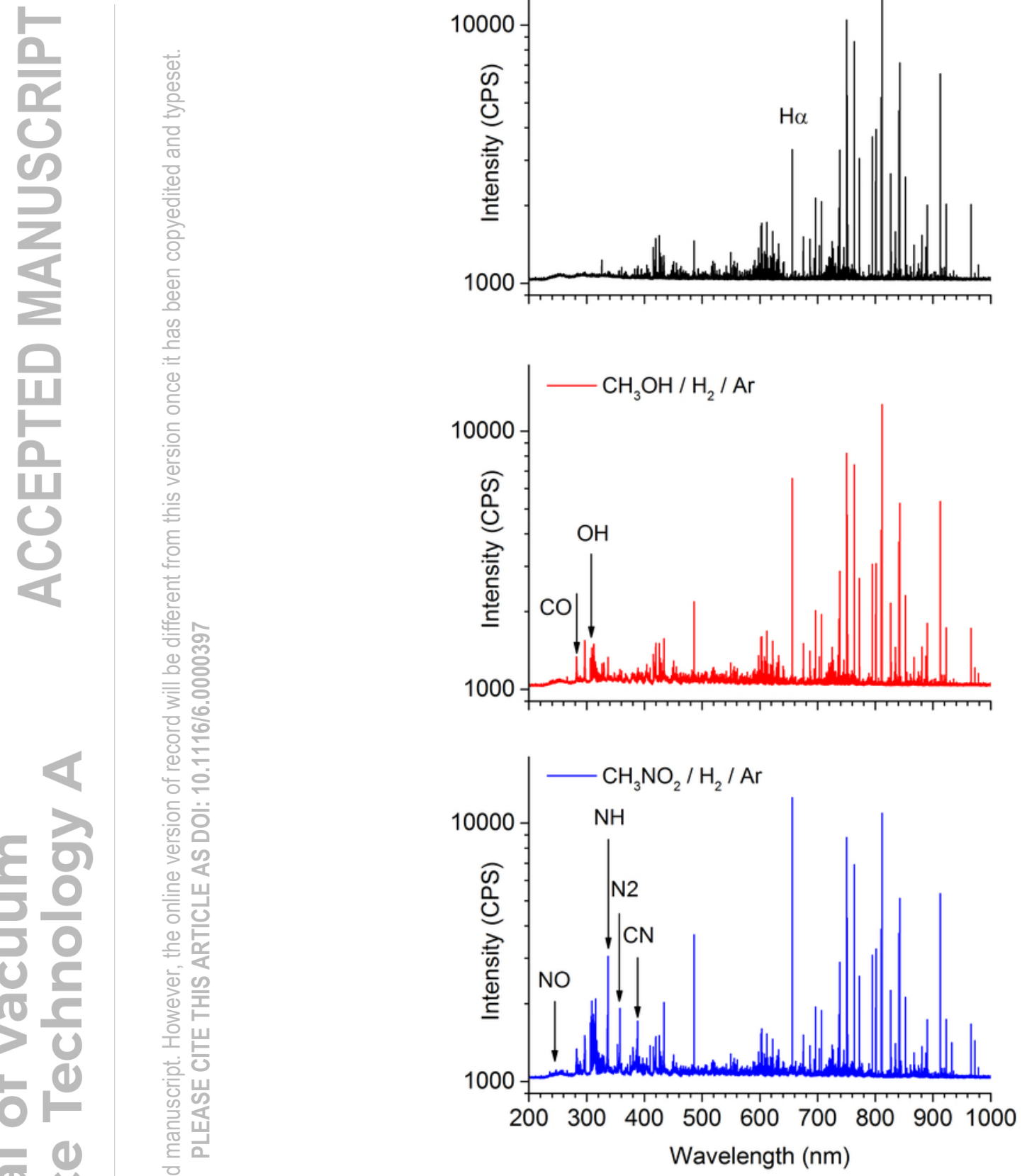



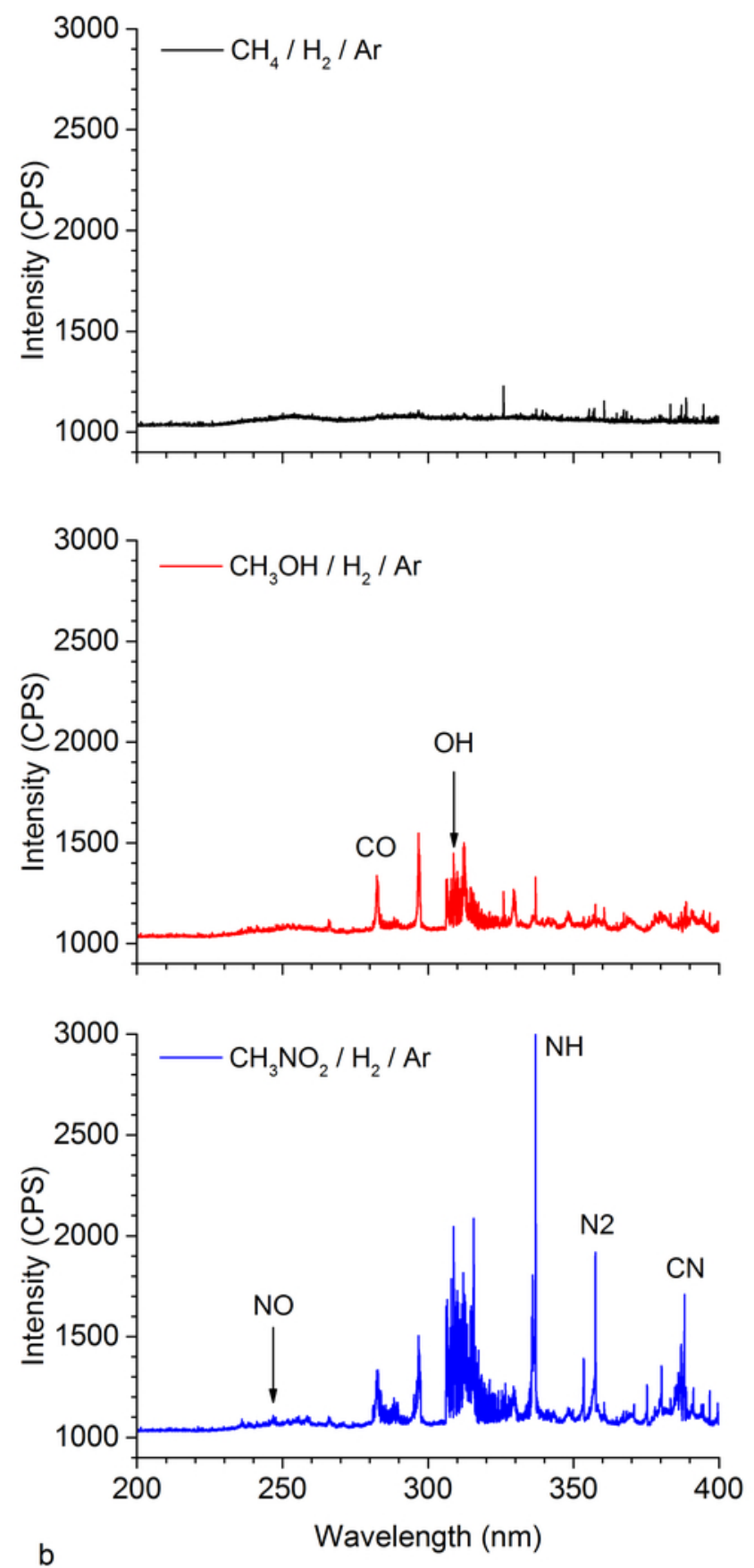


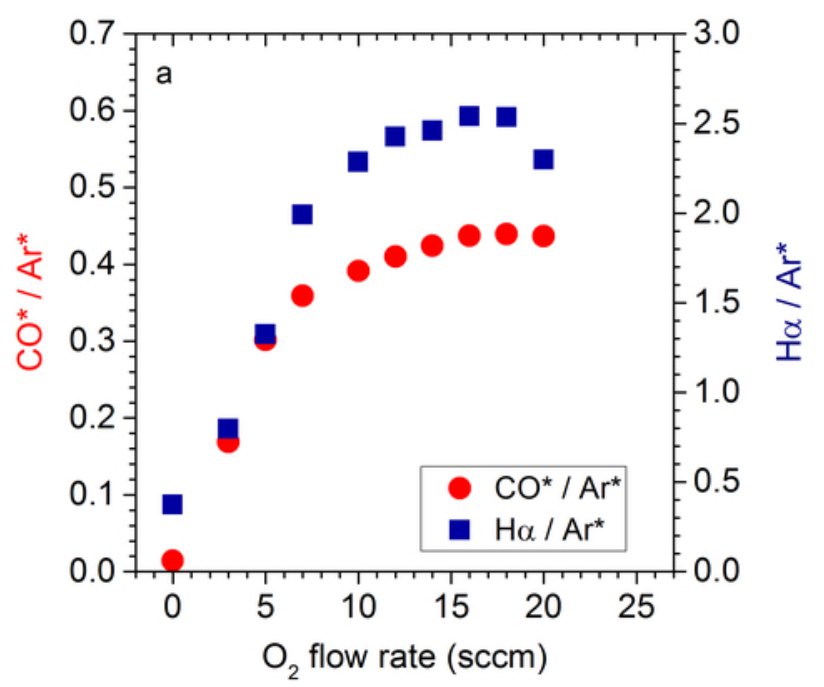




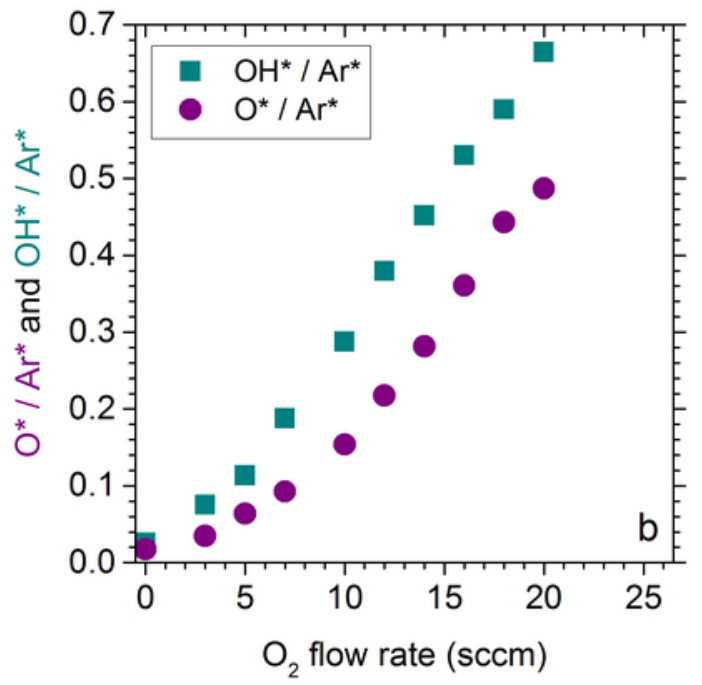




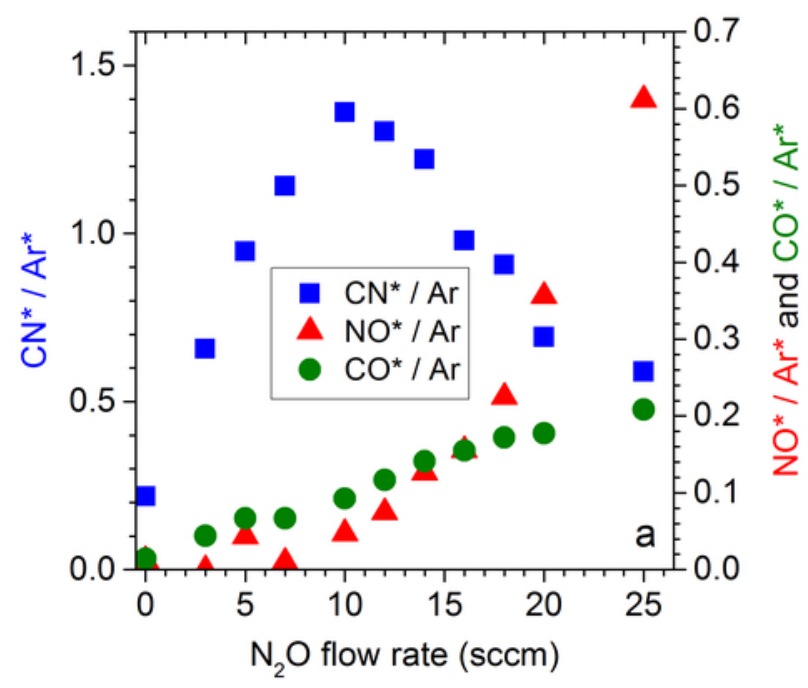




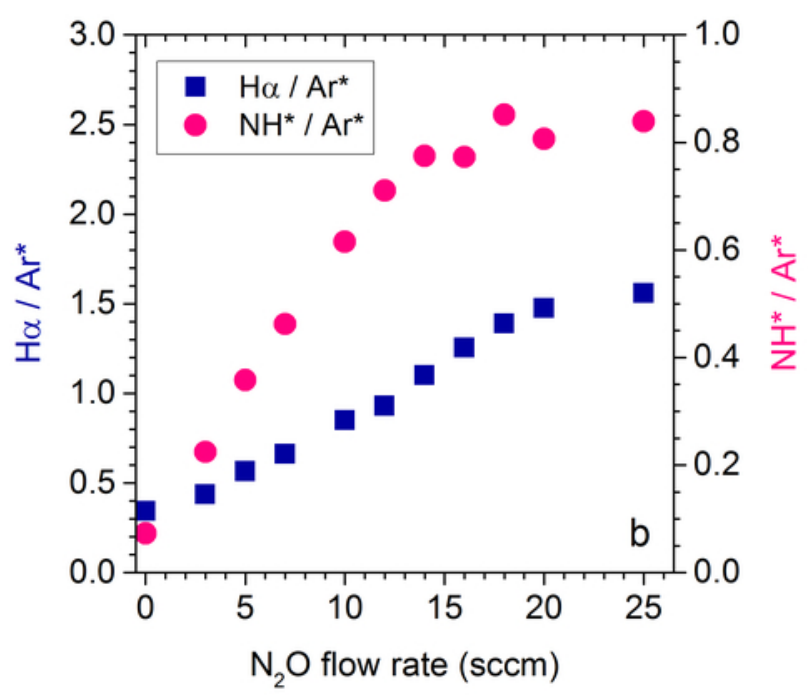




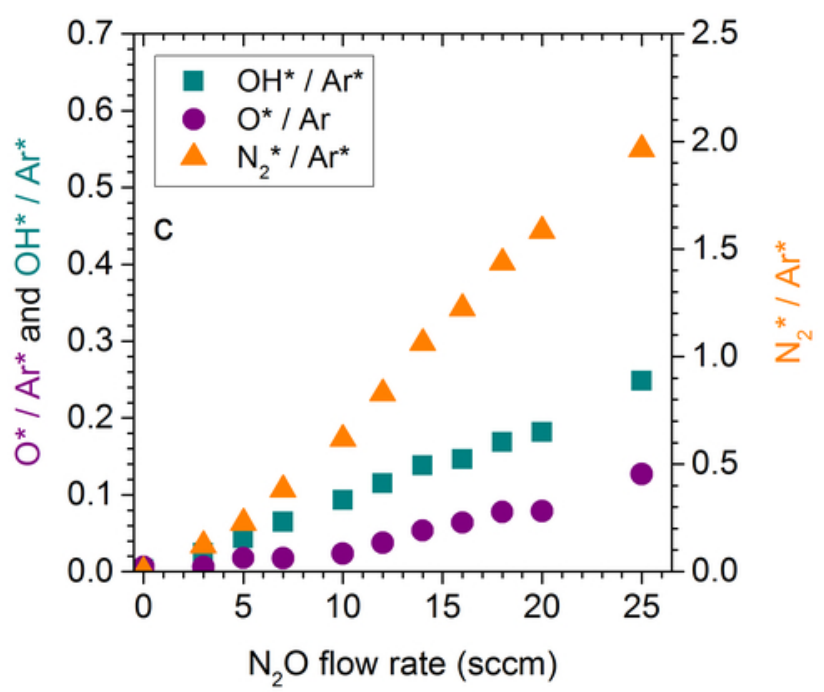




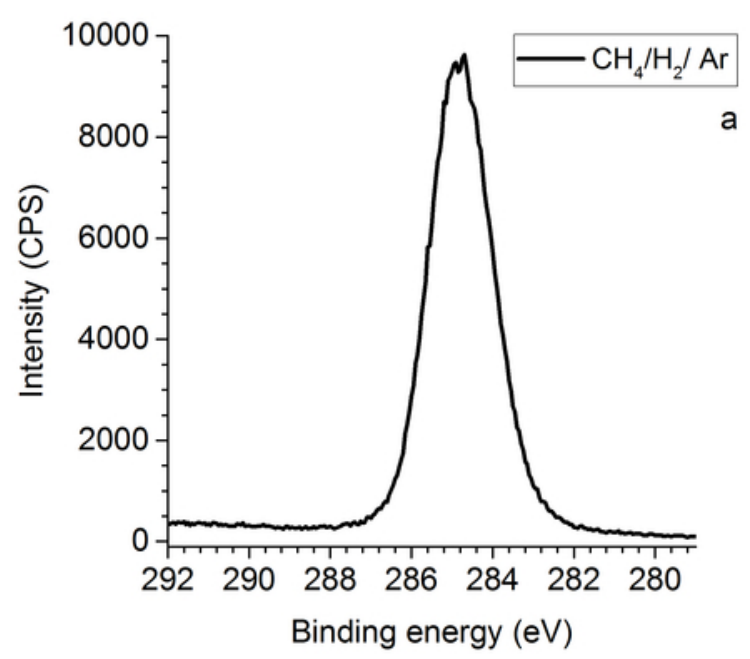




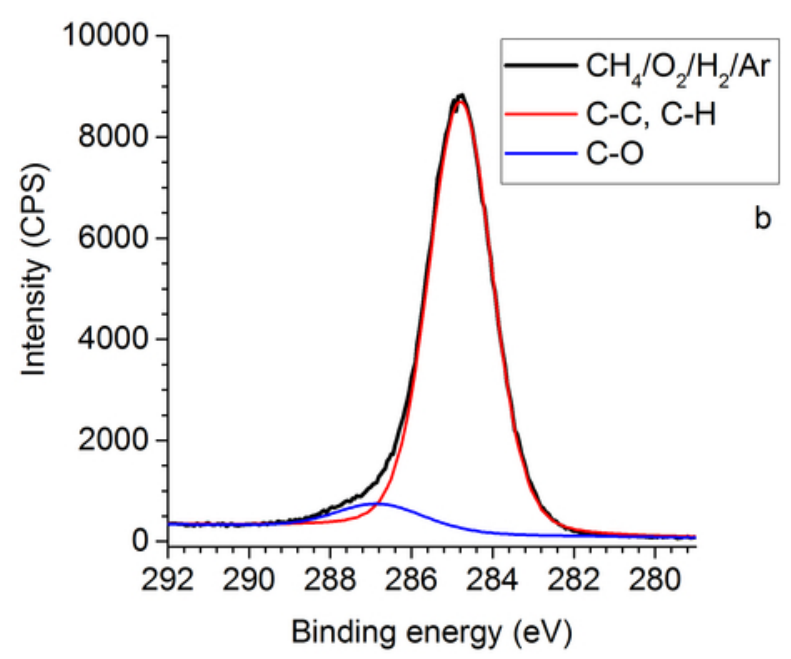




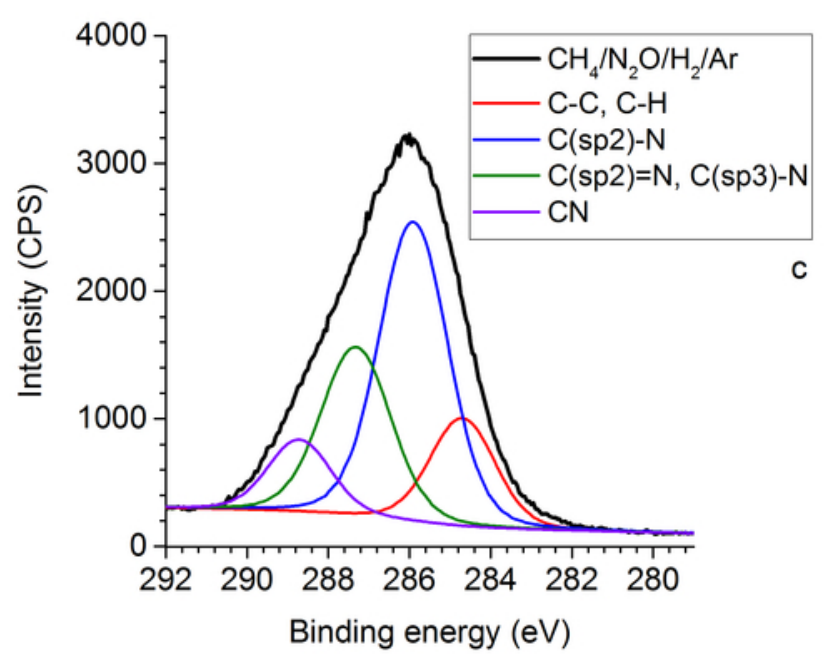




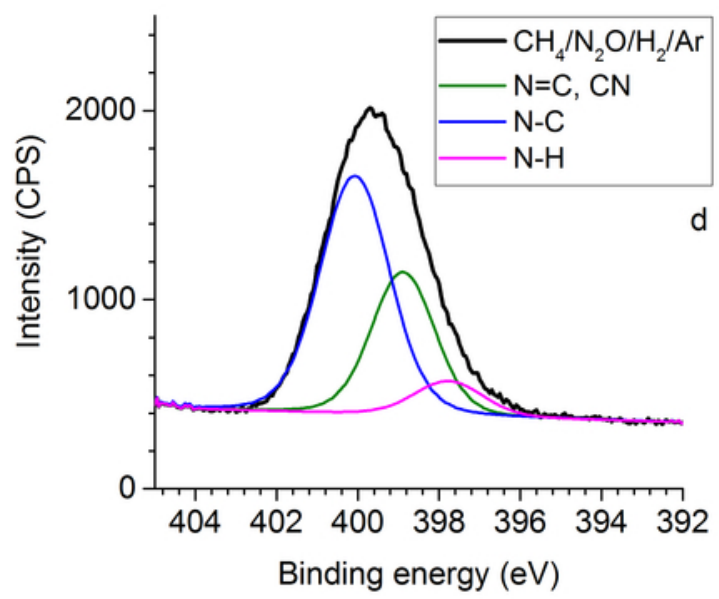




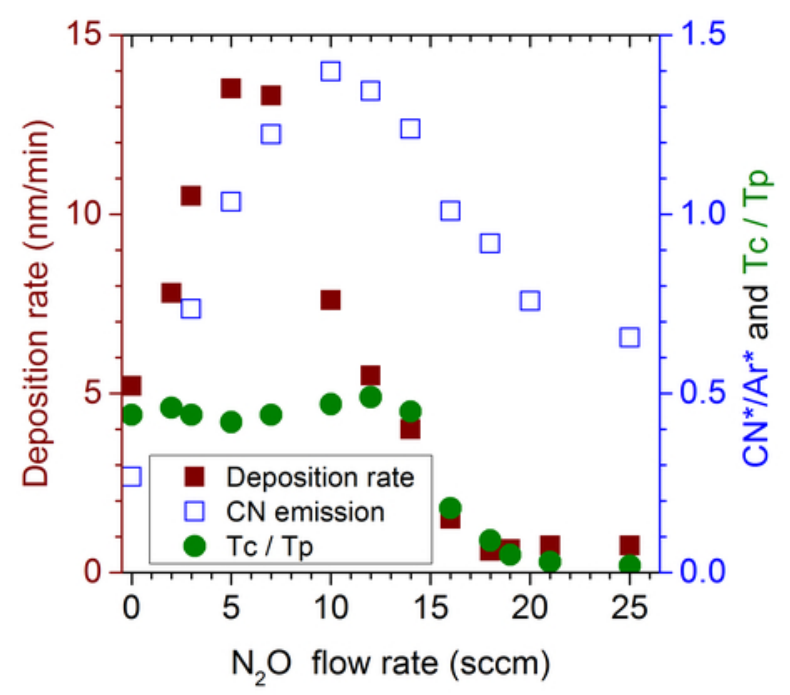




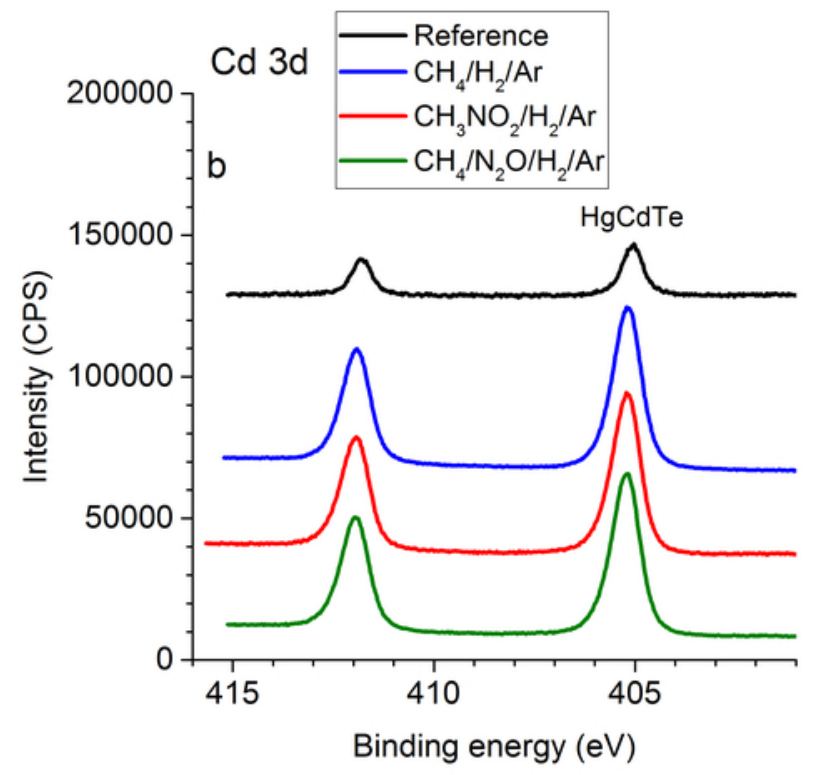




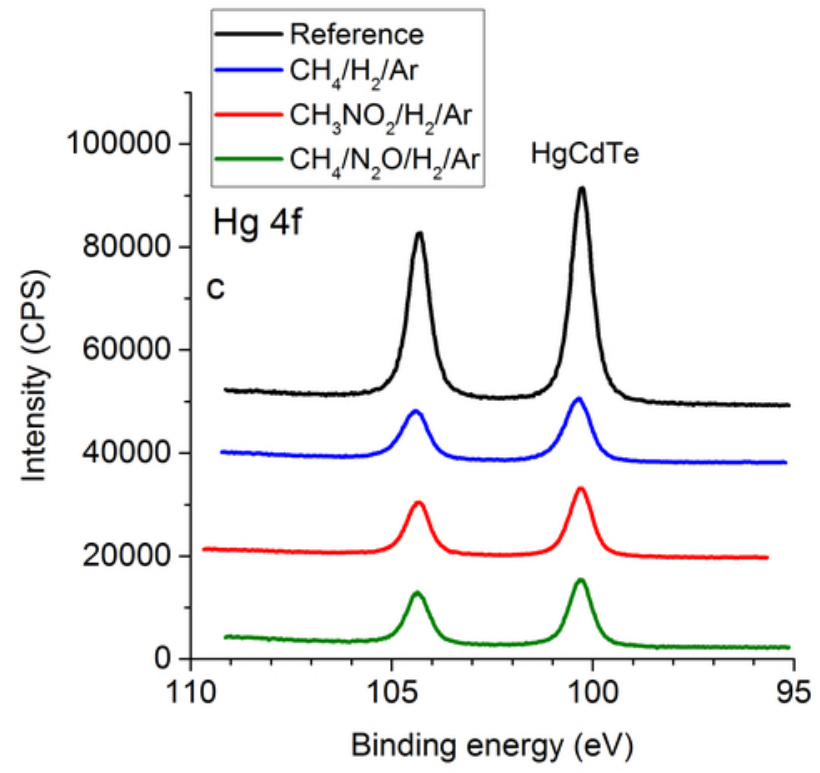




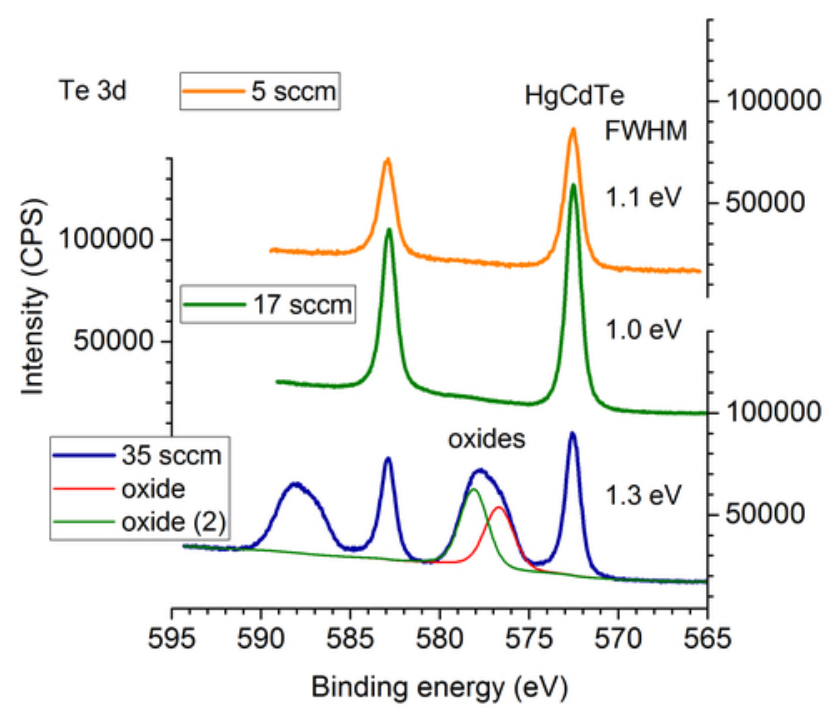




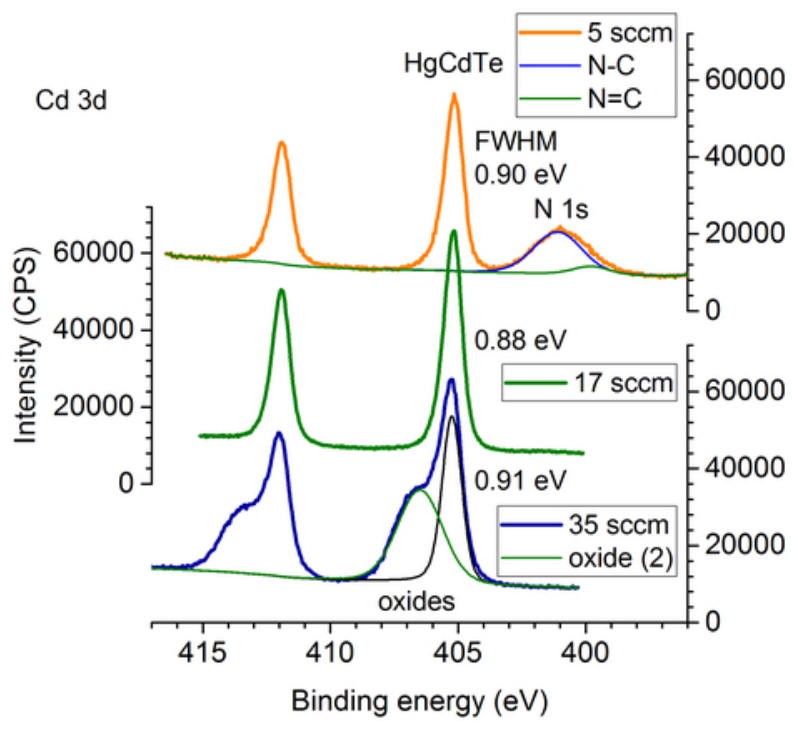




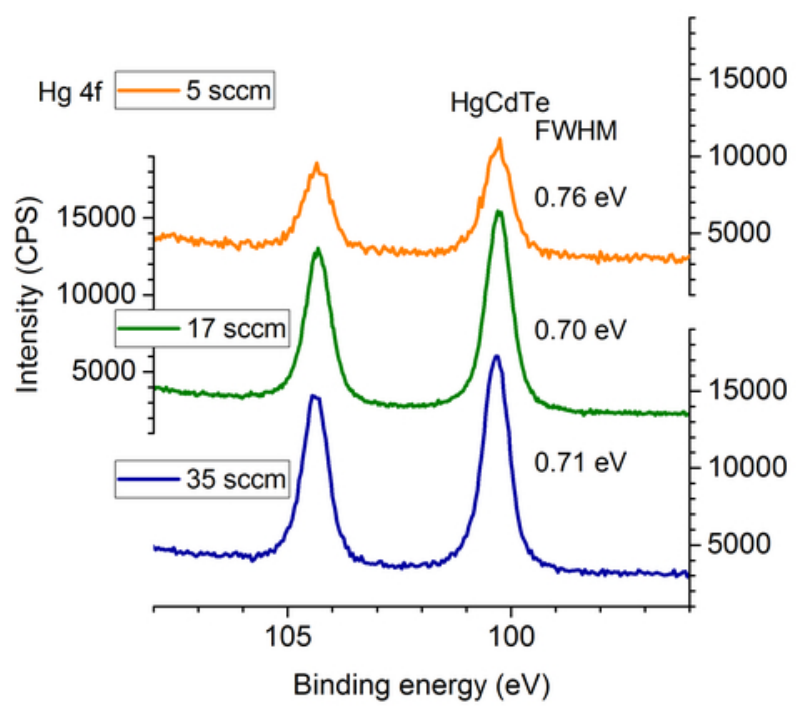




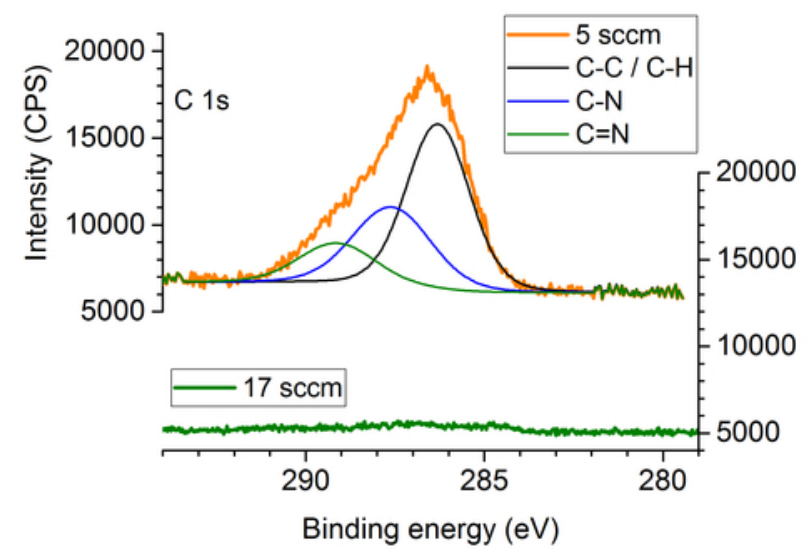




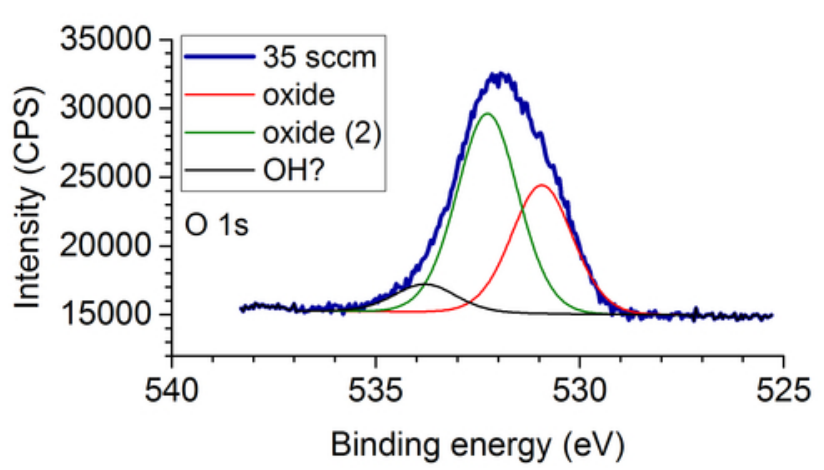




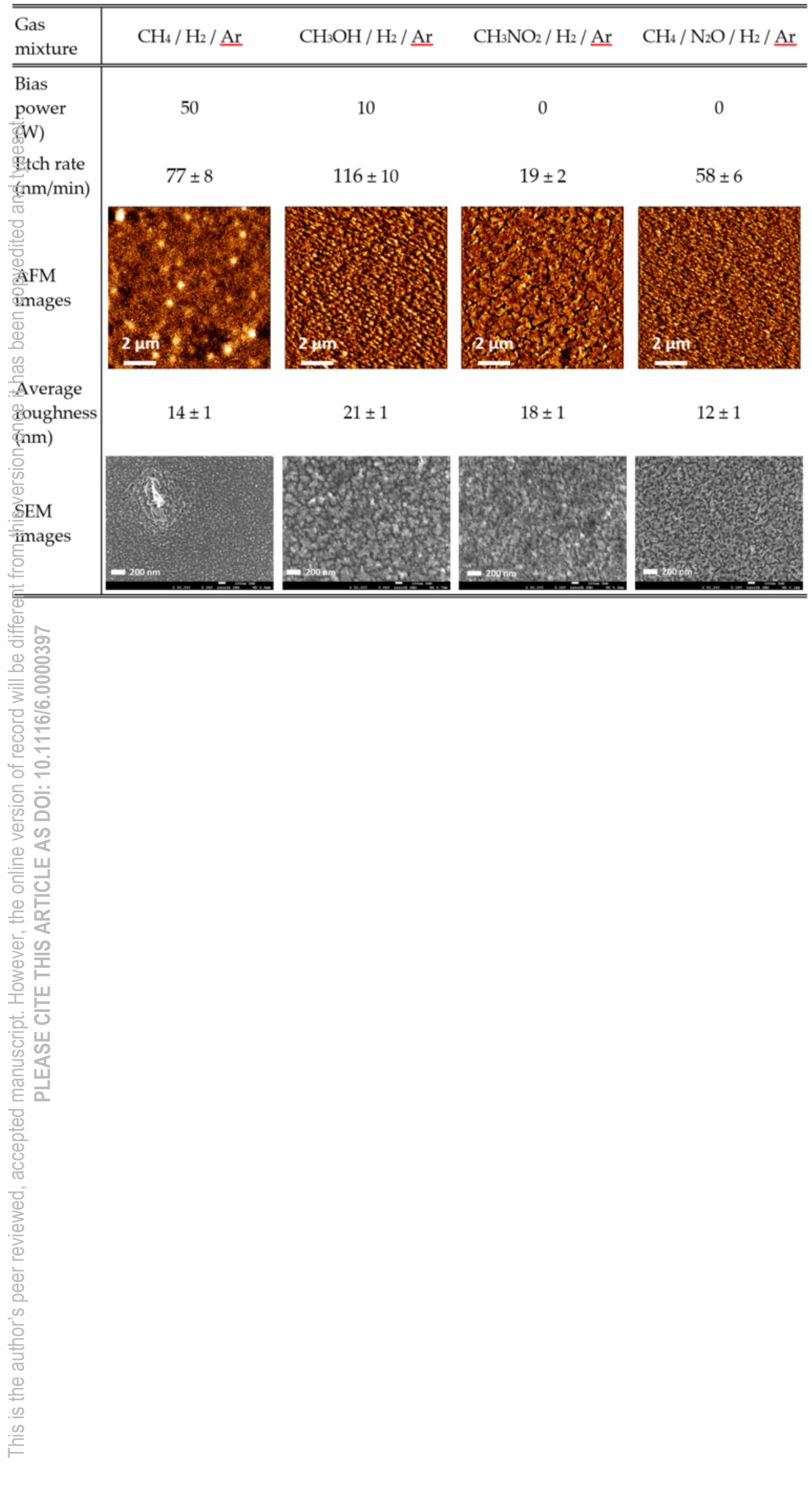


$\mathrm{N}_{2} \mathrm{O}$ flow rate

(sccm)

5

17

35

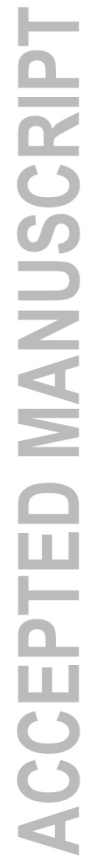

SEM image
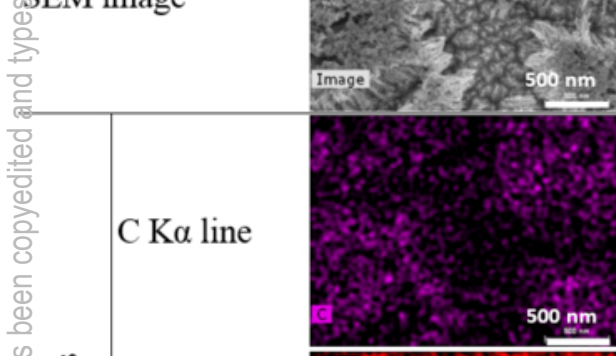

Image $50.500 \mathrm{~nm}$

$\mathrm{Cd} \operatorname{L} \alpha 1,2$

line
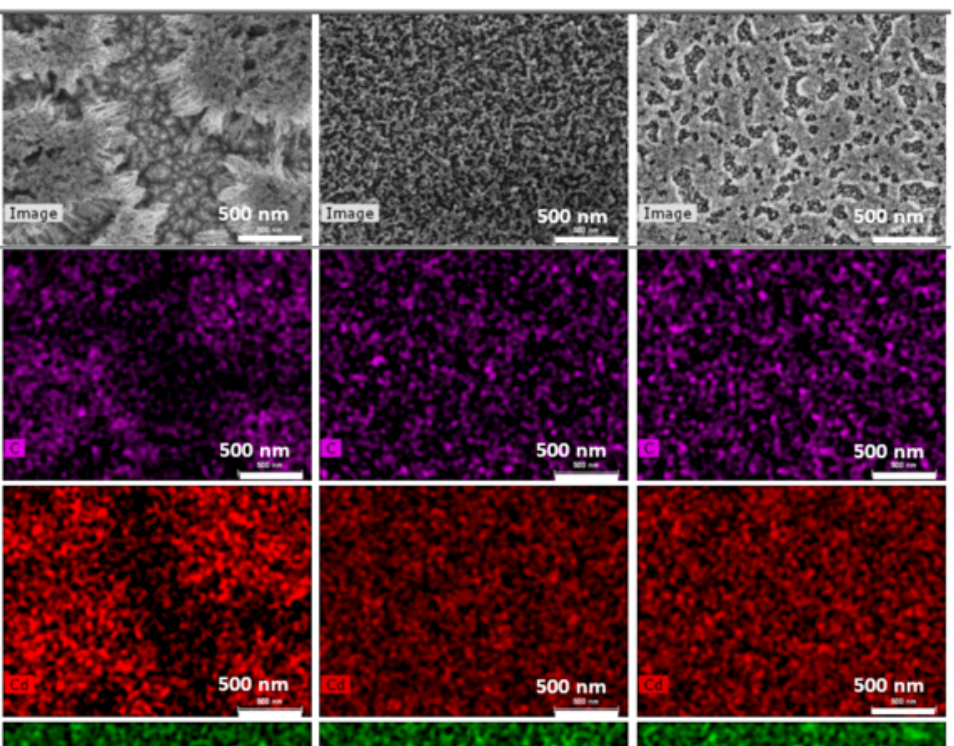

Te L $\alpha 1,2$
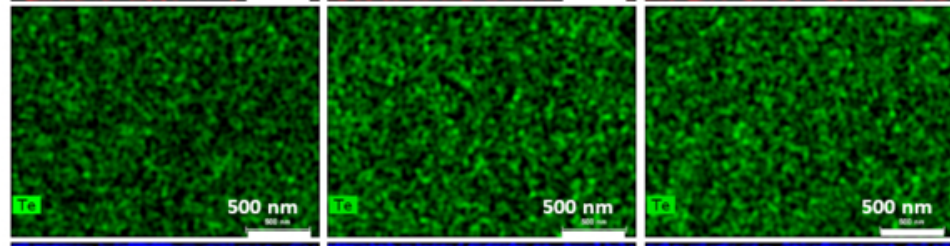

응ㅇㅇㅇ

30

Hg Mal line

1
$e$
0
0
0
0
0
0
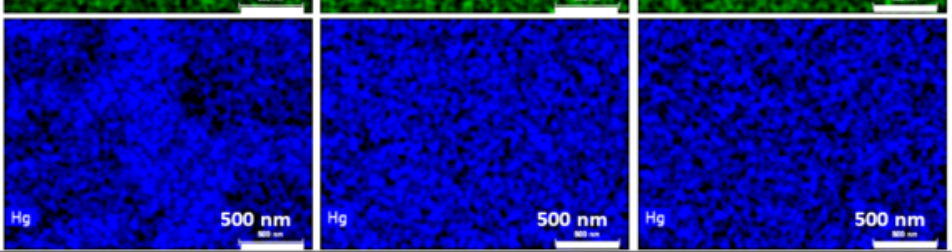

$\begin{array}{ll}10 & 0 \\ 0 & 0 \\ 0 & 0 \\ 0 & 0 \\ 0 & 0\end{array}$

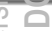

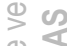

날

인

至

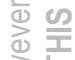

늠

오 튼

은번

造

ํㅡㄹ 믐

밈

్ㅗㅇ

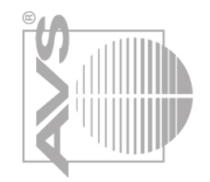

